\title{
Successful Weight Loss in Women Participating in The West Virginia WISEWOMAN Study: A Mixed Methods Approach
}

Jennifer A. Presley

West Virginia University

Follow this and additional works at: https://researchrepository.wvu.edu/etd

\section{Recommended Citation}

Presley, Jennifer A., "Successful Weight Loss in Women Participating in The West Virginia WISEWOMAN Study: A Mixed Methods Approach" (2010). Graduate Theses, Dissertations, and Problem Reports. 4643. https://researchrepository.wvu.edu/etd/4643

This Dissertation is protected by copyright and/or related rights. It has been brought to you by the The Research Repository @ WVU with permission from the rights-holder(s). You are free to use this Dissertation in any way that is permitted by the copyright and related rights legislation that applies to your use. For other uses you must obtain permission from the rights-holder(s) directly, unless additional rights are indicated by a Creative Commons license in the record and/ or on the work itself. This Dissertation has been accepted for inclusion in WVU Graduate Theses, Dissertations, and Problem Reports collection by an authorized administrator of The Research Repository @ WVU.

For more information, please contact researchrepository@mail.wvu.edu. 
Successful Weight Loss in Women Participating in

The West Virginia WISEWOMAN Study:

A Mixed Methods Approach

Jennifer A. Presley

Dissertation submitted to the School of Nursing at West Virginia University

in partial fulfillment of the requirements for the degree of

Doctor of Philosophy in Nursing

Irene Tessaro, DrPH, RN, Chair

Mary Jane Smith, PhD, RN

Joel Halverson, $\mathrm{PhD}$

Ruth Kershner, EdD, RN

Joy Buck, PhD, RN

School of Nursing

Morgantown, West Virginia

2010

Key Words: successful weight loss, restructuring, story theory, social support Copyright 2010 Jennifer A. Presley 
Successful Weight Loss in Women Participating in the West Virginia WISEWOMAN Study:

\title{
A Mixed Methods Approach
}

\author{
Jennifer A. Presley
}

\begin{abstract}
Objectives: This mixed-methods study was designed to examine sociodemographic, healthrelated lifestyle, quality of life, and social support factors associated with weight loss in women, and to describe the high points, low points and turning points in the stories of women who lost at least 5\% of their baseline weight in the West Virginia WISEWOMAN study.

Methods: Using chi square tests and t-tests, data from the West Virginia WISEWOMAN study were used to compare the 67 women who successfully lost at least $5 \%$ of their baseline weight to the 334 women who stayed within $5 \%$ of their baseline weight. For the qualitative portion of the study, the story path method of collecting stories was used to gather the stories of women who were successful at weight loss. The high points, low points and turning points in their stories of losing weight were analyzed.
\end{abstract}

Results: The only significant finding in the quantitative portion of the study was in social support: women who lost weight had fewer friends and family they felt comfortable talking to than women whose weight stayed the same $\left(X^{2}=18.85 ; \mathrm{p}=.001\right)$. For the qualitative portion of the study, 14 common elements were extrapolated from the high points, low points and turning points which described women's experiences with weight loss. Changes in well-being and view of self were found in the high points; low energy, challenging life circumstances, and variations in weight and eating patterns were revealed as low points; and turning points were described as meaningful moments when actions were taken to follow through with food choices and activity. Conclusions: Nurses can assist clients with identifying and obtaining effective support, and help them overcome the low points of weight loss in order to follow through with long-term health behavior changes. 


\section{Acknowledgments}

Doctoral study, and the dissertation process, is a long, challenging, and frequently frustrating experience. I would never have successfully completed an undertaking of this magnitude without the guidance, assistance and support of others. I want to thank Dr. Irene Tessaro, my committee chair, who was always optimistic, supportive and encouraging. There were times when I knew you were frustrated with me, and yet you always motivated me to continue on to completion. Dr. Tessaro, you have been a wonderful mentor. Thank you for your guidance and direction in the completion of this study.

My dissertation committee was vital to the success of this study. I want to thank Dr. Mary Jane Smith for guiding me through the qualitative portion of this study. I appreciate the many hours you spent with me, helping me understand story path and teaching me how to carry out the process of intentional dialogue and analyzing the results. And, thank you for making me sign that writing pledge! Dr. Kershner and Dr. Buck, thank you for critically reviewing my written work, asking challenging questions, and the editorial suggestions. You helped me look at the study and results in a multifaceted way. Dr. Joel Halverson, thank you for your positive feedback and saying just the right words to calm my nerves at defense!

My family has toiled with me through this process and without them I would never have made it this far! Mom, Dad, Beth, Tim, Sarah, Annie, and Timmie, thank you for your love and support. Mom, thanks for the phone calls, asking "are you working on your paper?."

Oftentimes, your calls were the nudges I needed to carry on. Dad, thanks for always making sure my car was mechanically sound and ready to travel.

I have been blessed with friends who listened to me whine and complain throughout the program. Thank you Missy, Steve R., Steve H., Lesta, Liz, Bobbie, Carla, Jeananne, Gordon, 
Brenda, Carolyn and Tim W. for your support and encouragement! J.P. Miller, thank you for helping me understand the statistical tables and answering my questions about the tests and results. You calmed my anxiety and were always optimistic and encouraging. Steve R. and Missy, thanks for being my audience for defense rehearsal, and asking tough questions.

I also want to thank the wonderful women who agreed to participate in my study. You took precious time out of your day to talk with me about your weight loss. I appreciate every precious minute and fondly recall our special conversations.

To my comrades: I would never have made it through the program without the support, guidance and humor of my classmates! Denise, Jill, Susan, Sue and Sara, you are the best! I appreciate your continual support, from our first day together, through graduation, and beyond! You are intelligent, dedicated, motivated and successful. It is an honor and privilege to know you, and to have shared this journey with you. Denise and Jill, I feel a very special bond with you. You listened to me through my struggles and successes: you laughed with me, cried with me, and motivated me to keep going. You continue to inspire me. 
Table of Contents

$\begin{array}{lll}20 & \text { Page }\end{array}$

$\begin{array}{ll}\text { Abstract } & \text { ii }\end{array}$

Acknowledgments

Table of Contents $\quad$ v

List of Tables $\quad$ viii

$\begin{array}{ll}\text { List of Figures } & \text { ix }\end{array}$

CHAPTER

1 INTRODUCTION OF THE PROBLEM 1

$\begin{array}{ll}\text { Purpose } & 2\end{array}$

$\begin{array}{ll}\text { Significance } & 2\end{array}$

Theoretical Framework $\quad 3$

Process of Restructuring in Weight Loss 3

2 REVIEW OF THE LITERATURE

Literature Search Process $\quad 5$

Theoretical Framework $\quad 5$

$\begin{array}{ll}\text { Story } & 7\end{array}$

Lifestyle Weight Loss Factors $\quad 8$

$\begin{array}{ll}\text { Dietary Factors } & 8\end{array}$

$\begin{array}{lr}\text { Physical Activity Factors } & 12\end{array}$

Multiple Related Lifestyle Factors $\quad 15$

$\begin{array}{ll}\text { Combining Diet and Physical Activity } & 15\end{array}$

$\begin{array}{ll}\text { Quality of Life } & 18\end{array}$ 
Social Support

Weight Loss Support

Experience of Weight loss $\quad 22$

$\begin{array}{ll}\text { Synthesis } & 23\end{array}$

3 METHODOLOGY 26

$\begin{array}{ll}\text { Research Design } & 26\end{array}$

West Virginia WISEWOMAN 26

West Virginia WISEWOMAN Interventions $\quad 27$

$\begin{array}{ll}\text { Study Population } & 28\end{array}$

$\begin{array}{ll}\text { Sample } & 29\end{array}$

Quantitative Design $\quad 29$

Research Question $\quad 29$

Study Variables 29

Dependent Variable $\quad 30$

$\begin{array}{ll}\text { Hypotheses } & 31\end{array}$

Independent Variables $\quad 32$

Quantitative Analysis $\quad 36$

$\begin{array}{ll}\text { Qualitative Design } & 37\end{array}$

$\begin{array}{ll}\text { Research Question } & 37\end{array}$

$\begin{array}{ll}\text { Story Path } & 37\end{array}$

$\begin{array}{ll}\text { Data Collection } & 38\end{array}$

$\begin{array}{ll}\text { Structure of the Conversation } & 38\end{array}$

Analysis of Story Method 38 
Institutional Review Board Approval

4 RESULTS 40

$\begin{array}{ll}\text { Quantitative Analysis } & 40\end{array}$

Qualitative Analysis $\quad 52$

5 DISCUSSION, LIMITATIONS AND FUTURE RESEARCH 61

$\begin{array}{ll}\text { Findings } & 61\end{array}$

Quantitative Findings $\quad 61$

Qualitative Findings $\quad 66$

Quantitative and Qualitative Findings Summary 71

$\begin{array}{ll}\text { Strengths and Limitations } & 73\end{array}$

$\begin{array}{ll}\text { Implications for Nursing Practice } & 74\end{array}$

Suggestions for Future Research $\quad 75$

$\begin{array}{ll}\text { REFERENCES CITED } & 76\end{array}$

$\begin{array}{ll}\text { APPENDICES } & 88\end{array}$

$\begin{array}{ll}\text { Appendix A: WISEWOMAN Questionnaire } & 88\end{array}$

Appendix B: Letters to Participants/Telephone Text 113

Appendix C: WISEWOMAN Questions 117 


\section{List of Tables}

Sample Descriptives................................................................ 41

Sociodemographic Variables...................................................43

Health Behavior Changes....................................................... 45

Quality of Life.............................................................. 47

Social Support for Behavior Changes................................................49

Health Conditions Variables................................................................

Hypotheses................................................................. 51

Common Elements......................................................................... 54 


\section{List of Figures}

Johnson's Model of Three Stages of Restructuring........................................ 


\section{Chapter 1}

\section{Introduction of the Problem}

It is estimated that $68 \%$ of adults in the United States are either overweight or obese (Ogden \& Carroll, 2010), including 35.3\% of American women (Centers for Disease Control and Prevention, 2007b). Based on the reported profits of the $\$ 40$ billion weight loss industry (Sherrid, 2003), it is obvious that Americans are trying to lose weight. And yet, the majority of Americans remain overweight or obese. The rate of obesity in West Virginia (31\%) is higher than the national rate $(25.1 \%)$ (West Virginia Health Statistics Center, 2008), and overweight West Virginians are more likely to have heart disease, diabetes, and hypertension than people who maintain a healthy weight (West Virginia Bureau of Public Health, 2004b). Sixty-seven percent of West Virginians are either overweight or obese (West Virginia Health Statistics Center, 2008). The leading cause of death in West Virginia is cardiovascular disease (CVD) (West Virginia Bureau of Public Health, 2004a); and obesity, a modifiable risk factor for CVD, is a major health problem for West Virginians (West Virginia Bureau of Public Health, 2004b).

There is a substantial body of research investigating barriers to weight loss (Paluck, Allerdings, Kealy, \& Dorgan, 2006; Parker \& Keim, 2004; Tessaro, et al., 1998), the process of losing weight (Daniels, 2006; Johnson, 1990), and various strategies for weight loss (McGuire, Wing, Klem, Seagle, \& Hill, 1998; Phelan, Wyatt, Hill, \& Wing, 2006; Simkin-Silverman, Wing, Boraz, \& Kuller, 2003; Technology Assessment Panel, 1993). Conversely, there is a gap in the literature related to identification and understanding of factors, characteristics, and experiences of middle-aged Appalachian women who successfully lose weight. 


\section{Purpose}

The purpose of this mixed methods, exploratory, descriptive study framed by the theory of restructuring (Johnson, 1990) is to examine socio-demographic, health-related, lifestyle, quality of life, and social support factors associated with weight loss in women and to describe high points, low points, and turning points (Smith \& Liehr, 2008) that shaped weight loss in the stories of women who lost at least $5 \%$ of their weight over a one year time period. Specifically, the aims of this study are to:

1. Examine selected factors associated with weight loss in low income, rural women, in a secondary analysis of data collected from The West Virginia WISEWOMAN research study.

2. Examine the stories of women enrolled in West Virginia WISEWOMAN who were successful in weight loss.

\section{West Virginia WISEWOMAN}

The West Virginia WISEWOMAN study, conducted in 2003 - 2008, was a two-group, experimental study investigating the effect of health behavior changes on cardiovascular risk factors in low-income women (Tessaro, 2003-2008). Interventions included diet modifications, increasing physical activity, and smoking cessation. The West Virginia WISEWOMAN study was part of a national study conducted by the CDC.

\section{Significance}

Nurses who work with, interact with, and care for women need to know how to assist them in successful, long-term weight loss. Unfortunately, within three to five years after losing weight, $80 \%$ of the people who have lost weight will regain the lost weight, and end up weighing more than they did prior to losing weight (Byrne, Cooper, \& Fairburn, 2003). The majority of 
people who lose weight will regain half of the lost weight within the first year (Byrne, et al., 2003). As health care providers and researchers, nurses need to be able to understand how some women are successful at making the changes necessary to lose weight, and yet other knowledgeable, resourceful women are not able to follow through with long-term health promoting behavior changes. It is important to identify and understand the factors and characteristics associated with successful weight loss so those attributes can be targeted, enhanced, or developed in nursing practice with overweight and obese women.

\section{Theoretical Framework}

\section{The Process of Restructuring in Weight Loss}

Johnson's theory of restructuring (1990) is the conceptual framework guiding this study. Johnson developed the social-psychological process of restructuring while working with women in a weight loss program. According to Johnson, the process includes both internal and external restructuring, and occurs in three stages. The first stage is gaining a sense of control; the second stage is changing perspective; and the third stage is integrating a new identity and/or way of life. Johnson describes gaining a sense of control as activities such as self-discipline, seeking social support, and joining weight loss groups. Experiencing the highs and lows of gaining control is an individual process of discovering what works and does not work for behavior modification. Changing perspective is manifested by deeper self-awareness and the realization that normal weight can be permanently achieved, and is desired. Realizing and believing that one is a thin, normal weight person is the hallmark of stage three, integrating a new identity and/or way of life. Values, behaviors, and beliefs from stages one and two are integrated in stage three (Johnson, 1990). Factors identified by Johnson as contributing to the integration of the new identity and way of life included effective social support and mastery of food intake. 
The approach to this mixed methods design is theoretical and includes two different analytical strategies. Restructuring will be the theoretical framework that serves as the rationale for this mixed methods study. Restructuring will be studied quantitatively through a secondary analysis of socio-demographic, health-related, lifestyle, quality of life, and social support factors associated with weight loss. The qualitative aspects of restructuring will be obtained through gathering the story and describing the high points, low points and turning points (Smith \& Liehr, 2008) experienced by women who have lost weight. The high points, low points and turning points relate to the three stages culminating in integration of a new identity and way of life (Johnson, 1990). 


\section{Chapter 2}

\section{Review of the Literature}

The purpose of this exploratory, descriptive study is to examine the factors associated with successful weight loss and to further explore the experience of women who have lost weight. This chapter will review the literature related to weight loss in women. Overweight and obesity will be defined based on Body Mass Index (BMI) according to CDC classifications (Centers for Disease Control and Prevention, 2007a). Overweight is based on a BMI of 25.0 $\mathrm{kg} / \mathrm{m}^{2}-29.9 \mathrm{~kg} / \mathrm{m}^{2}$, and obesity is based on a BMI $\geq 30.0 \mathrm{~kg} / \mathrm{m}^{2}$ (Centers for Disease Control and Prevention, 2007a).

\section{Literature Search Process}

Multiple literature searches for full-text studies were performed in Academic Search Complete, CINAHL, Business Source Premiere, Medline, Psych Articles, Women's Studies International, SPORTDiscus, and Health Source Nursing/Academic Edition, using several different key word phrases. Key word phrases included 'weight loss women', ' successful weight loss', 'women and weight', ' obesity in women', 'exercise women weight', 'diet and physical activity', 'Mediterranean diet', 'weight loss support', 'weight loss community', ‘ spiritual weight loss', 'National Weight Loss Registry', 'physical activity weight loss diet', and 'weight loss and quality of life'. Research studies focusing on weight loss strategies, lifestyle factors associated with successful weight loss, quality of life, social support, and the experience of weight loss in women will be reviewed.

\section{Theoretical Framework}

Johnson (1990) conducted a grounded theory study to understand the experience of a person in the process of losing weight. Thirteen white, well-educated, mainly professional 
women, between the ages of 25 and 54 years old, attending a structured weight-loss program were selected to participate in the study. Johnson observed 200 hours of activities at a weight loss center and conducted multiple interviews with the 13 participants, resulting in the identification of three stages of restructuring: gaining a sense of control; changing perspective; and integrating a new identity and/or way of life. During the third stage the individual is acting on the decision to change health behaviors, assimilating new health behaviors, and is in the process of developing a new identity (Johnson, 1990). Figure 1 illustrates the three stages of restructuring.

Using Johnson's emerging theory of restructuring as a component of the conceptual framework, a qualitative study was conducted using comparative case studies of two, single women (one Caucasian, one southern European) in the process of losing weight (Hayward, et al., 2000). The primary goal of the study was to describe the processes experienced by two different women participating in a weight loss program; a secondary goal was to identify factors influencing motivations for weight loss. Eight themes were uncovered in the study: support networks, internalization vs. externalization, routines, relapse, change in perspective, emotional issues, life balance, and rewards vs. punishment (Hayward, et al., 2000). Motivational factors identified by the researchers included: support from friends, family, health care providers, member of the weight loss group, and others; an externally structured weight loss program that becomes internally structured over time; feeling and looking good; and personal rewards such as getting a manicure, or taking time for physical activity. 
Figure 1: Johnson's Model of the Three Stages of Restructuring ${ }^{1}$

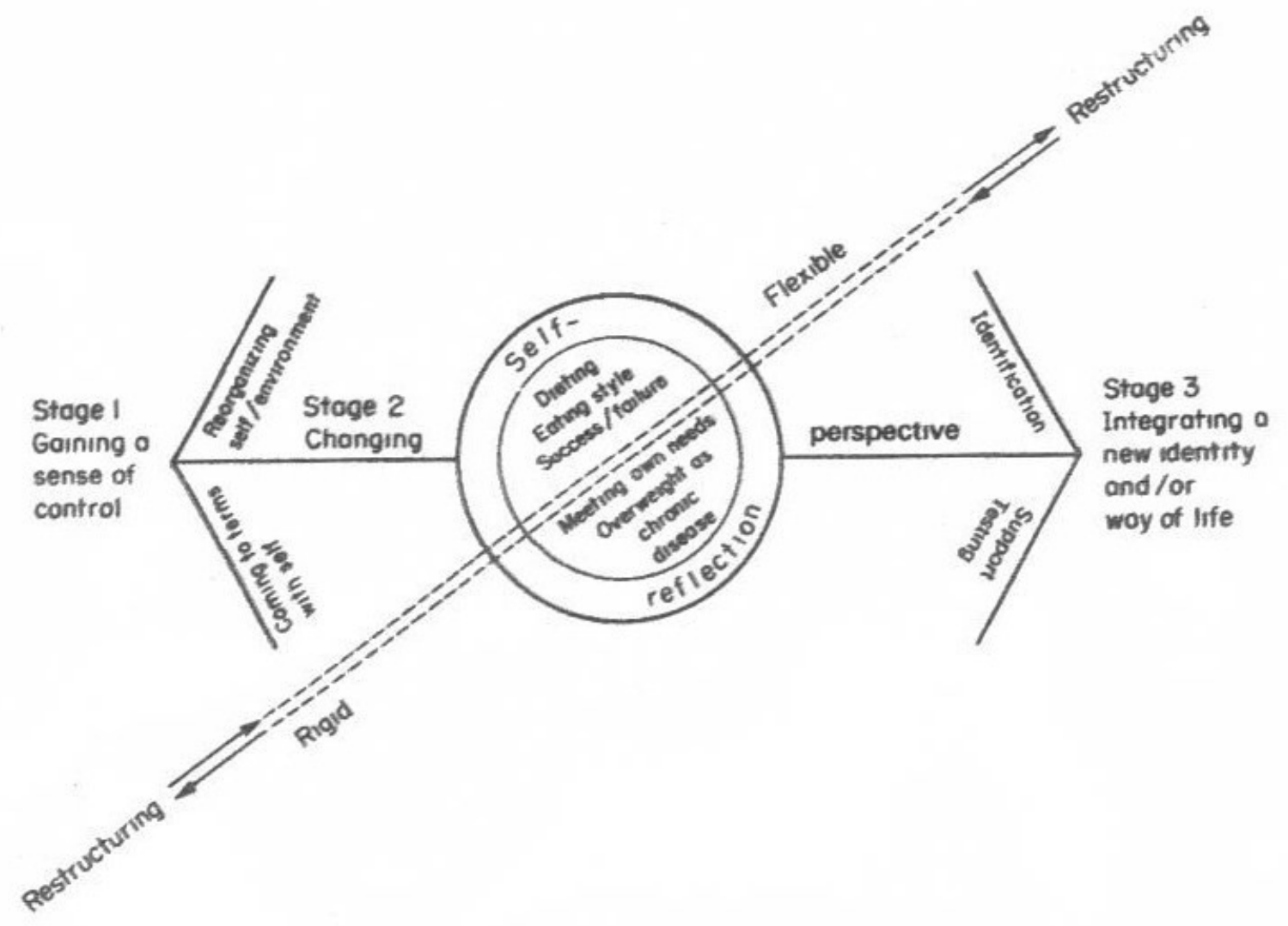

${ }^{1}$ From "Restructuring: An emerging theory on the process of losing weight," by R.

Johnson, 1990, Journal of Advanced Nursing, 15, p. 1291. Copyright 1990 by WileyBlackwell Publishing. Used By Permission.

\section{Story}

The restructuring process of successful weight loss is found in story. "Stories are a fundamental dimension of the human experience" (Smith \& Liehr, 2003, p. 167). The human experience of constructing a story about successful weight loss can be gathered through the dimensions of story described by Smith and Liehr. Story is "a narrative happening of connecting 
with self-in-relation through intentional dialogue to create ease" (Smith \& Liehr, 2008, p. 320). Intentional dialogue is focused on the story of the individual and what is meaningful to the individual surrounding the health challenge; connecting with self-in-relation is a reflective process involving remembering the past, looking into the future, while engaging in the present (Smith \& Liehr, 2008). The authors describe connecting with self-in-relation as involving thoughts, feelings, and relationships with others. Ease is created by helping the individual identify patterns in the story, comprehend meaning of the patterns, and to encompass both sides of the story or to see the whole story. When a person accepts the story as one's own, ease is created, which moves the person toward resolution of the health challenge (Smith \& Liehr, 2008).

Summary. Both Johnson (1990) and Hayward et al., (2000) found that losing weight is a process involving changing perspectives of self, with support from friends, families, and health care providers. The individual's story is focused on the individual and what is personally meaningful. The high points, low points and turning points (Liehr \& Smith, 2000) relate to the three stages of Johnson's theory (1990), culminating in integration of a new identity and/or way of life.

\section{Lifestyle Weight Loss Factors}

\section{Dietary Factors}

Women may use various techniques in the quest to lose weight, including diet modification. Numerous studies have been conducted to examine the influence of the various types of dietary modification on weight loss.

A 52-week randomized controlled study was conducted to compare the compliance rates and effect of two different protein diets (standard protein vs. high protein) on body composition 
and cardiovascular risk factors in 43 obese, hyperinsulinemic subjects, ages 20-65, with BMIs between $27.0 \mathrm{~kg} / \mathrm{m}^{2}$ to $43 \mathrm{~kg} / \mathrm{m}^{2}$ (Brinkworth, et al., 2004). Although both diet groups had weight losses, diet assignment was not found to be a significant factor. The authors noted that adherence to the dietary intervention was poor. Lean body tissue was preserved as overall weight loss in both groups was due to loss of fat mass $(\mathrm{p}<0.001)$ (Brinkworth, et al., 2004).

A randomized study of 50 men and women, ages 18-56 years old, with a 24 month follow-up was conducted to examine the effects of medium (MP) and high protein (HP) diets on body weight (Due, Toubro, Skov, \& Astrup, 2004). Although the researchers did not find a significant difference between groups on weight loss, the HP group lost more fat mass than the MP group ( $\mathrm{p}<0.001)$, had lower waist circumference, a lower waist/hip ratio $(\mathrm{p}<0.001)$, and had lower intra-abdominal adipose tissue compared to the MP group $(\mathrm{p}<0.01)$.

McAuley and colleagues (2005) compared the effects of the Atkins diet (HF=high fat), the Zone Diet ( $\mathrm{HP}=$ high protein), and a high carbohydrate diet (HC) on weight loss in 96 insulin resistant women, ages 30-70 years, in a randomized study. At the end of the 24 weeks all three groups had lost body weight, decreased waist circumference, decreased triglycerides, and decreased insulin levels, but the greatest decreases were in the HF and HP groups $(\mathrm{p}<0.01)$. The HP group lost $2.71 \mathrm{~kg}$ more than the HC group $(\mathrm{p}=0.003)$ and the HF group lost $2.82 \mathrm{~kg}$ more than the HC group ( $\mathrm{p}=0.002$ ); there was no significant difference between the HF and HP groups (p = .91) (McAuley, et al., 2005).

Another study compared the effects of popular diets including the Atkins, Ornish, Weight Watchers, and Zone diets on long-term weight loss (Dansinger, Gleason, Griffith, Selker, \& Schaefer, 2005). A randomized trial of 160 subjects, ages 22 -72 years, with BMIs between 
$27 \mathrm{~kg} / \mathrm{m}^{2}$ to $42 \mathrm{~kg} / \mathrm{m}^{2}$, and at least one other abnormal inclusion criteria (i.e., fasting blood sugar $\geq 110 \mathrm{mg} / \mathrm{dL}$, total cholesterol $\geq 200 \mathrm{mg} / \mathrm{dL}$, or systolic blood pressure $\geq 145 \mathrm{~mm} \mathrm{Hg}$ ) was conducted. At one year the four diet groups had statistically significant weight losses $(\mathrm{p}<0.01)$; there were no significant differences between diets $(\mathrm{p}=.40)$; women had a mean weight loss of $2.4 \mathrm{~kg}(\mathrm{SD}=5.1)$; and their waist circumference decreased by $2.3 \mathrm{~cm}(\mathrm{SD}=4.5)(\mathrm{r}=0.86$, $\mathrm{p}<0.001$ ) (Dansinger, et al., 2005).

Low-fat diets are touted as both the answer to the obesity epidemic and the cause of the obesity epidemic. A study was conducted to examine weight changes in 48,835 women, 50 - 79 years old, randomly assigned to either a control group or an intervention group (Howard, et al., 2006). The intervention consisted of a series of educational sessions with dietitians to decrease fat intake to $20 \%$ of calories, increase fruit/vegetable intake to at least five servings per day, and increase grain intake to at least six servings per day. The subjects in the intervention group had lost $2.2 \mathrm{~kg}$ by the end of the first year $(\mathrm{p}<0.001)$, and by the ninth year the weight loss was 0.5 $\mathrm{kg}(\mathrm{p}=0.01)$. The subjects in the control group gained weight over the study period, although younger women were more likely to gain weight and older women were more likely to lose weight. The women with the largest weight losses had the diets with the least fat $(\mathrm{p}<0.001$, both intervention and control groups). Throughout the study, women in the control group tended to weigh more than women in the intervention group. Weight trended downward for those who increased consumption of fruits and vegetables ( $\mathrm{p}<0.001$ for both groups) (Howard, et al., 2006).

The Mediterranean diet, which consists of fresh fruits and vegetables, monounsaturated fats, such as olive or canola oil, moderate to high amounts of fish, and minimal amounts of red meat and poultry, has been the subject of several studies. A six-month randomized 
interventional study was conducted to examine the effects of the Mediterranean Lifestyle Program (MLP) on body weight, eating patterns, physical activity, stress management, and perceived social support in a group of 279 post-menopausal women with Type 2 Diabetes Mellitus (Toobert, Strycker, Glasgow, Barrera, \& Angell, 2005). Compared to women in the control group, the women in the intervention group had a significant increase in time spent in activities to deal with stress, as well as a significant increase in the frequency, duration and intensity of physical activity. The investigators also found that the intervention group lost an average of $0.87 \mathrm{~kg}$, while the control group gained $0.90 \mathrm{~kg}$ (reported as statistically significant but no p-value given).

To investigate the relationship of the Mediterranean diet to BMI and waist-hip ratio a secondary analysis of the European Prospective Investigation into Cancer and Nutrition (EPIC) study was conducted (Trichopoulou, Naska, Orfanos, \& Trichopoulos, 2005). The study sample included 23,597 adults ( $\mathrm{n}=9612$ men, $\mathrm{n}=13,985$ women $)$, ranging from 20 to 86 years old. The Greek Mediterranean diet was not found to be associated with higher BMI levels in men or Women; women had a slight weight gain (150g, reported as not statistically significant), and only a slight increase in waist-hip ratio $(\beta=.004,95 \% \mathrm{CI})$ (Trichopoulou, et al., 2005).

Dietary adherence results in lower rates of obesity (Mendez, et al., 2006). A similar study to the Greek Mediterranean diet study was conducted in Spain to examine the effect of the Mediterranean diet on obesity, again using a sub-sample of the EPIC study. The Spanish sample included 17,238 women and 10,589 men. The investigators found that overweight people gained less weight annually than obese people $(\mathrm{p}<0.05)$ and women with high rates of adherence to the diet had lower incidences of obesity (OR + 0.69, $0.54-0.89)$ (Mendez, et al., 2006). 
Estruch and colleagues (2006) conducted a randomized, interventional study with 772 adults, between the ages of 55 to 80 years old, to compare the effect of two types of Mediterranean diets (one with virgin olive oil, one with nuts) and a low fat diet on cardiovascular risk factors, including body weight. The investigators found that all three groups had a slight weight loss, with no differences among the groups (Estruch, et al., 2006).

Summary. These ten studies examined some of the most popular diets employed by women in an effort to lose weight. Interestingly, according to the findings of these studies the specific type of diet does not make a major difference in weight loss. Subjects lost weight by eating high protein, medium protein or high carbohydrate/low fat diets (Brinkworth, et al., 2004; Dansinger, et al., 2005; Due, et al., 2004; Howard, et al., 2006). Additionally, three studies found that participants lost weight on high fat diets as well (Dansinger, et al., 2005; Estruch, et al., 2006; McAuley, et al., 2005). Two studies (Mendez, et al., 2006; Trichopoulou, et al., 2005) demonstrated that Mediterranean diets were not associated with overweight or obesity; and two studies found that a Mediterranean diet may be associated with weight loss (Estruch, et al., 2006; Toobert, et al., 2005) . Similar to real life experiences, two studies had high attrition rates (Dansinger, et al., 2005; Due, et al., 2004).

\section{Physical Activity Factors}

Women often seek to increase physical activity in an effort to lose weight. Walking is often recommended as an effective physical activity for weight loss and weight maintenance. A single-group, repeated-measures interventional study was conducted to ascertain the effect of a 10,000 steps-per-day exercise program on body weight, body composition and other cardiovascular risk factors in 56 men and women, 40 to 60 years old, with BMIs $25 \mathrm{~kg} / \mathrm{m}^{2}$ to 45 $\mathrm{kg} / \mathrm{m}^{2}$ (Schneider, Bassett, Thompson, Pronk, \& Bielak, 2006). The investigators found 
statistically significant partial correlations with an increase in number of steps per day with the following variables: change in body weight $(r=-.410 ; \mathrm{p}=.033)$, change in BMI $(r=-.419$; $\mathrm{p}=.030)$, change in hip circumference $(\mathrm{r}=-.405 ; \mathrm{p}=.036)$, change in percentage body fat $(\mathrm{r}=-.44 ; \mathrm{p}=.023)$, and change in fat mass $(\mathrm{r}=-.45 ; \mathrm{p}=.018)$. There was a marginal partial correlation for increase in number of steps per day and change in waist circumference $(r=-.349$; $\mathrm{p}=.074)$ (Schneider, et al., 2006).

Overweight and obese individuals begin an exercise program in an attempt to lose weight but do not know how much exercise is effective. A quasi-experimental study was conducted to compare the effect of multiple short episodes of exercise with one long episode on weight loss and to examine the effect of multiple short episodes of exercise using home exercise equipment on weight loss in 148 sedentary women, 25 to 45 years old, ranging from $20 \%$ to $75 \%$ over their ideal weight (Jakicic, Winters, Lang, \& Wing, 1999). Results showed that women who exercised at least 200 minutes or more per week lost $13.1 \mathrm{~kg}$, women who exercised $\geq 150$ minutes per week lost $8.5 \mathrm{~kg}$, and women who exercised $<150$ minutes per week lost $3.5 \mathrm{~kg}$ (mean weights). The women in the short episode group who also used exercise equipment lost significantly more weight at 18 months than the short episode group who did not use exercise equipment $(\mathrm{p}<.05)$. There were no significant differences between the short episode plus exercise equipment and the long episode without exercise equipment groups at 6 or 18 months in weight loss.

In an effort to examine the effect of moderate intensity exercise alone on total and intraabdominal body fat, a randomized controlled trial was conducted in 173 post-menopausal, sedentary women, ages 50 to 75 years old, with BMIs greater than $25 \mathrm{~kg} / \mathrm{m}^{2}$ (Irwin, et al., 2003). At the one year follow-up, exercisers lost an average $1.3 \mathrm{~kg}$ whereas the control group gained an 
average $0.1 \mathrm{~kg}(\mathrm{p}=.01)$. Women who exercised lost an average of $8.5 \mathrm{~g} / \mathrm{cm}^{2}$ of intra-abdominal body fat compared to the control group who gained a small amount at an average of $0.1 \mathrm{~g} / \mathrm{cm}^{2}$ $(\mathrm{p}=0.45)$. There was an average loss of $6.9 \%$ intra-abdominal body fat in women who exercised for more than 195 minutes each week; 5.9\% for those who exercised 136 - 195 minutes per week; and 3.4\% for those who exercised 135 minutes or less each week. The control group gained an average of $0.1 \%$ intra-abdominal fat.

Middle-age is the time of life that many people have difficulty maintaining or losing weight. Littman, Kristal and White (2005) conducted a secondary analysis of the Vitamins and Lifestyle study to ascertain what effect frequency, intensity, and type of physical activity have on weight gain in middle-aged men and women over a ten-year period. A total of 15, 500 participants (7944 women, 7556 men), between the ages of 53 and 57 years old at baseline, answered questions based on how they had changed since age 45. The study found that all levels of intensity of exercise in women were associated with less weight gain (Littman, Kristal, \& White, 2005). Moderate or fast walking, jogging, running, and aerobics were associated with less weight gain in women. Overall, women gained an average of 14 pounds since age 45 , men gained an average of 11 pounds. Women with increased frequency or intensity of exercise were more likely to lose weight or maintain weight than to gain weight (Littman, et al., 2005).

Summary. Findings of the four studies demonstrate that exercise is a key component to weight loss, with or without dieting. The empirical studies reveal that people successful with weight loss have higher levels of physical activity (Irwin, et al., 2003; Jakicic, et al., 1999; Littman, et al., 2005; Schneider, et al., 2006). Irwin and colleagues (2003) found that exercise alone was directly related to weight loss, and Jakicic, et al., (1999) found that weight loss was time dependent upon exercise: the more time spent exercising, the more weight a woman would 
lose. Littman, Kristal and White (2005) found that women could slow the process of gaining weight by increasing the frequency or intensity of exercise.

\section{Multiple Related Lifestyle Factors}

\section{Combining Diet and Physical Activity}

Successful weight loss involves more than modifications in diet and physical activity levels: women utilize various approaches in their efforts to lose weight. A longitudinal, randomized interventional study was conducted to examine the relationship between diet and exercise in a sample of 288 men and 674 women with a minimum BMI of $27.0 \mathrm{~kg} / \mathrm{m}^{2}$ over a two year time period in a managed care setting (Dunn, et al., 2006). Women who had high levels of exercise and only slightly decreased fat intake lost only a small amount of weight $\left(-0.2 \mathrm{~kg} / \mathrm{m}^{2}\right.$ BMI); women who had low levels of exercise and greatly decreased fat intake lost a moderate amount of weight $\left(-0.8 \mathrm{~kg} / \mathrm{m}^{2} \mathrm{BMI}\right)$; and women who had high levels of exercise and greatly decreased fat intake lost the largest amount of weight (-1.8 kg/m² BMI) (Dunn, et al., 2006). Women who exercised without dietary modifications did not experience significant weight loss.

Simkin-Silverman and colleagues (2003) conducted a secondary analysis of the Women's Healthy Lifestyle Project, a randomized intervention study designed to determine if there was a difference in weight and body composition of women who received the diet and physical activity intervention when compared to women in the control group. The volunteer sample included 535 premenopausal women, $44-50$ years old at entry into the study, with BMI $20-34 \mathrm{~kg} / \mathrm{m}^{2}$, and not receiving hormone replacement therapy. At 6- and 18-months the intervention group had lost more weight than the control group; and at 54-months, twice as many women in the intervention group were at or below their baseline weight as compared to the control group $(\mathrm{p}<0.001]$. Women in the intervention group also had a smaller waist circumference than the women in the 
control group $(\mathrm{p}<0.001)$. Women in the control group continued to consume 159.6 more dietary calories per day than the intervention group $(\mathrm{p}<0.01)$, and the control group continued to be less physically active than the intervention group at 30-, 42-, and 54 months $(\mathrm{p}<0.001)$ (Simkin-Silverman, et al., 2003).

Teixeira and colleagues (2002) identified psychosocial predictors of weight-loss readiness in 112 women, ages $40-55$ years, with BMI $25.0 \mathrm{~kg} / \mathrm{m}^{2}$ to $38.0 \mathrm{~kg} / \mathrm{m}^{2}$. Data were extracted from the first 4 months of a larger 2-year weight-loss/weight-maintenance lifestyle intervention program. Subjects who were most likely to lose weight exercised more $(\mathrm{p}<.001)$, regularly attended weight-loss meetings $(\mathrm{p}<.001)$, had a higher number of previous diets in the past year $(\mathrm{p}<.001)$, had recent weight losses and had higher weight loss expectations $(\mathrm{p}<.01)$, had higher self-motivation and lower body size dissatisfaction $(\mathrm{p}<.01)$, had more years at current weight, a high perceived impact of weight on quality of life, exercise perceived barriers, and self-efficacy $(\mathrm{p}<.05)$ (Teixeira, et al., 2002). Subjects who set high weight loss goals were less successful than those who were happy with losing small amounts of weight. Self-efficacy was not predictive of weight-loss, and neither was impact of weight on work or health (Teixeira, et al., 2002).

The National Weight Control Registry (NWCR) was founded by Wing and Hill (2010) for individuals 18 years old or older who had lost at least 30 pounds, and maintained that weight loss for at least one year. The NWCR provided researchers an opportunity to determine from successful weight loss maintainers the methods for their success. The initial findings of the NWCR in 1994 ( $n=784)$ were that successful weight loss maintainers followed low-calorie diets (1360 kcal/day), consumed $24 \%$ total calories from fat, expended approximately $2786 \mathrm{kcal} /$ week in physical activity, weighed themselves frequently, and ate regular meals, including breakfast 
(Phelan, et al., 2006). McGuire and colleagues (1998) examined data from the NWCR to examine methods for weight maintenance in a sample of 893 individuals, $81 \%$ of whom were women. The sample was divided into three groups: those who lost weight on their own $(n=447)$, those who lost weight through commercial diet programs (i.e., Weight Watchers or TOPS) ( $\mathrm{n}=313$ ), and those who lost weight through liquid diet formulas (i.e., Optifast or HMR) $(n=133)$. Although there were no statistically differences between groups, results indicated that the participants used similar strategies to maintain weight loss; all participants consumed less than $30 \%$ total calories from fat and less than $6100 \mathrm{~kJ} /$ day dietary energy (1452 cal/day) and each group expended more than $10,000 \mathrm{~kJ} /$ week in physical activity (2381 cal/week) (McGuire, et al., 1998).

Summary. Various factors and lifestyle modifications influence weight loss and weight maintenance. Findings of the studies reveal that the combination of diet modification with increasing levels of physical activity is associated with successful weight loss and weight maintenance in women (Dunn, et al., 2006; McGuire, et al., 1998; Phelan, et al., 2006; SimkinSilverman, et al., 2003; Teixeira, et al., 2002). In addition to diet and exercise, several psychosocial elements also affect weight loss, including goals, levels of self-motivation and perceived impact on quality of life (Teixeira, et al., 2002). Findings from the NWCR revealed that participants also eat regular meals every day, including breakfast (Phelan, et al., 2006).

\section{Quality of Life}

In addition to improving physiologic factors such as blood pressure and decreasing CVD risk factors, weight loss produces other benefits for successful individuals. Several studies have found that weight loss positively impacts psychosocial functioning, physical functioning and 
depression (Dixon, Dixon, \& O'Brien, 2003; Karlsson, Taft, Sjostrom, Torgerson, \& Sullivan, 2003; Kaukua, Pekkarinen, Sane, \& Mustajoki, 2003).

The psychosocial benefits of losing weight were documented in a study by Karlsson, Taft, Sjostrom, Torgerson and Sullivan (2004). Psychosocial functioning was measured by questions addressing how individuals functioned in social or public gatherings. The sample was divided into two groups, the intervention group which had undergone surgical intervention for weight loss, and the matched control group which was treated with conventional weight loss methods. Psychosocial functioning improved with weight loss and was strongly related to the amount of weight lost $(\mathrm{p}<0.0001, \mathrm{r}=0.38$ for surgical cases, $\mathrm{r}=0.31$ for conventional treatment) (Karlsson, et al., 2003).

A longitudinal study of 126 men and women, with $\mathrm{BMI} \geq 35 \mathrm{~kg} / \mathrm{m}^{2}$ participating in a structured weight loss program, was conducted to examine the relationship between weight loss and quality of life factors (Kaukua, et al., 2003). Although psychosocial problems decreased in all categories, including the weight gain category, the decrease was greater with greater weight loss [mean change (SD): weight gain -6.1 (9.8); with $0-9.9 \%$ weight loss, -13.5 (17.3); and with $\geq 10 \%$ weight loss, -33.9 (23.6)] (Kaukua, et al., 2003).

Dixon, Dixon and O'Brien (2003) conducted a one-year longitudinal analysis of 262 men and women who had undergone Lap-Band system interventional surgery for obesity to examine the relationship between weight loss and depression using the Beck Depression Inventory (BDI). Findings showed that weight loss was associated with lower depression scores as measured by the BDI in the female sample $(n=216, p<0.001)$; the greater the weight loss, the greater the fall in BDI scores (Dixon, et al., 2003). 
Summary. Findings of these studies found that weight loss positively impacts psychosocial functioning, physical functioning and depression (Dixon, et al., 2003; Karlsson, et al., 2003; Kaukua, et al., 2003).

\section{Social Support}

\section{Weight Loss Support}

In addition to diet modification and increasing physical activity, successful weight losers often seek support from health care practitioners, family members and friends. There are multiple facets of social support in the pursuit for weight loss success. A quantitative study was conducted by Wing, Marcus, Epstein, and Jawad (1991) to determine if spousal support was related to weight loss success in 49 men and women, diagnosed with Type II Diabetes, at least $20 \%$ above their ideal weight, and between the ages of 30 to 65 years. The study also included the participants' spouses, who were greater than $15 \%$ above their ideal weight and 30 to 70 years old (with or without diabetes). The participants were randomly assigned to one of two interventional groups, the control group, which was called the alone group and did not include spouses, or to the intervention group, called the together group, which included the participants and their spouses (Wing, Marcus, Epstein, \& Jawad, 1991). The investigators found that overall there was no significant difference in weight loss between the alone group and the together group at 20 weeks or at one year. However, the intervention group maintained more weight loss at the end of one year $(\mathrm{p}<.05)$. Interestingly, men were more successful with weight loss in the alone condition, while women were more successful with spousal support; in addition, spouses in the together group lost more weight than the participants (Wing, et al., 1991).

Wing and Jeffery (1999) evaluated the effects of intra-group support and inter-group competition on participants who were both familiar with each other and unknown to each other. 
The sample included 82 men and 84 women $(n=166)$ who had been recruited either alone or with three friends, aged 25 to 55 years, in general good health, who were 15 to 70 pounds over their ideal weight. The participants recruited with friends were placed in small groups of four who were known to each other and the participants recruited alone were placed in small groups of four unknown to each other. The small groups were then randomly assigned to one of four treatment conditions 1) participants unknown to each other receiving the standard intervention; 2) participants unknown to each other receiving the standard intervention plus social support and financial reward for weight maintenance; 3) participants and friends known to each other receiving the standard intervention (friendship/relationship not acknowledged); and 4) participants and friends known to each other receiving the standard intervention plus social support and financial reward for weight maintenance. Groups 2 and 4 were encouraged to interact with each other within the group, to teach, encourage and support each other, as well as compete against the other group, respectively. All participants received dietary fat and calorie goals, as well as exercise goals for each week, and were directed to participate in selfmonitoring. Results showed the participants with friends plus social support group had the highest completion rate (Fishers exact test $\mathrm{p}=.048$ ) (Wing \& Jeffery, 1999). The two participants plus friends groups had the most weight loss, but there was no significant difference between the group receiving the social support intervention and the group receiving the standard intervention. Participants with friends also maintained weight loss better than those recruited alone $(\mathrm{p}<.07)$ (Wing \& Jeffery, 1999).

To better understand the experience of women in a spiritually based, group support weight loss program, Reicks, Mills, and Henry (2004) conducted a qualitative study focusing on the phenomena of self-efficacy and locus of control. The researchers developed focus groups 
with 32 women who had been past participants in the church-based Weigh Down weight loss program. All of the women were white, educated, with a mean age of 50 years (range 34 to 72 years old), and moderate income levels (Reicks, Mills, \& Henry, 2004). The women indicated that the Weigh Down program had helped them rely more on physiological cues such as hunger pangs to instigate eating instead of using meal times. They no longer felt guilty about eating specific foods and purchased foods based on taste and desire, their eating behaviors had changed, especially when eating outside the home, and they had increased self-efficacy through sharing with each other, supporting each other and praising each other. In addition to the spiritual benefits, the group support helped the women adhere to their weight loss goals and they motivated each other (Reicks, et al., 2004).

Gorin, Phelan, Tate, Sherwood, Jeffery and Wing (2005) randomly assigned 202 volunteer participants, 25 to 50 years old, and 14 to $32 \mathrm{~kg}$ overweight, to one of two physical activity groups: the 1,000 kcal/week group or the 2,500 kcal/week group. Those in the high physical activity group were asked to invite up to three partners to participate in the study, if desired. Results indicated that weight loss was not significantly different between participants with support partners and those without support partners at 6, 12, and 18 months. Participants with at least one support partner who had lost at least $10 \%$ of their initial body weight $(n=30)$ lost significantly more weight at the 6,12 , and 18 month assessments than the participants without partners or without successful partners $(\mathrm{p}=.004)$ (Gorin, et al., 2005). The investigators concluded that individuals tend to lose weight when their support partners lose weight and adhere to programs when their partners adhere.

Summary. These studies identified that social support is a key component in successful weight loss. Findings showed that although spousal support was not associated with successful 
weight loss for men, it was associated with successful weight loss with women (Wing, et al., 1991); women achieve higher levels of self-efficacy through sharing and supporting each other in weight loss efforts (Reicks, et al., 2004); and weight loss is not impacted by having or not having a support partner, or by the number of support partners, but is enhanced by a support partner who had lost at least $10 \%$ body weight (Gorin, et al., 2005).

\section{Experience of Weight Loss}

As shown in the previous studies, weight loss does not occur in a vacuum. There are many factors which influence successful weight loss, creating an individualized experience. In a qualitative study describing the social factors that influenced their successful weight loss, Daniels (2006) recruited ten women, ages 32 to 55 years, who had lost at least $5 \%$ of their body weight, and were living with at least one other person. Two themes were identified: 1) dieting is work and 2) dieting is a "personal journey" (Daniels, 2006, p. 69). The investigator also identified five phases which women in the process of weight loss move through: 1) preparing for weight loss, 2) acting, 3) achieving a milestone, 4) consolidating a goal, and 5) transitioning to a more healthful lifestyle. Each of these phases included each woman's interactions with family and friends. In preparing for weight loss women sought information from family, friends and health care providers; during the acting phase women sought support from a coach or mentor, usually someone from outside the family; during the achieving the milestone phase the women found self-confidence in the success of meeting a small goal; in the consolidating to goal phase the women refocus on the major goal and seek reinforcement from family, friends, or health care workers; and in the transitioning to a more healthful lifestyle phase the women had met their weight loss goal and were trying to make a long-term lifestyle change (Daniels, 2006). During this final stage there was an ongoing need for continued support from coaches, family, and 
friends. The study identified that women find it difficult to stay with weight loss programs when family and friends are not supportive of them.

Lopez (1997) conducted a phenomenological study with six women to describe how women integrated weight loss programs into their day-to-day lives and the meaning of that experience. The women were recruited from three types of weight-loss programs: 1) physician prescribed and monitored, severely calorie restricted liquid weight-loss program;

2) commercially available weight-loss program, which sells food products; and 3) self-help, nonprofit weight-loss program, which provides list of foods that can be eaten based on weight of food (not calorie content). Feminist theory was used to guide a series of three in-depth interviews focusing on the woman's life up to the point where weight control became a problem, a description of the daily activities in her weight-loss program, and personal meanings of weight. The central theme identified in the study was value conflict: the conflict between needing to take care of self, family, and home versus meeting the goals of the program. Lopez found that although the women desire to lose weight, strict compliance with program guidelines and goals had a negative impact on quality of life.

Summary. Findings from the two studies of women is that women use support networks, including family, friends, health care workers, and members of weight loss groups as motivational supports (Daniels, 2006) but that women had value conflicts due to the pressures of trying to take care of themselves by meeting the needs of the weight loss program or to take care of their families and homes (Lopez, 1997).

\section{Synthesis}

Twenty-nine studies were examined in this literature review. Five of the studies were qualitative in nature and 24 were quantitative. According to the studies reviewed, subjects lost 
weight on various types of diets: adherence to diet was more important than the type of diet. The studies that focused on physical activity and weight loss were in agreement that physical activity, with or without dieting, was a key component of successful weight loss. The one dissenting result was in the study conducted by Dunn and colleagues (2006) which found that women who had high levels of physical activity but only slightly decreased dietary fat consumption had lost only a small amount of weight. Findings were that psychosocial and physical functioning improve with weight loss, and depression symptoms decrease. The studies also indicate that social support is a key factor for successful weight loss in women, yet do not reveal the nature or level of social support needed. The qualitative studies reveal that weight loss is a process, during which women depend on support from others to help them through the sometimes unpleasant experience of managing conflicting values.

The data obtained from these studies are mixed. The data relating to exercise are strong. It would be prudent for a health care practitioner or health educator to counsel overweight and obese women to slowly increase physical activity to 150 to 200 minutes per week in order to enhance weight management and potentially produce weight loss. There is agreement that frequency or intensity of exercise will impact weight. The message on diet strategy is confusing based on these studies alone. Based on the findings of these studies a woman can lose weight on a high fat diet as well as by following a high carbohydrate/low fat diet, high protein diet, or medium protein diet. Although following a Mediterranean diet is not associated with large amounts of weight loss, it is not associated with weight gain in women.

There were high dropout rates in several studies. Dansinger posits that randomization to groups in a research study may lead to high dropout rates as participants do not have the option of choosing the diet that most appeals to them (Dansinger, et al., 2005). Lack of adherence to 
diets over the long-term should not be surprising to researchers, and more closely mimics real life scenarios than following a strict diet for a lengthy time period. If overweight and obese people could follow a strict diet for a lengthy period of time without 'backsliding' they would be at a healthy weight.

It is difficult to generalize results from most of the studies to the general population due to small samples and lack of diversity. Seven studies used participant self-report for at least partial data collection. Although there is a moderate amount of literature available focusing on obesity in post-menopausal women and young women, there is a lack of literature on successful weight loss in middle-aged, women during the peri-menopausal years.

There is a need for more studies comparing and examining the effects of different types of diets on women's bodies, and more studies focusing on levels and nature of social support in weight loss and weight loss maintenance. Recommendations for research include examining diet strategies in middle-aged women (40 -64 years old), with and without exercise.

As more research is conducted on obese women, nurses and health care providers will be able to assist their patients and clients to successful realization of health goals. Long-term lifestyle changes that decrease the incidence of obesity will not only increase longevity of women, but will also increase quality of life through healthful living. This study will focus on factors associated with successful weight loss in middle-aged rural women. 


\section{Chapter 3}

\section{Methodology}

\section{Research Design}

This explorative, descriptive study was designed to examine socio-demographic, healthrelated lifestyle, quality of life, and social support factors associated with weight loss in women and to describe high points, low points, and turning points that shaped weight loss in the stories of women who lost at least $5 \%$ of their weight over a one year time period. Specifically, the aims of this study were to:

1. Examine selected factors associated with weight loss in low income, rural women, in a secondary analysis of data collected from The West Virginia WISEWOMAN research study.

2. Examine the stories of women enrolled in West Virginia WISEWOMAN who were successful in weight loss.

\section{West Virginia WISEWOMAN}

West Virginia WISEWOMAN was one of six enhanced (research) Well Integrated Screening and Evaluation for Women Across the Nation (WISEWOMAN) projects, developed by the Centers for Disease Control and Prevention (CDC) (Tessaro, 2003-2008). West Virginia WISEWOMAN helped uninsured or underinsured women within $250 \%$ of the federal poverty guidelines, aged 40-64, to acquire screening exams and lifestyle interventions to reduce their risk for life-threatening conditions, such as heart disease, stroke, and other chronic diseases. The West Virginia WISEWOMAN study, conducted in 2003-2008, was designed to examine the effectiveness of lifestyle intervention strategies on cardiovascular risk factors in women (Tessaro, 2003-2008). Targeted interventions included enhancing diet (increasing fruits and 
vegetables, decreasing fatty foods), increasing physical activity, and smoking cessation. As part of the West Virginia WISEWOMAN study, an experimental two group design was used to investigate health behavior changes in an intervention study. Thirteen participating clinics were randomly assigned to serve as intervention or control groups. Women in the intervention group received the lifestyle intervention offered through the West Virginia WISEWOMAN and the women in the control group received the standard care offered at the participating clinic. Weight loss was not a primary objective of the West Virginia WISEWOMAN study.

\section{West Virginia WISEWOMAN interventions. The West Virginia WISEWOMAN}

program employed three key interventions. Cookin' Up Health is an interactive computer-based nutritional program that promotes healthy meal preparation and food choices that takes into consideration cultural values and practices (Tessaro, et al., 2006). An earlier study found that Cookin' Up Health increased knowledge concerning dietary fat $(\mathrm{p}=.008)$, influenced dietary behaviors of reading food labels for calories $(p=.02)$, fat grams $(p=.003)$, increased levels of readiness to change for both fruit and vegetable intake $(\mathrm{p}=.016)$ and fat intake $(\mathrm{p}=.02)$ (Tessaro, Rye, Parker, Mangone, \& McCrone, 2007). The computer-based program was supplemented and supported with print-based materials developed specifically for this population (Tessaro, et al., 2006). In addition to the nutritional activity and information, each woman in the intervention group received a pedometer and booklet to record the number of steps walked per day. The third intervention was a "Quit for Life" smoking cessation handbook developed by the American Lung Association, which was given to any women who indicated a desire to stop smoking (Tessaro, et al., 2006).

Women participating in the WV WISEWOMAN study at 13 clinical sites were those women who had come to West Virginia Breast and Cervical Cancer Screening Program 
(WVBCCSP) clinics for health care (Tessaro, 2003-2008). At baseline and 12 months cardiovascular (CVD) risk factors were assessed with a health risk and behavioral survey, including Body Mass Index (BMI) calculation, blood pressure measurement, and blood lipid/glucose panel. Women who had multiple risk factors, and/or non-fasting total cholesterol results greater than or equal to $200 \mathrm{mg} / \mathrm{dl}$, high-density lipoprotein level (HDL) $\leq 40 \mathrm{mg} / \mathrm{dl}$, blood glucose level $>200 \mathrm{mg} / \mathrm{dl}$, systolic blood pressure $\geq 140$, or diastolic blood pressure $\geq 90$ were referred to clinic staff for clinical intervention (Tessaro, 2003-2008). Risk factors for CVD included cigarette smoking, hypertension, low HDL cholesterol, family history of premature CVD, and women 55 years old and older (National Cholesterol Education Program, 2001). Smoking status, level of physical activity, and frequency regarding consumption of vegetables, fruits and fats were assessed through a self-administered health risk and behavioral survey at baseline and 12 months (Tessaro, 2003-2008). Refer to Appendix A for Questionnaire.

\section{Study Population}

The study population for this study was women aged from 40 to 64 years, classified as overweight or obese according to BMI, recruited from 13 WVBCCSP clinics participating in the West Virginia WISEWOMAN project. Overweight and obesity were defined based on BMI according to World Health Organization classifications (World Health Organization, 2008). Overweight was based on a BMI of $25.0 \mathrm{~kg} / \mathrm{m}^{2}-29.9 \mathrm{~kg} / \mathrm{m}^{2}$, obesity class I was based on a BMI of $30.0 \mathrm{~kg} / \mathrm{m}^{2}-34.99 \mathrm{~kg} / \mathrm{m}^{2}$, obesity class II was based on a BMI of $35.00 \mathrm{~kg} / \mathrm{m}^{2}-39.99 \mathrm{~kg} / \mathrm{m}^{2}$, and obesity class III was based on a BMI of $\geq 40 \mathrm{~kg} / \mathrm{m}^{2}$. Women who had a below normal or normal BMI at baseline or who gained $5 \%$ or more of their body weight during the one year WISEWOMAN project were ineligible for this study. 
Sample. The sample for the quantitative portion of this study included 574 women who completed the one year follow-up visit. The women eligible for this study were the 401 overweight and obese women who either lost at least $5 \%$ of their body weight or stayed within $5 \%$ of their baseline weight. The 67 women who lost at least $5 \%$ of their baseline weight were compared with the 334 who stayed within $5 \%$ of their baseline weight. Women who gained more than $5 \%$ of their baseline weight, and those with normal or below normal BMI at baseline, were not included in this study.

The sampling frame for the qualitative study was the 67 overweight and obese women who lost at least $5 \%$ of their baseline weight. A random sample of these 67 women was selected for face-to-face conversations. Saturation was reached with the completion of ten conversations and no further conversations were held. Saturation was defined as the point when the researcher was no longer hearing new information.

\section{Quantitative Design}

\section{Research Question}

What are the factors associated with weight loss in a sample of women in West Virginia WISEWOMAN who have lost at least $5 \%$ of their weight over a one year time period compared to women whose weight stayed within $5 \%$ of their baseline weight?

Study Variables. Operational definitions of the variables for the descriptive and analytic portions of the study are listed below.

Dependent Variable. The dependent variable is weight loss. This study examined factors associated with at least $5 \%$ weight loss vs. maintaining weight within $5 \%$ of baseline. This rationale was based on studies that show that even modest weight loss produces health benefits (Amigo \& Fernandez, 2007; Hill \& Wing, 2003; Knowler, et al., 2002). In a study 
examining the relationship between lifestyle changes and risk of diabetes, researchers found that participants who lost $5 \%$ or more of their baseline weight had a significantly lower risk of developing diabetes mellitus (Tuomilehto, et al., 2001), and in a separate study 5\% weight loss was associated with reductions in the rennin-angiotensin-aldosterone system levels in both blood and adipose tissues, with resulting lowered blood pressure (Engeli, et al., 2005). In this study the variable weight loss was defined as having lost at least 5\% of the woman's initial weight. Weight was measured without shoes using standardized scales, and height measured using a tape measure .

\section{The Hypotheses were:}

Socio-demographic

1. Women who lost at least $5 \%$ of their baseline weight will be younger compared to women whose weight stayed within $5 \%$ of their baseline weight.

2. Women who lost at least $5 \%$ of their baseline weight will have higher levels of education compared to women whose weight stayed within 5\% of their baseline weight.

3. Women who lost at least $5 \%$ of their baseline weight will be more likely to be married compared to women who stayed within $5 \%$ of their baseline weight.

Health Behavior

4. Women who lost at least $5 \%$ of their baseline weight will have made dietary changes compared to women who stayed within $5 \%$ of their baseline weight (Time 1 - Time 2). 
5. Women who lost at least $5 \%$ of their baseline weight will have met physical activity recommendations compared to women who stayed within $5 \%$ of their baseline weight.

Psychosocial

6. Women who lost at least $5 \%$ of their baseline weight will have higher quality of life measures compared to women who stayed within 5\% of their baseline weight.

7. Women who lost at least $5 \%$ of their baseline weight will have higher levels of social support compared to women who stayed within 5\% of their baseline weight.

\section{Health Conditions}

8. Women who lost at least $5 \%$ of their baseline weight will be more likely to report a history of hypertension when compared to women who stayed within $5 \%$ of their baseline weight.

9. Women who lost at least 5\% of their baseline weight will have higher rates of self-reported history of high cholesterol compared to women who stayed within $5 \%$ of their baseline weight.

10. Women who lost at least $5 \%$ of their baseline weight will be more likely to report a history of diabetes mellitus compared to women who stayed within 5\% of their baseline weight.

Control versus Intervention Group

11. Women in the intervention group will be more likely to have lost at least $5 \%$ of their baseline weight compared to women in the control group. 


\section{Independent Variables}

1. Age was measured in years, based on date of birth.

2. Educational level was measured categorically as less than $9^{\text {th }}$ grade or some high school, high school graduate or GED, and some college or higher. Refer to question number 46 in the WISEWOMAN questionnaire in Appendix A.

3. Marital status was dichotomized into married or living with a partner (yes, no). Refer to question number 38 in the WISEWOMAN questionnaire in Appendix A.

4. Change in diet was measured with a variable created to address the difference from baseline (Time 1) to follow-up (Time 2) on total fruits and vegetables intake (continuous variable). A variable created to address Meeting 5-A-Day recommendations (dichotomous) was created based on total fruits and vegetables intake. Tessaro (2003-2008) measured the fruit and vegetable variable using an instrument validated with data from the National Health and Nutrition Examination Survey II (Block, et al., 1986). The instrument was adapted to create a 40-item food checklist, with 16 fruit and vegetable items, and modifications for foods commonly eaten in Appalachia (Tessaro, 2003-2008). The question posed to participants was "Think about your eating habits during the past 4 weeks. About how often did you eat each of the following foods?" (Tessaro, 2003-2008, p. 6). Participants then selected from 8 response options to calculate the number of servings eaten per day: never ( 0 servings $), 1$ per month (0.03 servings), 2-3 per month (0.08 servings), 1 per week (0.14 servings), 2 per week (0.29 servings), 3-4 per week (0.50 servings, corrected from original), 5-6 per week ( 0.79 servings), 1 per day ( 1 serving), and 2 or more per day (2 
servings). Food models were shown to participants for comparison. Portion sizes were calculated by asking participants to state if their serving was 'less' ( 0.5 of the amount), 'the same' (equal to the amount), or 'more' (1.5 times the amount) than the example. A continuous measure of fruit and vegetable servings was determined by multiplying the responses by the portion size and then summing the results. Participants were considered to have met fruit and vegetable recommendations if they consumed at least 5 servings per day (Tessaro, 20032008). The ability of participants to stay away from high fat foods (dichotomous) was also addressed by a question asking "Do you stay away from foods high in fat...?." Refer to questions number 11 and 15 in the WISEWOMAN questionnaire in Appendix A.

5. Physical activity measurements were constructed by the WISEWOMAN study (Tessaro, 2003-2008) using a modified Community Healthy Activities Model Program for Seniors (CHAMPS) survey (Stewart, et al., 2001). This survey is a frequency-based checklist of 30 activities with metabolic equivalent (MET) values from 2 to 6 based on activities including recreational and leisure-time activity, occupation-related activity, and home-related activity (Tessaro, 20032008). Some sedentary activities were omitted and activities related to occupation were added for the WISEWOMAN study. Participants were asked which activities they did in a typical week during the last month, and those who responded yes were then asked to indicate the number of times and number of hours each week the activity was done. Hours per week were measured according to the following scale: $<1$ hour per week, 1-2 hours per week, 3-4 hours per 
week, 5-6 hours per week, 7-8 hours per week, and $\geq 9$ hours per week.

Calculations were as follows: <1 hour per week, 30 minutes of duration was used; beginning with answer choices 1-2 hours per week and thereafter, 0.75 was added to the first number to calculate duration per week.

Total met hours were calculated by multiplying the duration per week times the met value of the activity and summing the results. Participants met physical activity guidelines if they accumulated either 150 minutes of moderate intensity $(\mathrm{MET} \geqq 3)$ for 5 or more days per week or 60 minutes of vigorous intensity (MET $\geqq 4$ ) for 3 or more days per week (Tessaro, 2003 - 2008, p. 5).

Meeting physical activity recommendations was dichotomized into "met physical activity recommendations" and "did not meet physical activity recommendations." Refer to question number 28 in the WISEWOMAN questionnaire in Appendix A.

6. Health Related Quality of Life was measured using 4 items from the Healthy Days core questions of the Behavioral Risk Factor Surveillance System (BRFSS). These items included: 1) general health status; 2) number of days physical health not good; 3) number of days mental health not good; and 4) number of days poor physical or mental health impinged on normal activities during the past 30 days (Ogden \& Carroll, 2010). The general health status question was dichotomized as fair or poor health versus excellent, very good or good health. Questions on number of days of poor physical health and number of days of poor mental health were dichotomized into $<14$ days and $\geqq 14$ 
days. Participants were also asked how many days out of the past 30 days poor physical or poor mental health impinged on their normal activities (choices were to state the number of days or "I don't know"). Refer to questions number 1, 35, 36, and 37 in the WISEWOMAN questionnaire in Appendix A.

7. Social Support includes questions addressing number of close friends or family they feel comfortable with and number of friends or family they see or hear from at least once a week (answer choices for both questions were 0,1 , or 2 , about 3 to 5 , about 6 to 9,10 or more which were recoded into none to 2 , about 3 to 5 , about 6 to 9 , and 10 or more). Support for eating healthier foods was addressed by a question asking if they felt support for eating healthier and support for physical activity was addressed by a question asking if they felt support for physical activity (answer choices for both questions were $1=\mathrm{a}$ lot, $2=$ somewhat, $3=$ very little or not at all). Refer to questions number 13, 24, 40 and 41 in the WISEWOMAN questionnaire in Appendix A.

8. High blood pressure awareness was measured by a specific question asking if the participant has been told by a health care provider that she has high blood pressure (yes, no). Refer to question number 5 in the WISEWOMAN questionnaire in Appendix A.

9. High cholesterol level awareness was measured by a specific question asking if the participant has been told by a health care provider that she has high blood cholesterol levels (yes, no). Refer to question number 5 in the WISEWOMAN questionnaire in Appendix A. 
10. Diabetes awareness was measured by a specific question asking if the participant has been told by a health care provider that she has diabetes (yes, no). Refer to question number 5 in the WISEWOMAN questionnaire in Appendix A.

\section{Quantitative Analysis}

Aim 1: To examine the selected factors associated with weight loss in women.

Prior to analysis, the data were reviewed for outliers and missing data. Missing data was removed in pairwise fashion. The quantitative portion of this study was analyzed using the 2008 Statistical Package for Social Sciences (SPSS, 2008). Descriptive statistics were conducted on all independent variables. Frequencies, percentages and measures of central tendency were used to describe the data.

Bivariate analysis was performed to test for differences between groups. Chi square analysis was performed for the categorical variables of education; marital status; meeting fruit and vegetable recommendations; staying away from high fat foods; meeting physical activity recommendations; general health; physical and mental health; social support for meeting fruit and vegetable recommendations; social support for meeting physical activity recommendations; social support for having friends and relatives to talk to; social support for the number of relatives or friends one sees or hears from; and for history of health conditions (hypertension, blood cholesterol, and diabetes). T-tests were performed for the continuous variables of age, total fruits and vegetables consumed per day (change from time 1 to time 2) and quality of life measures (poor physical or mental health days impinging on normal activities). Two-sided tests of significance were conducted with the alpha level set at 0.05 . 


\section{Qualitative Design}

\section{Research Question}

What are the high points, low points, and turning points in the stories of women in West Virginia WISEWOMAN who have lost at least 5\% of their weight?

\section{Story Path}

Story theory (Liehr \& Smith, 2000) is a method for gathering stories that uses a story-line with markings that represent participant descriptions of high points, low points and turning points in their experience of successful weight loss. Conversations were held with women who lost at least 5\% of their body weight. The investigator used a meaningful consistent structure to encourage the participants to share their story of "what matters most" about the high points, low points and turning points in their experience of losing weight (Smith \& Liehr, 2008, p. 330).

The method to gather story was the story path (Liehr \& Smith, 2000). The investigator drew a line on a white sheet of paper, asked the participant to mark the present moment on the story line and to begin telling the story of weight loss. The participant was asked to mark the times when things went well with their weight loss (high points that shaped their weight loss) and the times when things did not go well with their weight loss (low points that shaped their weight loss). The participant was then asked to mark the time(s) when something changed (turning points that shaped their weight loss) and she was determined to lose weight or knew she was going to be successful with weight loss. The markings helped create the intentional dialogue. The investigator returned to each specific time recorded by the participant to ascertain the story in more detail. Further inquiry about what was going on in their life at each of the points and how this context shaped losing weight was part of the conversation. The conversation was recorded. 
Data Collection. Potential participants were randomly selected from the 67 women who lost $5 \%$ or more of their baseline weight. These women were contacted by letter describing the study and asking them to consider being a participant (refer to letter in Appendix B). A followup phone call was made by the investigator to ask if the woman was willing to participate in the study (refer to Appendix B for telephone text). If she was willing, a date, time and place for the conversation were set. The conversations lasted between 25 minutes to 60 minutes, usually approximately 40 minutes. The conversation process was audio-taped and transcribed by the investigator.

Structure of the conversation:

1. I would like to begin with you telling me about your experience of weight loss. Tell me, when did it first come to you that you were losing weight?

2. Tell me about the times when things were going really well for you with your weight loss.

3. Tell me about times when things were not going so well with your weight loss.

4. Tell me about times when you said "yes, I am losing weight" focused on actions taken to lose weight.

5. Is there anything else you would like to tell me about your weight loss?

\section{Analysis of Story Method.}

Aim 2: To qualitatively describe the experience of women who lose weight.

The qualitative analysis strategy included the following steps: first, each taped conversation was transcribed and then read very carefully; second, a listing of descriptions for high points, for low points, and for turning points in the language of the participant was 
described (Smith \& Liehr, 2008) (high points are defined as when times have gone well with weight loss; low points are when times did not go well with weight loss; and turning points are when something happened to cause a person to make a change in behavior or lifestyle that impacted weight); third, common elements extrapolated from the high points, low points and turning points were identified; and lastly, a synthesized description of high points, low points and turning points for persons who were successful in losing weight was described.

\section{Confidentiality}

Quantitative data were analyzed using identification numbers from the West Virginia WISEWOMAN study. Face-to-face conversations were held between participants in the West Virginia WISEWOMAN study and the primary investigator for this study. All documents and tape recordings were secured in a locked file, and the quantitative and qualitative data were not matched in any way. All identifier documents and tape recordings will be kept in a locked cabinet in the investigator's home until the three year required time period has expired. At that time, all identifier documents and tape recordings will be destroyed.

\section{Institutional Review Board Approval}

Application was made to the West Virginia University Institutional Review Board and acknowledgement of the study was received. Participants in the West Virginia WISEWOMAN study who lost at least $5 \%$ of initial body weight were contacted by the primary investigator for this study and asked if they were willing to participate in a face-to-face conversation about their weight loss experience. The investigator scheduled conversations in the participant's hometown, at a place and time convenient for the participant. After obtaining consent from the participant, the investigator conducted the conversation. 


\section{Chapter 4}

\section{Results}

\section{Quantitative Analysis}

This study examined socio-demographic, health-related, lifestyle, quality of life, and social support factors associated with weight loss in women participating in the West Virginia WISEWOMAN project who lost at least $5 \%$ of their baseline weight over a one year time period. The aim of the quantitative part of this study was to examine selected factors associated with weight loss in low income, rural women in a secondary analysis of data collected from West Virginia WISEWOMAN. The specific questions assessed in the WISEWOMAN questionnaire are recorded in Appendix C. The quantitative data were analyzed using the 2008 Statistical Package for Social Sciences (SPSS, 2008). Participants with missing data were dropped.

The total sample for this quantitative study was 401 overweight and obese women who participated in the West Virginia WISEWOMAN research study. The women were divided into two groups: those who lost at least $5 \%$ of their baseline weight $(n=67)$ and those who stayed within $5 \%$ of their baseline weight $(n=334)$. The mean weight loss for the 67 women who lost at least $5 \%$ of their baseline weigh was 19.36 pounds $(\mathrm{SD}=9.64)$ or $9.52 \%(\mathrm{SD}=4.28)$ of their baseline weight. A majority of the 401 women were 51 to 65 years old (63.8\%), married $(65.3 \%)$ and had a high school diploma or GED (48.9\%). The mean age for the women who lost weight was 52.99 years and 53.06 years for the women who did not lose weight. Sociodemographic descriptors addressing age, marital status and education are recorded in Table 1. 
Table 1

Sample Descriptives

\begin{tabular}{lc}
\multicolumn{1}{c}{ Characteristics } & $\begin{array}{c}\text { Number of participants } \\
(\mathrm{n}=401)\end{array}$ \\
$\mathrm{n}$ & $\%$ \\
\hline Participants, by group & $67(16.7 \%)$ \\
Lost at least 5\% or more of baseline weight & $334(83.3 \%)$ \\
Stayed within 5\% of baseline weight & \\
Education & \\
Less than HS & $79(19.7 \%)$ \\
HS grad/GED & $196(48.9 \%)$ \\
College and above & $126(31.4 \%)$ \\
Marital Status & \\
Yes & \\
No & $262(65.3 \%)$ \\
Age & $139(34.7 \%)$ \\
$40-50$ years old & \\
$51-65$ years old & $145(36.2 \%)$ \\
\end{tabular}

*Some categories have missing data. Missing data were excluded for all analyses.

\section{Research Question}

What are the factors associated with weight loss in a sample of women in West Virginia WISEWOMAN who lost at least $5 \%$ of their weight over a one year time period compared to women whose weight stayed within $5 \%$ of their baseline weight?

Weight loss associated with age and marital status. Women who lost at least $5 \%$ of their baseline weight $(n=67)$ were compared to women whose weight stayed within $5 \%$ of their baseline $(n=334)$ according to age. Women who lost weight were not more likely to be younger than women who did not lose weight $(\mathrm{t}=-.087, \mathrm{p}=.931, \mathrm{SE}=.899)$. There were also no significant differences in weight loss according to age categories $\left(x^{2}=.000, p=1.000\right)$. In addition, women who lost weight were not more likely to be married as compared to women who 
did not lose weight $\left(X^{2}=.129, p=.720\right)$. Due to unbalanced cells in the original chi square test a Fisher's Exact was calculated. Since Fisher's Exact did not show a significant difference between groups, the original test statistic was used.

Weight loss associated with education. Weight loss was compared to educational level by modifying the WV WISEWOMAN data, which had 4 categories for education. Two categories of education were combined to create a total of three categories for this study. "Less than ninth grade" and "some high school" were combined into one category; the second category was "high school graduate or GED"; and the third category was "some college or higher". There were no significant differences among groups $\left(\mathrm{x}^{2}=.356, \mathrm{p}=.837\right)$. Refer to Table 2 . 
Table 2

Sociodemographic Variables

\begin{tabular}{|c|c|c|c|c|}
\hline \multirow[t]{3}{*}{ Variable } & $\begin{array}{l}\text { Number of } \\
\text { participants }\end{array}$ & $\begin{array}{l}\text { At least } 5 \% \\
\text { weight loss }\end{array}$ & $\begin{array}{l}\text { Stayed within } \\
5 \% \text { of baseline } \\
\text { weight }\end{array}$ & \multirow[t]{3}{*}{$\begin{array}{l}\text { *Test Statistic } \\
\quad(\mathrm{p} \text {-value })\end{array}$} \\
\hline & \multirow{2}{*}{$\begin{array}{c}(\mathrm{n}=401) \\
\mathrm{n} \quad \%\end{array}$} & $(\mathrm{n}=67)$ & $(\mathrm{n}=334)$ & \\
\hline & & & & \\
\hline \multicolumn{5}{|l|}{ Age } \\
\hline $\begin{array}{l}\text { (mean, SD) } \\
{[\mathrm{SE}]}\end{array}$ & $\begin{array}{c}53.05+6.708 \\
{[.335]}\end{array}$ & $\begin{array}{c}52.99+6.795 \\
{[.830]}\end{array}$ & $\begin{array}{c}53.06 \pm 6.700 \\
{[.367]}\end{array}$ & $\mathrm{T}=-.087(.931)$ \\
\hline \multicolumn{5}{|l|}{ Age } \\
\hline $40-50$ years & $145(36.2 \%)$ & $24(35.8 \%)$ & $121(36.2 \%)$ & $X^{2}=.000$ \\
\hline $51-65$ years & $256(63.8 \%)$ & $43(64.2 \%)$ & $213(63.8 \%)$ & $(1.000)$ \\
\hline \multicolumn{5}{|l|}{ Education } \\
\hline Less than HS & $79(19.7 \%)$ & $14(20.9 \%)$ & $65(19.5 \%)$ & $X^{2}=.356$ \\
\hline HS grad/GED & $196(48.9 \%)$ & $34(50.7 \%)$ & $162(48.5 \%)$ & $(.837)$ \\
\hline $\begin{array}{c}\text { College and } \\
\text { above }\end{array}$ & $126(31.4 \%)$ & $19(28.4 \%)$ & $107(32 \%)$ & \\
\hline \multicolumn{5}{|l|}{ Marital Status } \\
\hline Yes & $262(65.3 \%)$ & $42(62.7 \%)$ & $220(65.9 \%)$ & $X^{2}=.129$ \\
\hline No & $139(34.7 \%)$ & $25(37.3 \%)$ & $114(34.1 \%)$ & $(.720)$ \\
\hline
\end{tabular}

*Some categories have missing data. Missing data were excluded for all analyses.

Weight loss associated with dietary changes. Two questions on the WISEWOMAN

Questionnaire addressed dietary changes. Total fruits and vegetables intake and meeting 5-a-day recommendations were analyzed using a question from WISEWOMAN asking "Think about your eating habits during the past 4 weeks. About how often do you eat each of the following foods? Remember breakfast, lunch, dinner, snacks and eating out." Answer choices included standard portions of specific families of fruits and vegetables with ratings for frequency of consumption. Calculations were then performed to determine each participant's total servings of 
fruits and vegetables per day. A variable named "total fruits and vegetables final" was created by subtracting the "total fruits and vegetables at baseline" (indicating the number of servings of fruits and vegetables consumed per day at baseline) from the "total fruits and vegetables 2" (indicating the number of servings of fruits and vegetables consumed per day at 12 month follow-up) to reveal changes in diet. A variable was then created to address whether the participants met the "five-a-day" recommendation for fruits and vegetables by recoding: $0=$ did not meet recommendations and $1=$ met recommendations. Participants consuming 0 to 4 servings of fruits and vegetables per day were coded as 0 , indicating that the participants did not meet recommendations. Participants consuming 5 or more fruits and vegetables per day were coded as 1 , indicating that the participants did meet the five-a-day recommendations. The second question assessed participants' ability to stay away from high fat foods. The answer choices were "no" and "yes", each with modifiers. The researcher recoded these as 0 for no, and 1 for yes. There were no significant differences between groups based on dietary changes. Women who lost at least $5 \%$ of their baseline weight were not more likely to increase the total number of servings of fruits and vegetables $(t=.708, p=.479, \mathrm{SE}=.2903)$, to meet the 5-A-Day recommendation $\left(\mathrm{x}^{2}=.403, \mathrm{p}=.525\right)$, or have the ability to stay away from high fat foods $\left(\mathrm{x}^{2}=\right.$ $1.736, \mathrm{p}=.188)$ than women who stayed within $5 \%$ of their baseline weight. The Fisher's Exact calculations for meeting the 5-A Day recommendation and ability to stay away from high fat foods were not different from the original chi square test results. Refer to table 3.

Weight loss associated with physical activity. Physical activity was measured by a modified CHAMPS (Community Healthy Activities Model Program for Seniors) survey (Time 1 - Time 2). Responses on the CHAMPS survey were converted to metabolic equivalent (MET) values, and participants were categorized as meeting or not meeting the recommended physical 
activity guidelines based on these values. There were no significant differences between women who lost at least $5 \%$ of their baseline weight and women who stayed within $5 \%$ of their baseline weight in meeting physical activity recommendations $\left(\mathrm{x}^{2}=.487, \mathrm{p}=.485\right)$. The Fisher's Exact calculation for meeting physical activity recommendations was in agreement with the original chi square results, showing no significant difference between groups. Refer to Table 3.

Table 3

Health Behavior Change

\begin{tabular}{|c|c|c|c|c|}
\hline \multirow[t]{3}{*}{ Variable } & \multirow{2}{*}{$\begin{array}{c}\begin{array}{c}\text { Number of } \\
\text { participants }\end{array} \\
(\mathrm{n}=401)\end{array}$} & \multirow{2}{*}{$\begin{array}{l}\text { At least 5\% } \\
\text { weight loss } \\
\quad(n=67)\end{array}$} & $\begin{array}{l}\text { Stayed within } \\
5 \% \text { of baseline } \\
\text { weight }\end{array}$ & \multirow[t]{3}{*}{$\begin{array}{c}* \text { Test } \\
\text { Statistic } \\
\text { (p-value) }\end{array}$} \\
\hline & & & $(\mathrm{n}=334)$ & \\
\hline & $\mathrm{n} \quad \%$ & $\mathrm{n} \quad \%$ & $\mathrm{n} \quad \%$ & \\
\hline \multicolumn{5}{|l|}{ Dietary Changes } \\
\hline $\begin{array}{l}\text { Total F and V Final } \\
\text { (mean, SD) } \\
\text { [SE] }\end{array}$ & $\begin{array}{c}-.3067 \pm 2.167 \\
{[.108]}\end{array}$ & $\begin{array}{c}-.1355 \pm 2.36 \\
{[.288]}\end{array}$ & $\begin{array}{c}-.3411 \pm 2.129 \\
{[.116]}\end{array}$ & $\begin{array}{c}\mathrm{T}=.708 \\
(.479)\end{array}$ \\
\hline \multicolumn{5}{|l|}{ Dietary Changes } \\
\hline $\begin{array}{l}\text { Meet 5-a-day } \\
\text { recommendations }\end{array}$ & $130(32.4 \%)$ & $19(28.4 \%)$ & $111(33.2 \%)$ & \multirow{2}{*}{$\begin{array}{c}X^{2}=.403 \\
\quad(.525)\end{array}$} \\
\hline $\begin{array}{l}\text { Did not meet 5-a-day } \\
\text { recommendations }\end{array}$ & $271(67.6 \%)$ & $48(71.6 \%)$ & $223(66.8 \%)$ & \\
\hline \multicolumn{5}{|l|}{ Dietary Changes } \\
\hline Stayed away high fat & $213(53.1 \%)$ & $41(61.2 \%)$ & $172(51.5 \%)$ & \multirow{2}{*}{$\begin{array}{c}X^{2}=1.736 \\
(.188)\end{array}$} \\
\hline Did not stay away..fat & $188(46.9 \%)$ & $26(38.8 \%)$ & $162(48.5 \%)$ & \\
\hline \multicolumn{5}{|l|}{ Physical Activity (PA) } \\
\hline $\begin{array}{l}\text { Met PA } \\
\text { recommendations }\end{array}$ & $179(44.6 \%)$ & $33(49.3 \%)$ & $146(43.7 \%)$ & \multirow{2}{*}{$\begin{array}{c}X^{2}=.487 \\
\quad(.485)\end{array}$} \\
\hline $\begin{array}{l}\text { Did not meet PA } \\
\text { recommendations }\end{array}$ & $222(55.4 \%)$ & $34(50.7 \%)$ & $188(56.3 \%)$ & \\
\hline
\end{tabular}

*Some categories have missing data. Missing data were excluded for all analyses.

Weight loss associated with health related quality of life. Women with at least a 5\%

weight loss were not different from women whose weight stayed within 5\% of their baseline in 
four measures of health related quality of life indicators. Four questions from the WISEWOMAN dataset were used to examine these indicators. Participants were asked to rate their general health as $1=$ excellent, $2=$ very good, $3=$ good, $4=$ fair, and $5=$ poor. The responses were then categorized as $1=$ excellent, very good and good, and $2=$ fair and poor. There were no significant differences reported in general health perceptions between women who lost at least $5 \%$ of their baseline weight and women who stayed within $5 \%$ of their baseline weight $\left(\mathrm{X}^{2}=.899, \mathrm{p}=.343\right)$. Participants were also asked to answer questions addressing how many days per month their physical health was not good and how many days per month their mental health was not good. "Poor physical days" and "poor mental days" were coded as $0=$ less than 14 days per month and $1=14$ or more days per month. Participants reporting 14 or more days per month of poor physical health were categorized as physically unhealthy and participants reporting 14 or more days per month of poor mental health were categorized as mentally unhealthy. Another question addressed the number of days during the past 30 days that mental or physical health impinged on normal activities. There were no significant differences in reported number of days of poor physical health $\left(\mathrm{X}^{2}=.402, \mathrm{p}=.526\right)$, number of days of poor mental health $\left(\mathrm{X}^{2}=.001, \mathrm{p}=.979\right)$ or number of poor health days impinging on normal activities $(\mathrm{t}=-.944, \mathrm{p}=.346, \mathrm{SE}=1.231)$ between the two groups of women. Refer to Table 4. 
Table 4

Quality of Life

\begin{tabular}{|c|c|c|c|c|}
\hline \multirow[t]{3}{*}{ Variable } & $\begin{array}{l}\text { Number of } \\
\text { participants }\end{array}$ & $\begin{array}{l}\text { At least } 5 \% \\
\text { weight loss }\end{array}$ & $\begin{array}{c}\text { Stayed within } \\
5 \% \text { of } \\
\text { baseline } \\
\text { weight }\end{array}$ & \multirow[t]{3}{*}{$\begin{array}{l}\text { *Test Statistic } \\
\quad(\mathrm{p} \text {-value })\end{array}$} \\
\hline & $(n=401)$ & $(n=67)$ & $(n=334)$ & \\
\hline & & & & \\
\hline \multicolumn{5}{|l|}{ General Health } \\
\hline $\begin{array}{l}\text { Excellent, Very Good, } \\
\text { Good }\end{array}$ & $258(64.3 \%)$ & $47(70.1 \%)$ & $211(63.2 \%)$ & \multirow[t]{2}{*}{$\begin{array}{c}\mathrm{X}^{2}=.899 \\
\quad(.343)\end{array}$} \\
\hline Fair, Poor & $143(35.7 \%)$ & $20(29.9 \%)$ & $123(36.8 \%)$ & \\
\hline \multicolumn{5}{|l|}{ Poor Physical Days } \\
\hline Less than 14 days & $251(73 \%)$ & $37(68.5 \%)$ & $214(73.8 \%)$ & \multirow{2}{*}{$\begin{array}{l}\mathrm{X}^{2}=.402 \\
\quad(.526)\end{array}$} \\
\hline More than 14 days & $93(27 \%)$ & $17(31.5 \%)$ & $76(26.2 \%)$ & \\
\hline \multicolumn{5}{|l|}{ Poor Mental Days } \\
\hline Less than 14 days & $241(66.2 \%)$ & $37(67.3 \%)$ & $204(66 \%)$ & \multirow{2}{*}{$\begin{array}{c}\mathrm{X}^{2}=.001 \\
\quad(.979)\end{array}$} \\
\hline More than 14 days & $123(33.8 \%)$ & $18(32.7 \%)$ & $105(34 \%)$ & \\
\hline $\begin{array}{l}\text { Poor health days } \\
\text { impinging on activities } \\
\text { (mean, SD) } \\
{[\mathrm{SE}]}\end{array}$ & $\begin{array}{c}5.10 \pm 8.52 \\
{[.450]}\end{array}$ & $\begin{array}{c}4.12 \pm 7.964 \\
{[1.055]}\end{array}$ & $\begin{array}{c}5.28 \pm 8.622 \\
{[.496]}\end{array}$ & $\begin{array}{c}\mathrm{T}=-.944(.346) \\
{[1.231]}\end{array}$ \\
\hline
\end{tabular}

*Some categories have missing data. Missing data were excluded for all analyses.

Weight loss associated with social support. Social support was measured with several questions centering on family and friends. The questions addressing "the number of relatives or friends participants feel comfortable talking to" and "the number of relatives or friends the participants see or hear from" had 5 answer choices: $0=$ none; $1=$ about 1 or two; $2=$ about 3 to $5 ; 3=$ about 6 to 9 ; and $4=10$ or more. Two new variables were created by recoding the answer choices into $1=$ none to $2 ; 2=$ about 3 to $5 ; 3=$ about 6 to 9 ; and $4=10$ or more. Two other questions addressing feeling support for eating healthier and feeling support for being physically active had three answer choices: $1=\mathrm{a}$ lot; 2 = somewhat; and $3=$ very little or not at all. When 
comparing women who lost weight to those who did not lose weight on social support variables there were no significant differences in number of friends and family that participants see or hear from at least once a week $\left(x^{2}=3.476, p=.342\right)$, feeling support for eating healthier $\left(x^{2}=.955, p\right.$ $=.620)$, or feeling support for physical activity $\left(\mathrm{x}^{2}=4.506, \mathrm{p}=.105\right)$. There was a significant difference between the two groups in the number of close friends and family the participants felt comfortable talking with $\left(\mathrm{X}^{2}=18.26, \mathrm{p}=.000\right)$. Those women who lost weight had fewer close relatives and friends they felt comfortable talking to. Refer to Table 5. 
Table 5

Social Support for Behavior Changes

\begin{tabular}{|c|c|c|c|c|}
\hline \multirow[t]{3}{*}{ Variable } & $\begin{array}{l}\text { Number of } \\
\text { participants }\end{array}$ & $\begin{array}{l}\text { At least } 5 \% \\
\text { weight loss }\end{array}$ & $\begin{array}{c}\text { Stayed within } \\
5 \% \text { of } \\
\text { baseline } \\
\text { weight }\end{array}$ & \multirow[t]{3}{*}{$\begin{array}{c}\text { *Test Statistic } \\
\quad(\mathrm{p}-\mathrm{value})\end{array}$} \\
\hline & $(n=401)$ & $(n=67)$ & $(\mathrm{n}=334)$ & \\
\hline & $\mathrm{n} \quad \%$ & $\mathrm{n} \quad \%$ & $\mathrm{n} \quad \%$ & \\
\hline
\end{tabular}

Social Support

F \& F comfortable talking

None to 2

3 to 5

$\begin{array}{cccc}110(27.4 \%) & 31(46.3 \%) & 79(23.7 \%) & X^{2}=18.263 \\ 148(36.9 \%) & 13(19.4 \%) & 135(40.4 \%) & (.000) \\ 60(15 \%) & 12(17.9 \%) & 48(14.4 \%) & \\ 83(20.7 \%) & 11(16.4 \%) & 72(21.6 \%) & \end{array}$

6 to 9

10 or more

$83(20.7 \%) \quad 11(16.4 \%)$

$72(21.6 \%)$

Social Support

$\mathrm{F} \& \mathrm{~F}$ see/hear from

None to 2

3 to 5

6 to 9

10 or more

$\begin{array}{ccrc}117(29.2 \%) & 25(37.3 \%) & 92(27.5 \%) & \mathrm{X}^{2}=3.476 \\ 155(38.7 \%) & 25(37.3 \%) & 130(38.9 \%) & (.342) \\ 64(16 \%) & 7(10.4 \%) & 57(17.1 \%) & \\ 65(16.2 \%) & 10(14.9 \%) & 55(16.5 \%) & \end{array}$

Social Support

Support for eating

healthier

$\begin{array}{lrccr}\text { A lot } & 167(41.6 \%) & 25(37.3 \%) & 142(42.5 \%) & X^{2}=.955 \\ \text { Somewhat } & 159(39.7 \%) & 27(40.3 \%) & 132(39.5 \%) & (.620) \\ \text { Very little/none } & 75(18.7 \%) & 15(22.4 \%) & 60(18 \%) & \end{array}$

Social Support

Support for being

Physical active

$\begin{array}{lrrrc}\text { A lot } & 175(43.6 \%) & 27(40.3 \%) & 148(44.3 \%) & X^{2}=4.506 \\ \text { Somewhat } & 144(35.9 \%) & 20(29.9 \%) & 124(37.1 \%) & (.105) \\ \text { Very little/none } & 82(20.4 \%) & 20(29.9 \%) & 62(18.6 \%) & \end{array}$

*Some categories have missing data. Missing data were excluded for all analyses.

Weight loss associated with high blood pressure awareness, high cholesterol

awareness and diabetes awareness. Comparisons were made based on the questions "have you 
ever been told by a health professional that you have high blood pressure?", "have you ever been told by a health professional that you have high cholesterol?", and "have you ever been told by a health professional that you have diabetes?." Answers were coded as $0=$ no and $1=$ yes. "I don't know" answers were removed from analysis. Women who lost at least 5\% of their baseline weight did not differ significantly from women who stayed within 5\% of their baseline weight on high blood pressure awareness $\left(\mathrm{x}^{2}=.129, \mathrm{p}=.719\right)$, high cholesterol awareness $\left(\mathrm{x}^{2}=\right.$ $.000, \mathrm{p}=1.000)$, or diabetes awareness $\left(\mathrm{x}^{2}=1.555, \mathrm{p}=.212\right)$. There were no differences between groups based on Fisher's Exact calculations for high blood pressure awareness, diabetes awareness and high blood cholesterol awareness. Refer to Table 6 .

Table 6

Health Conditions Variables

\begin{tabular}{|c|c|c|c|c|}
\hline \multirow[t]{3}{*}{ Variable } & $\begin{array}{l}\text { Number of } \\
\text { participants }\end{array}$ & $\begin{array}{l}\text { At least 5\% } \\
\text { weight loss }\end{array}$ & $\begin{array}{c}\text { Stayed within } \\
5 \% \text { of } \\
\text { baseline } \\
\text { weight }\end{array}$ & \multirow[t]{3}{*}{$\begin{array}{c}* \text { Test Statistic } \\
\text { (p-value) }\end{array}$} \\
\hline & $(\mathrm{n}=401)$ & $(\mathrm{n}=67)$ & $(\mathrm{n}=334)$ & \\
\hline & $\mathrm{n} \quad \%$ & & & \\
\hline \multicolumn{5}{|l|}{ Awareness of Hypertension } \\
\hline Yes & $221(55.7 \%)$ & $38(58.5 \%)$ & $183(55.1 \%)$ & \multirow{2}{*}{$\begin{array}{c}X^{2}=.129 \\
\quad(.719)\end{array}$} \\
\hline No & $176(44.3 \%)$ & $27(41.5 \%)$ & $149(44.9 \%)$ & \\
\hline \multicolumn{5}{|l|}{ Awareness of High } \\
\hline \multicolumn{5}{|l|}{ Cholesterol } \\
\hline Yes & $226(58.5 \%)$ & $38(58.5 \%)$ & $188(58.6 \%)$ & \multirow{2}{*}{$\begin{array}{c}X^{2}=.000 \\
(1.000)\end{array}$} \\
\hline No & $160(41.5 \%)$ & $27(41.5 \%)$ & $133(41.4 \%)$ & \\
\hline \multicolumn{5}{|l|}{ Awareness of Diabetes } \\
\hline Mellitus & & & & \multirow{3}{*}{$\begin{array}{c}\mathrm{X}^{2}=1.555 \\
\quad(.212)\end{array}$} \\
\hline Yes & $109(27.4 \%)$ & $23(34.3 \%)$ & $86(26 \%)$ & \\
\hline No & $289(72.6 \%)$ & $44(65.7 \%)$ & $245(74 \%)$ & \\
\hline
\end{tabular}

*Some categories have missing data. Missing data were excluded from all analyses. 
Weight loss associated with intervention and control groups. There were no significant differences in weight loss associated with being in the WISEWOMAN intervention group or the control group $\left(\mathrm{x}^{2}=1.295, \mathrm{p}=.255\right)$. The intervention group had 202 participants (50.4\% of total sample). The control group had 199 participants ( $49.6 \%$ of total sample). Of the 67 women who lost at least $5 \%$ of their baseline weight, 29 women $(43.3 \%)$ were in the intervention group compared to 38 women (56.7\%) in the control group. Fisher's Exact calculations are in alignment with the original chi square results.

Summary. Women who lost at least $5 \%$ of their baseline weight were compared to women whose weight stayed within $5 \%$ of their baseline. The only significant difference between the two groups of women was the number of relatives and friends that participants felt comfortable talking with. Those who lost at least $5 \%$ of their baseline weight had fewer close friends and family members in comparison to those whose weight stayed within 5\% of their baseline. Hypotheses and findings are recorded in Table 7.

Table 7

Hypotheses

Hypothesis Met or Not Met

Women who lost at least $5 \%$ of their baseline Not met weight will be younger compared to women whose weight stayed within $5 \%$ of their baseline weight.

Women who lost at least $5 \%$ of their baseline Not met weight will have higher levels of education compared to women whose weight stayed within $5 \%$ of their baseline weight.

Women who have lost at least $5 \%$ of their baseline weight will be more likely to be married compared to women who stayed within $5 \%$ of their baseline weight. 
Women who have lost at least 5\% of their baseline weight will have made dietary changes compared to women who stayed within 5\% of their baseline weight.

Women who have lost at least 5\% of their baseline weight will have increased levels of physical activity compared to women who stayed within 5\% of their baseline weight.

Women who have lost at least $5 \%$ of their baseline weight will have higher quality of life measures compared to women who stayed within $5 \%$ of their baseline weight.

Women who have lost at least 5\% of their baseline weight will have higher levels of social support compared to women who stayed within 5\% of their baseline weight.

Women who have lost at least 5\% of their baseline weight will be more likely to report a history of hypertension when compared to women who stayed within $5 \%$ of their baseline weight.

Women who have lost at least $5 \%$ of their baseline weight will be more likely to report a history of diabetes when compared to women who stayed within 5\% of their baseline weight.

Women who have lost at least $5 \%$ of their baseline weight will be more likely to report a history of high blood cholesterol when compared to women who stayed within 5\% of their baseline weight.
Not met

Not met

Not met

Not met. The results show that women who lost weight had fewer close friends and family members they felt comfortable talking with than women who did not lose weight.

Not met

Not met

Not met

\section{Qualitative Analysis}

The research question guiding the qualitative analysis was "what are the high points, low points, and turning points in the stories of women in the WV WISEWOMAN program who had lost at least $5 \%$ of their weight?." The story path method was used to gather the stories of the 
women. Conversations were held with ten women. These conversations were audio-taped, transcribed, and read very carefully.

Participants. Ten participants were randomly selected from the 67 women in WV WISEWOMAN who lost at least 5\% of their baseline weight. Nine were Caucasian, one African American. Ages ranged from 48 to 66 years. Six of the participants were married, four were not married. Two women had completed less than high school education, six women were high school graduates or equivalent, and two women had college education and above. Seven of the women had maintained their weight loss following the WISEWOMAN study, three had not.

Data Collection. The story was gathered using the story path method (Liehr \& Smith, 2000). Conversations were held with each participant to elicit her story of weight loss. The purpose of the conversations was to make known the high points, low points and turning points in the participant's weight loss experience.

Data Analysis. To set the context of the story gathering, participants were asked when it first came to them that they were losing weight. Descriptive expressions for this question included "my clothes started getting too big on me, I just didn't really realize it that I was losing like that"; "well, my clothes starting getting a little looser and started feeling better"; "whenever I went back to the doctor"; and "well, I was seeing the doctor too and you get weighed each time you go in."

The qualitative analysis addressed the research question "what are the high points, low points and turning points in the stories of women in the WV WISEWOMAN program who had lost at least $5 \%$ of their weight?." The specific aim related to the question was to describe the experience of women who lost weight. First, each taped conversation was transcribed and read 
carefully. Secondly, a description of each participant's high points, low points, and turning points was created, in the language of the participant.

The third phase of the analysis included identifying the common elements extrapolated from the listing of high points, low points and turning points. A common element was defined as an abstract statement naming a major theme extrapolated from the listing of high points, low points and turning points. Common elements were explicit or implicit in a majority of the descriptions and compatible with all. This listing of common elements can be found in Table 8 . Table 8

Common Elements

\begin{tabular}{|c|c|c|}
\hline High Points & Low Points & Turning Points \\
\hline Vigilantly Taking Control & Impact of Illness & $\begin{array}{l}\text { Making Strategic Food } \\
\text { Choices }\end{array}$ \\
\hline Increased Assurance & Vacillating Eating Patterns & Engaging in Exercise \\
\hline Enhanced Appearance & Fluctuating Weight & Following Through \\
\hline Feeling of Well-being & Sadness/Low Spirits & \\
\hline Becoming More Fit & $\begin{array}{l}\text { Stessful Life Circumstances } \\
\text { Reduced Energy }\end{array}$ & \\
\hline
\end{tabular}

\section{High Points}

Five common elements were inductively analyzed from the participants' descriptions of high points. These elements were Vigilantly Taking Control, Increased Assurance, Enhanced Appearance, Feeling of Well-being, and Becoming More Fit.

Vigilantly Taking Control. For the element of Vigilantly Taking Control, participants described noticing that weight was being lost, watching what was being eaten, canning and preserving fruits and vegetables, eating better, and watching weight come off. When asked 
about things going well with weight loss, one participant responded “...just watching what I ate...mostly fruits and vegetables...we put out a garden, and can a lot of stuff, and we're good"; another participant responded "I was eating better."

Increased Assurance. For the element of Increased Assurance, participants described a change in attitude, more self-confidence, feeling like a better person, being proud of self, feeling good about self because looked like other people, feeling good about being able to buy new clothes, having a better mentality because could buy clothes in the regular section instead of plus-size, and feeling good about achieving something and doing something for self. One participant said "my attitude changed, I had more confidence in myself"; another stated "it felt good, I had better mentality because I could buy clothes in the regular section instead of plussizes"; and another participant said "finally had something... and I liked the idea of earning the mug and earning the jacket."

Enhanced Appearance. For the element of Enhanced Appearance, participants described dropping sizes and fitting into smaller clothes, clothes getting too big, looking nice, others noticing weight loss or saying she was too skinny, not being embarrassed when wearing tank tops and shorts, feet not feeling as big, hands not as swollen, looking better and being small all over, being able to wear clothes that were too tight but are now too big, noticing clothes getting baggy in the abdominal area, and not having a stomach. Dropping sizes was described by one participant as "had to buy smaller clothes, got down to a size 6 ...people would tell me that I was too skinny or had lost a lot of weight" and another participant said she noticed she was "dropping sizes and getting to fit into smaller clothes."

Feeling of Well-Being. For the element of Feeling of Well-Being, participants described feeling better mentally and physically, feeling great, having less depression, being "tickled" 
about losing weight, having a better mood and not being depressed, feeling better when moving and not having time to pay attention to all the little aches and pains. One participant described feeling better as 'feeling better when I'm moving and don't have time to pay attention to all these little aches and pains that I have" and said she had a "better mood, wasn't depressed." And another participant said "mentally and physically you feel better."

Becoming More Fit. For the element of Becoming More Fit, participants described having more energy, not being so tired, walking, building up leg muscles, being able to take the extreme physical therapy more than the mild, being able to drive a car and go to the gym, getting stronger every day, moving around easier, being able to breath and walk, and being more active with a smaller appetite. One participant said "I felt great, more energy, plus, my joints weren't as painful and creaky", and another participant stated "I'm getting stronger every day. I'm working on being a new me."

\section{Low Points}

Six common elements were inductively analyzed from the participants' descriptions of low points. These elements were Impact of Illness, Vacillating Eating Patterns, Fluctuating Weight, Sadness/Low Spirits, Stessful Life Circumstances, and Reduced Energy.

Impact of Illness. For the element of Impact of Illness, participants described not being able to eat a lot of foods because they caused sickness, feeling like she was dying because was so sick, having tubes everywhere and needing to use a walker, experiencing irritable bowel flare ups, swelling due to steroidal medication, Crohn's disease making it hard to do physical activity, not being able to walk due to restless leg syndrome, not trying to exercise due to leg pain, and dislike of needing insulin injections to treat diabetes. Some of the women experienced illness before, during or after participating in the West Virginia WISEWOMAN study. One participant 
described the struggles, saying “it wasn’t going so well for me...it was rough when I came out of the hospital because I came home with feeding tubes, walkers; I had tubes everywhere. It was rough, that's all it was; it was just rough." When referring to her past weight loss and her present condition, another participant said "I think it was mainly the walking. It was the walking, yeah. But now I can't do walking...I have restless leg syndrome, and it kills me just to stand at work on them."

Vacillating Eating Patterns. For the element of Vacillating Eating Patterns, participants described having hungry spells and not being able to get enough to eat, eating until getting sick and then going 2-3 days without eating anything, and eating everything in sight when feeling depressed. One participant described eating erratically when depressed: "I ate until I was sick. Then after I did that I could go 2 or 3 days without eating anything. It filled me up." Another participant said, "if I get depressed, I'll eat everything in sight."

Fluctuating Weight. For the element of Fluctuating Weight, participants described weight going up and down especially around holidays, gaining weight in winter and losing it in summer, having a hard time holding weight down and keeping it off even when working hard at it. One participant described weight changes, saying "I just know I lose it in the summer time and gain it in the winter time." Another participant said "...my weight has always fluctuated up and down, it's always been a problem for me. I have a hard time holding my weight down to one weight."

Sadness/Low Spirits. For the element of Sadness/Low Spirits, participants described feeling embarrassed and guilty of weight loss due to relationships with people who had not lost weight, feeling depressed and aggravated, not having the will to try to lose weight, and feeling upset, depressed and frustrated when not losing weight. One participant described her low spirits 
as "you get upset, you get depressed. I got really upset with myself because it's like my sister said, you're losing inches too but you can't see that, it don't come off as a pound or two pounds...it seemed like I wasn't doing anything." Another participant said "I didn't have the will to try, honestly, before he (referring to husband) had his open heart surgery."

Stressful Life Circumstances. For the element of Stressful Life Circumstances participants described having a lot of stress, children sharing problems which could not be cured, having friends die, family affairs on the mind, and caring for terminally ill mother. A participant described having "children keep me upset all the time; they share problems and I can't cure them all." Another participant said "I had a lot of stress in my life...with my children, with my family. I would not eat, I would sit there and worry; I would walk back and forth, I would walk the streets."

Reduced Energy. For the element of Reduced Energy participants described feeling so tired, did not feel like fixing anything (to eat), could hardly function, and not feeling good or feeling like doing anything. Referring to a time when both her husband and son were having medical tests performed, one participant said “well, I was tired. And, just didn't want anything to eat...just didn't want anything to do with anybody. I don't know, I was just so tired I didn't feel like fixing anything..." Another participant talked about having gallbladder disease around the time she was in the WISEWOMAN study, saying "I couldn't function hardly."

\section{Turning Points}

Three common elements were inductively analyzed from the participants' descriptions of turning points. These elements were Making Strategic Food Choices, Engaging in Exercise, and Following Through. 
Making Strategic Food Choices. For the element of Making Strategic Food Choices participants described not really eating all that much, when craving sweets choosing a tiny piece of pie or cake and fresh fruit, cutting down on bread, not eating anything between 9:00 P.M. and 7:00 A.M., drinking only water, using a portion plate, learning to balance binges, eating fruits, vegetables and whole grains, learning to live without candy, cookies, brownies, sweet rolls and cake, eating smaller portions, making lunch the biggest meal of the day, eating more vegetables and less fat stuff, choosing diabetic cookies instead or regular cookies, walking past candy without eating any, leaving desserts and breads alone, using new recipes, reading labels, baking, broiling and grilling instead of frying, and purposely not changing diet because of not being good at following diets. A participant describes managing food intake as "I don't eat anything after 9:00 (pm) to 7:00(am). I drink nothing but water; I don't care how hungry I get, how bad they tempt me, I ain't eating it." Another participant said "I eat fruits, vegetables and whole grains. I learned to live without candy, cookies, brownies, sweet rolls and cake."

Engaging in Exercise. For the element of Engaging in Exercise participants described walking for over 30 minutes 1 to 3 times a week, using a pedometer to monitor and encourage walking, being able to walk to the top of a hill, and walking 4 miles every evening. One participant was very excited about walking, saying "I walked and where I live there's a big hill and I live clear on top of the hill, and I mean there's another hill and every day I would walk. My goal was to get to the top of that hill, because I mean it just goes straight up and I finally made it...I was glad. I didn't think I'd ever walk that far." Another participant said "the pedometer was the main key though. It was like my motivator."

Following Through. For the element of Following Through participants described living, learning and overcoming to prove to self that one can really do it, thinking about making 
good choices daily, thinking about portion sizes, learning about healthy foods and changing recipes, and putting one's mind to it: keeping busy and moving. One woman said "I always believe you have to live and learn and after that if you could just overcome and prove to yourself that you can really do it, then life really isn't that bad." Another participant was reflecting on her weight loss and said, "I did it. I mean, I just put my mind to it and I did it."

Synthesis. The experience of losing weight for these 10 participants who were successful at weight loss surfaced as an awareness that they were losing weight with changes in the way their clothes fit and the numbers on the scale. High points in their experience were illuminated through changes in well-being and view of self. Low points in their experience were revealed as low energy, challenging life circumstances, and variations in weight and eating patterns. Turning points were experienced as meaningful moments when actions were taken to follow through with food choices and activity. This synthesis represents the findings of the study that addresses the high points, low points and turning points in the stories of women in the WV WISEWOMAN program who have lost at least $5 \%$ of their weight. 


\section{Chapter 5}

\section{Discussion, Limitations and Future Research}

\section{Purpose}

The purpose of this mixed-methods study was to examine socio-demographic, healthrelated lifestyle, quality of life, and social support factors associated with weight loss in women participating in the West Virginia WISEWOMAN project who lost at least $5 \%$ of their baseline weight. The aims were 1) to examine selected factors associated with weight loss in low income, rural women and 2) to qualitatively describe the experience of women who lose weight. The research questions were:

1. What are the factors associated with weight loss in a sample of women in West Virginia WISEWOMAN who have lost at least 5\% of their weight over a one year time period compared to women whose weight stayed within $5 \%$ of their baseline weight?

2. What are the high points, low points, and turning points in the stories of women in West Virginia WISEWOMAN who have lost at least $5 \%$ of their weight?

\section{Findings}

The findings of this study address the gap in the literature pertaining to successful weight loss in middle-aged women. This study adds to the body of literature both quantitatively and qualitatively. Significant findings in relation to the literature will be discussed below.

\section{Quantitative Findings}

Interpretation of findings related to Theory of Restructuring. Johnson theorizes weight loss as a process with three stages: gaining a sense of control, changing perspective and 
integrating a new identity and/or a way of life (Johnson, 1990). In Johnson's theory support from family and friends assists women with the integration of a new identity as a thin person, and a new way of life by sharing meals, partnering in physical activity, and positive feedback. In this study, social support was a significant factor in weight loss. The findings suggest that women who lost weight had fewer friends and family they felt comfortable talking with than women who did not lose weight. It appears that having a few close friends and family members to rely on for support in weight loss is more advantageous than having many friends and family members, which may be more stressful.

Interpretation of findings related to demographic factors. In this study there were no differences in weight loss based on age, education or marital status between women who lost at least $5 \%$ of their baseline weight and those who stayed within $5 \%$ of their baseline weight. Interestingly, a study predicting weight loss in individuals diagnosed with diabetes found that older participants and married participants were more likely to lose weight (Wray, Blaum, Ofstedal, \& Herzog, 2004); yet an earlier study conducted by Roberts and Ashley examining the characteristics of successful weight losers did not find age to be a significant factor (Roberts \& Ashley, 1999). Perhaps socio-demographic factors were not critical factors in successful weight loss for these women; or differences could not be seen because these women were a homogeneous group socioeconomically (mid-life, lower SES, little or no health insurance, and mostly rural, living in a rural state ). Other reasons for non-significant findings may be due to the narrow weight loss margin of $5 \%$ or the small sample size.

Interpretation of findings related to health behaviors. This study did not find any difference in dietary changes or meeting physical activity recommendations between women who lost at least $5 \%$ of their baseline weight and women who stayed within $5 \%$ of their baseline 
weight. Several studies have shown that dietary changes do enhance weight loss (Arefhosseini, Edwards, Malkova, \& Higgins, 2009; Dansinger, Tatsioni, Wong, Chung, \& Balk, 2007; Davis, et al., 2009). Davis and colleagues (2009) found that overweight adults lose weight with either low-carbohydrate or low-fat diets; Arefhosseini and colleagues (2009) found that women following a low-fat diet had significantly lower BMIs at the end of 4 weeks; and Dansinger and colleagues (2007) conducted a meta-analysis and found that adults receiving dietary counseling experienced significant decreases in BMI as compared to those receiving the usual care. In contrast, a study investigating the relationship between diet changes and weight found that although there was a significant difference in weight between intervention and control groups at 1-year, there were no difference at 4 years (Saquib, et al., 2009). The results for the women in the WV WISEWOMAN program were obtained at 12 months. There were also no differences in meeting physical activity recommendations. This finding contradicts other studies which have shown physical activity to be a significant factor in weight loss (Folta, et al., 2009; Silva, et al., 2009; Teixeira, Going, et al., 2004). In a study examining successful weight management in women, participants who lost $5 \%$ or more of their baseline weight, and maintained the loss, reported more time spent in exercise than those who did not lose weight (Teixeira, Going, et al., 2004) and women who walked more steps per day lost more weight than those who walked less (Folta, et al., 2009). In an intervention study looking at physical activity and weight loss, women who walked at least 2000 more steps-per-day than the control group lost significantly more weight than the control group (Silva, et al., 2009). Yet, in a study by Teixeira and colleagues reexamining exercise and weight loss, exercise was not associated with weight loss (Teixeira, Palmeira, et al., 2004). This study did not find significant differences in dietary modifications or levels of physical activity. Since women can lose weight by making diet changes or increasing 
physical activity, perhaps the women who lost weight did so through the combination of diet and physical activity, which this study did not investigate. Participants could have also changed diet and physical activity in ways that were not ascertained with WISEWOMAN questions. In addition, the $5 \%$ weight loss parameter was too narrow, or the sample was too small to detect differences between the groups.

Interpretation of findings related to quality of life measures. Women who lost weight did not differ from women who did not lose weight in quality of life measures. This finding is perplexing, as other studies have found a difference in quality of life measures after weight loss. Blissmer and colleagues found that one year after the weight loss, intervention participants had improved mental health, physical functioning, general health and vitality scores (Blissmer, et al., 2006) and in another study, participants in the low-carbohydrate diet group experienced improved mental health scores and participants in the low-fat diet group experienced improved physical health scores (Yancy, et al., 2009). Although quality of life may have improved enough for the participants to notice, as was discussed by women in the qualitative portion of the study, the improvements may not have been large enough to be statistically significant. For some of the women a $5 \%$ weight loss was less than 10 pounds, which may not have been enough to produce significant changes in quality of life measures. Yet, statistical analysis showed that there was an average weight loss of 19.36 pounds, so it is unclear why that amount of weight loss would not affect quality of life measures. In addition, the small sample size may be another reason for the non-significant findings.

Interpretation of findings related to levels of social support. Significant differences were found in levels of social support for women who lost at least $5 \%$ of their baseline weight and those who stayed within 5\% of their baseline weight in this study. Interestingly, it appears 
women who were successful with weight loss in this study had fewer friends and family they felt comfortable talking with than women who did not lose weight. This finding is supported by a study conducted by Tessaro, et al. (2006). During the development of the weight loss intervention Cookin' Up Health, researchers found that families were both a support and barrier for changes in health behaviors (Tessaro, et al., 2006). Perhaps the close relationships women develop with a few friends or family members is more beneficial than having a higher number of friends and family members they interact with weekly, which may be because some of this interaction may be stressful. There were no significant differences between groups for the number of friends and family the women see or hear from at least once a week. Assuming that 'comfortable talking with' denotes quality in personal relationships, this would signify that women find support for weight loss in close, personal relationships rather than in the number of friends and family members in their lives.

\section{Interpretation of findings related to awareness of hypertension, diabetes, or high}

blood cholesterol. Women who successfully lost weight in this study were not different from women who did not lose weight based on awareness of having hypertension, diabetes or high blood cholesterol. This study supports an earlier study investigating how women decide what to weigh in relation to weight control: the study found that weight decisions were based on selfimage and unattractive appearance, and not on health issues (Allan, 1988). In contrast, another study with both men and women as participants found that the decision to lose weight was usually based on health, appearance, trigger age, competition, or fear (Brink \& Ferguson, 1998), but the study did not differentiate findings between men and women. In addition, Wray and colleagues (2004) found that a diagnosis of diabetes was a predictor of weight loss. Health issues may not be important weight loss motivators for women. Other factors such as 
appearance, and self-image may be more important. In addition, the West Virginia WISEWOMAN program was not a weight loss program and women did not enter it with the purpose of losing weight, therefore having hypertension, diabetes or high blood cholesterol would not have been significant factors in successful weight loss in this study. The narrow 5\% weight loss margin and small sample size may have also been factors in the non-significant findings in this study.

\section{Qualitative Findings}

Findings related to the theory of Restructuring. The high points and turning points can be described in relation to the theory of restructuring. Restructuring is an alteration in a person's life during and after change from overweight to normal weight (Johnson, 1990). Stages of the theory include gaining a sense of control, changing perspective, and integrating a new identity and/or way of life.

Gaining a sense of control (Johnson, 1990) is primarily related to the turning points, but also to the high points. Gaining a sense control of relates to the common elements of Making Strategic Food Choices, Engaging in Exercise, Following Through, and Vigilantly Taking Control. Participants' descriptions of Making Strategic Food Choices included cutting down on bread, drinking only water, using a portion plate and eating smaller portions, using new recipes, reading labels, and baking, broiling and grilling instead of frying. These descriptions are methods participants apply in gaining a sense of control over what foods and beverages they consume. Engaging in Exercise was described by participants as walking for over 30 minutes 1 to 3 times a week, using a pedometer to monitor and encourage walking, being able to walk to the top of a hill, and walking 4 miles every evening. Participants used exercise as a way to gain 
a sense of control over physical activity. Gaining a sense of control also includes thinking about making good choices daily, thinking about portion sizes, and learning about healthy foods and changing recipes, all components of Following Through. Participants gained a sense of control as they were Vigilantly Taking Control, described as noticing that weight was being lost, watching what was being eaten, canning and preserving vegetables, eating better, and watching weight come off.

Changing perspective (Johnson, 1990) can be found in the high points. Increased Assurance, Enhanced Appearance, Feeling of Well-Being and Becoming More Fit pertain to changing perspective. Participants' descriptions of Increased Assurance include a change in attitude, more self-confidence, feeling like a better person, being proud of self, and feeling good about achieving something and doing something for self. These descriptions also relate to changing perspective. Enhanced Appearance included descriptions such as dropping sizes and fitting into smaller clothes, looking nice, not being embarrassed when wearing tank tops and shorts, looking better and being small all over, and being able to wear clothes that were too tight but are now too big. The women developed a change in perspective about themselves through enhanced appearance. Feeling of Well-Being was described by participants as feeling better mentally and physically, feeling great, having less depression, being "tickled" about losing weight, having a better mood and not being depressed, feeling better when moving and not having time to pay attention to all the little aches and pains. With the element Becoming More Fit, participants described having more energy, not being so tired, walking, building up leg muscles, being able to drive a car and go to the gym, getting stronger every day, moving around easier, and being more active with a smaller appetite. Participants began seeing themselves as becoming more fit and feeling well, facets of changing perspective. 
Integrating a new identity and/or way of life (Johnson, 1990) is related to the common element of Following Through. Participants follow through with lifestyle decisions such as living, learning and overcoming to prove to self that one can really do it, thinking about making good choices daily, thinking about portion sizes, learning about healthy foods and changing recipes, and putting one's mind to it: keeping busy and moving.

The experience of losing weight for these 10 participants was a process of restructuring their life through high points, low points and turning points. In the restructuring: a sense of control experienced as turning points when actions were taken to follow through with food choices and activity; a changing perspective experienced as high points with changes in well being and view of self; and both high points and turning points in integrating a new way of life. Through the process of weight loss low points were also experienced as times of low energy and challenges. Low points are not specifically addressed in the model of the theory of restructuring, however the author describes the highs and lows of gaining a sense of control, and the meaning of success and failure in changing perspective (Johnson, 1990). Johnson found the level of rigidity or flexibility in the strategies used in gaining a sense of control for weight loss was based on success or failure in previous attempts at weight loss. In addition, although overeating and weight gain are usually perceived as failure, participants experienced a change in perspective as they learned how to manage the overeating and ensuing weight gain, resulting in a feeling of success.

\section{Findings Related to High Points}

Common elements in the high points of Becoming More Fit, Vigilantly Taking Control, and Feeling of Well-Being in this study are supported by a study examining weight maintenance after successful weight loss (Elhag \& Rossner, 2005). Weight maintenance is associated with 
having a physically active lifestyle, regular meal rhythm, control of overeating and self-

monitoring of behaviors, and more psychological strength and stability (Elhag \& Rossner, 2005). A high quality diet and exercise program improved depressive symptoms in overweight women (Kerr, et al., 2008). In addition, Feeling of Well-being is further supported by two studies: one finding that physical functioning, general health, vitality and mental health scores improved for a group of overweight adult men and women after a diet and exercise intervention (Blissmer, et al., 2006); and another finding that fatigue and vitality scores improved for previously sedentary obese women after a supported exercise and nutrition information program (Annesi, 2007). As women took control of their diets and increased levels of physical activity, they began to lose weight, and felt better mentally and physically. Continuing these behaviors resulted in feeling more fit.

Becoming More Fit and Feeling of Well-being are further supported by a study finding that obese women participating in the Curves International exercise and weight loss program had increased relative peak oxygen uptake, decreased resting heart rates, decreased systolic blood pressure, and decreased mean arterial pressure, as well as significant improvements in physical functioning, bodily pain, general health, vitality, and mental health (Kerksick, et al., 2009). Also, the common element Enhanced Appearance is supported by a study that found women who exercised, regardless of diet, had improved body image (Kerksick, et al., 2009). In another study, body image improved after weight loss intervention but was not related to weight loss (Foster, Wadden, \& Vogt, 1997). As women felt better and became more fit, they realized that both their health and appearance were improving. These bodily and self-image changes led to a changing perspective (Johnson, 1990), and increased assurance. 
The elements Becoming More Fit and Engaging in Exercise have some degree of overlap. A study examining a diet and exercise program found that women were strongly motivated by the physical activity component, which increased fitness and triggered the desire to find other types of physical activity (Herriot, Thomas, Hart, Warren, \& Truby, 2008). Weight maintenance is more successful with consistent physical activity (Wing, et al., 2008).

Increased Assurance is supported by a study in which participants verbalized an increase in self-confidence and self-esteem (Herriot, et al., 2008). Other studies offer support for Making Strategic Food Choices, Vigilantly Taking Control and Engaging in Exercise. Strategies for weight loss employed by rural Australian residents included changing types of foods purchased and consumed, setting a BMI goal, and self-monitoring of body and food intake (Heading, 2008). Self-monitoring of exercise and higher levels of weekly exercise has been associated with greater weight loss (Carels, et al., 2005). Participants in this study developed more selfassurance as they effectively managed food choices, routinely engaged in exercise, and achieved goals. In addition, as the participants lost weight and increased activity levels, they felt more fit and healthy.

\section{Findings Related to Low Points}

Analysis of low points in this study is supported by other studies, particularly Vacillating Eating Patterns, Sadness/Low Sprits, Stressful Life Circumstances and Low Energy. Excessive eating when stressed or sad was described by this study. Disinhibited eating, binge eating, and eating in response to negative emotions and stress may lead to weight regain (Elhag \& Rossner, 2005; Wing, et al., 2008). Weight fluctuations, especially seasonal in nature, were expressed as low points. Weight cycling also has a negative effect on long-term weight maintenance (Elhag and Rossner, 2005). Stressful life events and binging on carbohydrates were noted as stumbling 
blocks for rural Australian adults (Heading, 2008) and emotional eating as a method of dealing with stress and fatigue had negative effects on daily living for women in a study examining racial differences in perceptions of obesity in women (Thomas, Stallings, Nichols-English, \& Wagner, 2008). Sadness/Low Spirits was described in this study, and is supported in a study that found men and women are hurt by others' remarks, are dissatisfied with their bodies, have low selfesteem and lack of self-confidence (Bidgood \& Buckroyd, 2005).

During the weight loss experience women encountered struggles and difficulties. The participants discussed feeling sad, overindulging when stressed, and extreme tiredness. Learning to manage and overcome these struggles and difficulties with weight loss was vital for success.

\section{Findings Related to Turning Points}

Common elements in turning points are described as women are Following Through with making decisions to change lifestyle behaviors. Autonomy and assuming responsibility in life (Elhag \& Rossner, 2005) and viewing behavior changes as permanent lifestyle changes are important in successful weight loss and weight maintenance (Herriot, et al., 2008).

Transformation from an overweight woman to a normal weight woman involves following through with lifestyle behavior changes and integrating a new way of life. This identity change, as described by Kearney and O’Sullivan (2003), takes time and is reinforced by continued lifestyle behavior changes. The identity shift subsequently sustains the lifestyle behavior changes, and the lifestyle changes continue to support the identity shift (Kearney \& O'Sullivan, 2003).

\section{Quantitative and Qualitative Findings Summary}

In the qualitative study the experience of losing weight for these 10 participants who were successful at weight loss surfaced as an awareness that they were losing weight with 
changes in the way their clothes fit and the numbers on the scale. High points in their experience were illuminated through changes in well-being and view of self. Low points in their experience were revealed as low energy, challenging life circumstances, and variations in weight and eating patterns. Turning points were experienced as meaningful moments when actions were taken to follow through with food choices and activity. Although the quantitative findings found no significant changes in diet, qualitatively women identified Making Strategic Food Choices, which included eating more fruits and vegetables, staying away from high fat foods and controlling portions. Quantitatively there were also no significant differences in physical activity between weight losers and weight maintainers. In the qualitative study women were Engaging in Exercise, identified as walking multiple times per week and using pedometers to monitor progress. In addition, there were no significant differences found between groups in quality of life measures, yet Feeling of Well-Being and Becoming More Fit were identified as common elements in the women's experiences of weight loss. Feeling of Well-Being was described by the women as feeling happier, having a better mood, having less depression and feeling better mentally and physically. Becoming More Fit was described by having more energy, not being so tried, and feeling better. This study also found that women who were successful at weight loss had a smaller number of friends and family to turn to for social support compared to women who did not lose weight. Although social support did not present as a common element in the stories of women who lost weight, the element Stressful Life Circumstances, described by some of the women as family-related challenges, was identified. Perhaps a larger number of family and friends presents more challenging situations for women, and negatively impacts the weight loss process. 
Reasons why the quantitative portion of this study did not find significant changes in diet change, physical activity levels, quality of life measures or awareness of chronic diseases may be due to the small sample, the $5 \%$ weight loss level, which was not high enough to obtain significant differences between groups, or the homogeneity of the participants. It is interesting to note women who lost at least $5 \%$ of their baseline weight were not more likely to be in the intervention group. Although the West Virginia WISEWOMAN study was not focused on weight loss, dietary and physical activity recommendations were provided to participants that were similar to recommendations offered in weight loss programs. Again, the sample may be too small or the $5 \%$ weight loss parameter too narrow to find statistically significant differences.

\section{Strengths and Limitations}

The West Virginia WISEWOMAN program is a national program, with strong support and supervision. A large quantity of data were collected by the WISEWOMAN study, which was used for secondary analysis in this study. Another strength of this study is the depth and richness of information gathered in the conversations.

This study was limited by the small, geographically limited sample. Only women from West Virginia WISEWOMAN were included in the study, which was a very small sample of Appalachian women from one region of Appalachia. Furthermore, the sample was a convenience sample, limited to women who visited select clinics in the state for health care and agreed to participate in the study. Women who agreed to talk with the investigator may be significantly different, or had a different experience, than the women who agreed to talk. Due to these limitations on the sample generalization to a larger population is not possible. Additionally, some of the data was self-reported from the participants and the qualitative data 
was collected 2 years after original weight loss. The study also used previously collected data for secondary analysis.

\section{Implications for Nursing Practice}

Women in this study discussed monitoring food choices, watching weight come off, exercising regularly, and feeling better as some of the high points of successful weight loss. Although the findings of this study cannot be generalized to a larger population, the findings can be transferred to a similar group of women in the process of losing weight. Nurses can offer continual support to obese and overweight rural women, such as frequently offering educational materials, assisting with weight monitoring with a record-keeping booklet or journal, encourage the use of pedometers or other methods for monitoring and motivating exercise, and being available and approachable to answer questions and give feedback. Primary care practitioners need to talk with women about weight, health issues related to weight, various methods to lose weight, and encourage them to strive for increased levels of fitness. The women in this study discussed feeling depressed, tired, and facing challenging life situations. Nurses can assess women for these issues and conditions, monitor them, and help them achieve an optimum level of well-being. Recognizing that women have different high, low, and turning points in the process of losing weight, strategies aimed at recognizing and supporting the high points and turning points may facilitate effective management of the low points. The difference between groups based on social support was the only finding that was statistically significantly related to the process of ups and downs in weight loss. It appears from this study that women are most successful when they have a small number of friends or family who they can depend on for support. Nurses can help overweight and obese women identify appropriate and effective social 
supports, and discuss ways that friends and family can effectively support them during the weight loss process.

\section{Suggestions for Future Research}

The findings from this study require substantiation with a larger, more diverse sample. It should also be repeated with participants who did not lose weight, or who gained weight. To determine if the weight loss parameter of $5 \%$ was too low to discern statistical significance the study should be repeated comparing women who lost at least $10 \%$ of their baseline weight with those who stayed within $10 \%$ of their baseline weight. There is minimal research on social support for successful weight loss in women, especially examining the levels and nature of social support. Health care practitioners, specifically nurses, can act as support for women desiring to lose weight. Research needs to be carried out examining the role of the professional nurse as a social support. Further examination of control group and interventional group differences should be carried out in order to determine why the control group was more likely to lose weight when compared to the intervention group.

The description of low points in the experience of weight loss was a major finding in this study related to the theory of restructuring, which does not address specific low points. More research is needed to investigate the nature of the low points, and interventions need to be developed and tested to help women in the process of losing weight move through and overcome the low points. 


\section{References}

Allan, J. D. (1988). Knowing what to weight: women's self-care activities related to weight. Advances in Nursing Science, 11, 47-60.

Amigo, I., \& Fernandez, C. (2007). Effects of diets and their role in weight control. Psychology, Health and Medicine, 12(321-327).

Annesi, J. (2007). Relations of changes in physical self-appraisal and perceived energy with weight change in obese women beginning a supported exercise and nutrition information program. Social Behavior and Personality, 35(10), 1295 -1300.

Arefhosseini, S. R., Edwards, C. A., Malkova, D., \& Higgins, S. (2009). Effect of advice to increase carbohydrate and reduce fat intake on dietary profile and plasma lipid concentrations in healthy postmenopausal women. Annals of Nutrition and Metabolism, 54(2), 138-144.

Bidgood, J., \& Buckroyd, J. (2005). an exploration of obese adults' experience of attempting to lose weight and to maintain a reduced weight. Counseling and Psychotherapy Research, 5(3), 221-229.

Blissmer, B., Riebe, D., Dye, G., Ruggiero, L., Greene, G., \& Caldwell, M. (2006). Healthrelated quality of life following a clinical weight loss intervention among overweight and obese adults: interventions and 24 month follow-up effects. Health and Quality of Life Outcomes, 4, 43 - 48

Block, G., Hartman, A., Dresser, C., Carroll, M. D., Gannon, J., \& Gardner, L. (1986). A databased approach to diet questionnaire design and testing. American Journal of Epidemiology, 124(453-469). 
Brink, P. J., \& Ferguson, K. (1998). The decision to lose weight. Western Journal of Nursing Research, 20, 84-102.

Brinkworth, G., Noakes, M., Keogh, J., Luscombe, N., Wittert, G., \& Clifton, P. (2004). Longterm effects of a high-protein, low-carbohydrate diet on weight control and cardiovascular risk markers in obese hyperinsulinemic subjects. International Journal of Obesity, 28, 661-670.

Byrne, S., Cooper, Z., \& Fairburn, C. (2003). Weight maintenance and relapse in obesity: A qualitative study. International Journal of Obesity \& Related Metabolic Disorders, 27(8), $955-962$.

Carels, R., Darby, L., Rydin, S., Douglass, O., Cacciapaglia, M., \& O'Brien, W. (2005). The relationship between self-monitoring, outcome expectancies, difficulties with eating and exercise, and physical activity and weight loss treatment outcomes. Annals of Behavioural Medicine, 30(3), 182-190.

Centers for Disease Control and Prevention (2007a, 7/29/2009). BMI-Body Mass Index. Retrieved 10/15/2007, from www.cdc.gov/nccdphp/dnpa/bmi/adult_BMI/about_adult_BMI.htm

Centers for Disease Control and Prevention (2007b, 6/11/2009). New CDC study finds no increase in obesity among adults; but levels still high. Retrieved 11/02/08, from http://www.cdc.gov/nchs/PRESSROOM/07newsreleases/obesity.htm

Daniels, J. (2006). Women's descriptions of a successful weight-loss experience: A qualitative study. The American Journal of Nurse Practitioners, 10(67-74).

Dansinger, M. L., Gleason, J. A., Griffith, J. L., Selker, H. P., \& Schaefer, E. J. (2005). Comparison of the Atkins, Ornish, Weight Watchers, and Zone Diets for weight loss and 
heart disease risk reduction: A randomized trial. Journal of the American Medical Association, 293, 43-53.

Dansinger, M. L., Tatsioni, A., Wong, J. B., Chung, M., \& Balk, E. (2007). Meta-analysis: The effect of dietary counseling on weight loss. Annals of Internal Medicine, 147(1), 41-50.

Davis, N., Tomuta, N., Schechter, C., Isasi, C. R., Segal-Isaacson, C. J., Stein, D., et al. (2009). Comparative study of the effects of a 1-year dietary intervention of a low-carbohydrate diet versus a low-fat diet on weight and glycemic control in Type 2 Diabetes. Diabetes Care, 32(7), 1147-1152.

Dixon, J., Dixon, M., \& O'Brien, P. (2003). Depression in association with severe obesity: changes with weight loss. Archives of Internal Medicine, 163(17), 2058-2065.

Due, A., Toubro, S., Skov, A., \& Astrup, A. (2004). Effect of normal fat diets, either medium or high in protein, on body weight in overweight subjects: A randomized 1-year trial. International Journal of Obesity, 28, 1283-1290.

Dunn, C. L., Hannan, P. J., Jeffery, R. W., Sherwood, N. E., Pronk, N. P., \& Boyle, R. (2006). The comparative and cumulative effects of a dietary restriction and exercise on weight loss. International Journal of Obesity, 30(1), 112-121.

Elhag, K., \& Rossner, S. (2005). Who succeeds in maintaining weight loss? A conceptual review of factors associated with weight loss maintenance and weight regain. [Review]. The International Association for the Study of Obesity, 6, 67-85.

Engeli, S., Bohnke, J., Gorzelniak, K., Janke, J., Schling, P., Bader, M., et al. (2005). Weight loss and the renin-angiotensis-aldosterone system. Hypertension: Journal of the American Heart Association, 45, 356-362. Retrieved from 
http://hyper.ahajournals.org/cgi/content/full/45/3/356.

doi:10.1161/01.HYP.0000154361.47683.d3

Estruch, R., Martinez-Gonzalez, M. A., Corella, D., Salas-Savado, J., Ruiz-Gutierrez, V., Covas, M. I., et al. (2006). Effects of a Mediterranean-style diet on cardiovascular risk factors: A randomized trial. Annals of Internal Medicine, 145(1), 1-11.

Folta, S. C., Lichtenstein, A. H., Sequin, R. A., Goldberg, J. P., Kuder, J. F., \& Nelson, M. E. (2009). The StrongWomen--Healthy Hearts Program: Reducing cardiovascular disease risk factors in rural sedentary, overweight, and obese midlife and older women. American Journal of Public Health, 99(7), 1271-1277.

Foster, G., Wadden, T., \& Vogt, R. (1997). Body image in obese women before, during, and after weight loss treatment. Health Psychology, 16(3), 226 - 229.

Gorin, A., Phelan, S., Tate, D., Sherwood, N., Jeffery, R., \& Wing, R. (2005). Involving support partners in obesity treatment. Journal of Consulting and Clinical Psychology, 73(2), 341343.

Hayward, L. M., Nixon, C., Jasper, M. P., Murphy, K. M., Harlan, V., Swirda, L., et al. (2000). The process of restructuring and the treatment of obesity in women. Health Care for Women International, 21(7), 615-630.

Heading, G. (2008). Rural obesity, healthy weight and perceptions of risk: Struggles, strategies and motivation for change. Australian Journal of rural Health, 16(2), 86-91.

Herriot, A. M., Thomas, D. E., Hart, K. H., Warren, J., \& Truby, H. (2008). A qualitative investigation of individuals' experiences and expectations before and after completing a trial of commercial weight loss programmes. Journal of Human Nutrition and Dietetics, $21(1), 72-80$. 
Hill, J., \& Wing, R. (2003). The National Weight Control Registry. The Permanente Journal, 7(Supplement), 39-42.

Howard, B. V., Manson, J. E., Stefanick, M. L., Beresford, S. A., Frank, G., Jones, B., et al. (2006). Low-fat dietary pattern and weight change over 7 years: The women's health initiative dietary modification trial. Journal of the American Medical Association, 295(1), $39-49$.

Irwin, M. L., Yasui, Y., Ulrich, C. M., Bowen, D., Rudolph, R. E., Schwartz, R. S., et al. (2003). Effect of exercise on total and intra-abdominal body fat in postmenopausal women: A randomized controlled trial. Journal of the American Medical Association, 289(3), 323330.

Jakicic, J. M., Winters, C., Lang, W., \& Wing, R. R. (1999). Effects of intermittent exercise and use of home exercise equipment on adherence, weight loss, and fitness in overweight women. Journal of the American Medical Association, 282(16), 1554-1560.

Johnson, R. (1990). Restructuring: An emerging theory on the process of losing weight. Journal of Advanced Nursing, 15(11), 1289-1296.

Karlsson, J., Taft, C., Sjostrom, L., Torgerson, J. S., \& Sullivan, M. (2003). Psychosocial functioning in the obese before and after weight reduction: Construct validity and responsiveness of the Obesity-related Problems scale. International Journal of Obesity \& Related Metabolic Disorders, 27(5), 617-630.

Kaukua, J., Pekkarinen, T., Sane, T., \& Mustajoki, P. (2003). Health-related quality of life in obese outpatients losing weight with very-low-energy diet and behaviour modification--a 2-y follow-up study. International Journal of Obesity \& Related Metabolic Disorders, 27(10), 1233-1241. 
Kearney, M., \& O'Sullivan, J. (2003). Identity shifts as turning points in health behavior change. Western Journal of Nursing Research, 25(2), 134-152.

Kerksick, C., Thomas, A., Campbell, B., Taylor, L., Wilborn, C., Marcello, B., et al. (2009). Effects of a popular exercise and weight loss program on weight loss, body composition, energy expenditure and health in obese women. Nutrition and Metabolism, 6(23), 1 - 17

Kerr, J., Patrick, K., Norman, G., Stein, M., Calfas, K., Zabinski, M., et al. (2008). Randomized control trial of a behavioral intervention for overweight women: impact on depressive symptoms. Depression and Anxiety, 25(7), 555-558.

Knowler, W., Barrett-Conner, E., Fowler, S., Hamman, R., Lachin, J., Walker, E., et al. (2002). Reduction in the incidence of type 2 diabetes with lifestyle intervention or metformin. New England Journal of Medicine, 346(6), 393-403.

Liehr, P., \& Smith, M. J. (2000). Using story theory to guide nursing practice. International Journal for Human Caring, 4(2), 13-18.

Littman, A., Kristal, A., \& White, E. (2005). Effects of physical activity intensity, frequency, and activity type on 10-y weight change in middle-aged men and women. International Journal of Obesity, 29(5), 524 - 533.

Lopez, K. M. (1997). Value conflict: The lived experience of women in treatment for weight loss. Health Care for Women International, 18(6), 603-611.

McAuley, K. A., Hopkins, C. M., Smith, K. J., McLay, R. T., Williams, S. M., Taylor, R. W., et al. (2005). Comparison of high-fat and high-protein diets with a high-carbohydrate diet in insulin-resistant obese women. Diabetologia, 48(1), 8-16.

McGuire, M. T., Wing, R. R., Klem, M. L., Seagle, H. M., \& Hill, J. O. (1998). Long-term maintenance of weight loss: Do people who lose weight through various weight loss 
methods use different behaviors to maintain weight? International Journal of Obesity, 22(6), 572-577.

Mendez, M. A., Popkin, B. M., Jakszyn, P., Berenguer, A., Tormo, M. J., Sanchez, M. J., et al. (2006). Adherence to a Mediterranean diet is associated with reduced 3-year incidence of obesity. The Journal of Nutrition, 136(11), 2934-2938.

National Cholesterol Education Program (2001). Third report of the National Cholesterol Education Program (NCEP) expert panel on detection, evaluation, and treatment of high blood cholesterol in adults (Adult Treatment Panel III), Executive Summary. Retrieved 05.14.08. from http://www.nhlbi.nih.gov/about/ncep/.

Ogden, C., \& Carroll, M. (2010). Prevalence of Overweight, Obesity, and Extreme Obesity Among Adults: United States, Trends 1976-1980 Through 2007-2008

National Center for Health Statistics: Health and Stats Retrieved 12/04/2010, from http://www.cdc.gov/NCHS/data/hestat/obesity_adult_07_08/obesity_adult_07_08.pdf

Paluck, E., Allerdings, M., Kealy, K., \& Dorgan, H. (2006). Health promotion needs of women living in rural areas: An exploratory study. Canadian Journal of Rural Medicine, 11(2), 111-116.

Parker, S., \& Keim, K. (2004). Emic perspectives of body weight in overweight and obese white women with limited income. Journal of Nutrition, Education and Behavior, 36(6), 282289.

Phelan, S., Wyatt, H. R., Hill, J. O., \& Wing, R. R. (2006). Are the eating and exercise habits of successful weight losers changing? Obesity, 14(4), 710-716. 
Reicks, M., Mills, J., \& Henry, H. (2004). Qualitative study of spirituality in a weight loss program: Contribution to self-efficacy and locus of control. Journal of Nutrition, Education and Behavior, 36(1), 13-19.

Roberts, A., \& Ashley, G. (1999). What are the characteristics of overweight and obese patients who achieve weight loss and what factors are most helpful? A quantitative and qualitative study of patients and interventions in a rural general practice. Journal of Human Nutrition and Dietetics, 12(Supplement 1), 20 - 27.

Saquib, N., Rock, C., Natarajan, L., Flatt, S., Newman, V., Thomson, C., et al. (2009). Does a healthy diet help wieght management among overweight and obese people? Health Education and Behavior, 36(3), 518 - 531.

Schneider, P. L., Bassett, D. R., Thompson, D. L., Pronk, N. P., \& Bielak, K. M. (2006). Effects of a 10,000 Steps per Day Goal in overweight adults. The American Journal of Health Promotion, 21(2), 85-89.

Sherrid, P. (2003). Piling on the profit. US News and World Report, 134(2), 41-43.

Silva, M., Vieira, P., Coutinho, S., Minderico, C., Matos, M., Sarsinha, L., et al. (2009). Using self-determination theory to promote physical activity and weight control: a randomized controlled trial in women. Journal of Behavioral Medicine, 33(2), 110 - 122.

Simkin-Silverman, L. R., Wing, R. R., Boraz, M. A., \& Kuller, L. H. (2003). Lifestyle intervention can prevent weight gain during menopause: Results from a 5-year randomized clinical trial. Annals of Behavioural Medicine, 26(3), 212-220.

Smith, M., \& Liehr, P. (Eds.). (2008). Middle range theory for nursing. New York: Springer Publishing Company. 
Smith, M. J., \& Liehr, P. L. (Eds.). (2003). Middle range theory for nursing. New York: Springer Publishing Company.

SPSS (2008). SPSS Statistics GradPack 17.0 [Computer Software]. (Version 17.0). Chicago, IL: Statistical Package for Social Sciences.

Stewart, A. L., Mills, K. M., King, A. C., Haskell, W. L., Gillis, D., \& Ritter, P. L. (2001). CHAMPS physical activity questionnaire for older adults: outcomes for interventions. Medicine \& Science in Sports \& Exercise, 33(7), 1126-1141.

Technology Assessment Panel (1993). Methods for voluntary weight loss and control: Technology Assessment Conference Statement. Annals of Internal Medicine, 119(7), 764-770.

Teixeira, P. J., Going, S. B., Houtkooper, L. B., Cussler, E. C., Martin, C. J., Metcalfe, L. L., et al. (2002). Weight loss readiness in middle-aged women: Psychosocial predictors of success for behavioral weight reduction. Journal of Behavioral Medicine, 25(6), 499-523.

Teixeira, P. J., Going, S. B., Houtkooper, L. B., Cussler, E. C., Metcalfe, L. L., Blew, R. M., et al. (2004). Pretreatment predictors of attrition and successful weight management in women. International Journal of Obesity, 28, 1124-1133.

Teixeira, P. J., Palmeira, A. L., Branco, T. L., Martins, S. S., Minderico, C. S., Barata, J. T., et al. (2004). Who will lose weight? A reexamination of predictors of weight loss in women. International Journal of Behavioral Nutrition and Physical Activity, 1(12), 1 - 12.

Tessaro, I., Campbell, M., Benedict, S., Kelsey, K., Heisler-MacKinnon, J., Belton, L., et al. (1998). Developing a worksite health promotion intervention: health works for women. American Journal of Health Behavior, 22(6), 434-442. 
Tessaro, I., Rye, S., Parker, L., Mangone, C., \& McCrone, S. (2007). Effectiveness of a nutrition intervention with rural low income women. American Journal of Health Behavior, 31(1), $35-43$.

Tessaro, I., Rye, S., Parker, L., Trangsrud, K., McCrone, S., \& Leslie, N. (2006). Cookin' Up Health: Developing a Nutrition Program for a Rural Appalachian Population. Health Promotion Practice, 7(2), 252-257.

Tessaro, I. P. I. (2003-2008). West Virginia WISEWOMAN: Centers for Disease Control and Prevention, West Virginia University.

Thomas, A., Stallings, R., Nichols-English, G., \& Wagner, P. (2008). Perceptions of Obesity: Black and White differences. Journal of Cultural Diversity, 15(4), 174-180.

Toobert, D. J., Strycker, M. A., Glasgow, R. E., Barrera, M., \& Angell, K. (2005). Effects of the Mediterranean Lifestyle Program on multiple risk factor behaviors and psychosocial outcomes among women at risk for heart disease. Annals of Behavioural Medicine, 29(2), 128-137.

Trichopoulou, A., Naska, A., Orfanos, P., \& Trichopoulos, D. (2005). Mediterranean diet in relation to body mass index and waist-to-hip ratio: the Greek European Prospective Investigation into Cancer and Nutrition Study. American Journal of Clinical Nutrition, $82(5), 935-940$.

Tuomilehto, J., Lindstrom, J., Eriksson, J., Valle, T., Hamalainen, H., Ilanne-Parikka, P., et al. (2001). Prevention of type 2 diabetes mellitus by changes in lifestyle among subjects with impaired glucose tolerance. The New England Journal of Medicine, 344(18), 1343-1350.

West Virginia Bureau of Public Health (2004a). The Burden of Cardiovascular Disease in West Virginia., from http://www.wvdhhr.org/bph/oehp/hsc/burdencvd/default.htm 
West Virginia Bureau of Public Health (2004b). Obesity: Facts, Figures, Guidelines., from http://www.wvdhhr.org/bph/oehp/obesity/default.htm.

West Virginia Health Statistics Center (2008). 2006 West Virginia Behavioral Risk Factor Survey Report, from http://www.wvdhhr.org/bph/hsc/pubs/BRFSS/2006/ObesityAndOverweight.pdf

Wing, R., \& Hill, J. (2010). The National Weight Control Registry Retrieved 8.8.10, 2010, from Www.nwcr.ws

Wing, R., \& Jeffery, R. (1999). Benefits of recruiting participants with friends and increasing social support for weight loss and maintenance. Journal of Consulting and Clinical Psychology, 67(1), 132-138.

Wing, R., Papandonatos, G., Fava, J., Gorin, A., Phelan, S., McCaffery, J., et al. (2008). Maintaining large weight losses: the role of behavioral and psychological factors. Journal of Consulting and Clinical Psychology, 76(6), 1015-1021.

Wing, R. R., Marcus, M. D., Epstein, L. H., \& Jawad, A. (1991). A "family-based" approach to the treatment of obese type II diabetic patients. Journal of Consulting and Clinical Psychology, 59(1), 156-162.

World Health Organization (2008). BMI classification. Retrieved 10.04.08, from http://www.who.int/bmi/index.jsp?introPage=intro_3.html

Wray, L. A., Blaum, C. S., Ofstedal, M. B., \& Herzog, R. (2004). Diabetes diagnosis and weigh tloss in middle-aged adults. Research on Aging, 26(1), 62-81. 
Yancy, W. S., Almirall, D., Maciejewski, M. L., Kolotkin, R. L., McDuffie, J. R., \& Westman, E. C. (2009). Effects of two weight-loss diets on health-related quality of life. Quality of Life Research, 18(3), 281-289. 
Appendix A

West Virginia WISEWOMAN Questionnaire 
00 Baseline

06 Six Months

12 Twelve Months

\title{
WISEWOMAN Questionnaire
}

\author{
West Virginia University \\ School of Nursing
}

Interviewer

Date of Interview

Location of Interview

(clinic)

Length of Interview

(minutes)

Start Time 


\section{HEALTH STATUS Let's start with some questions about your health} history.

1 Would you say that in general your health is:

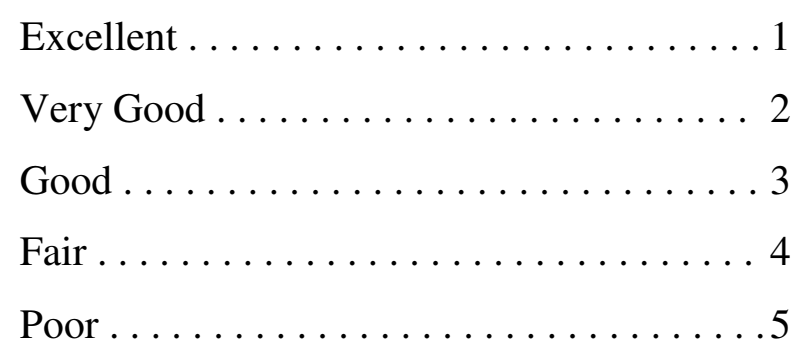

2 Do you have a regular physician, nurse practitioner or physician's assistant you usually go to for health care?

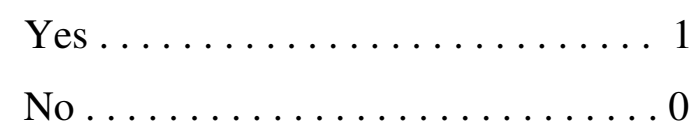

3 Have you ever had the following?

\begin{tabular}{|c|c|c|c|}
\hline Test & Yes & No & DK \\
\hline $\begin{array}{l}\text { A. A mammogram: an x-ray of each breast to look for } \\
\text { breast cancer }\end{array}$ & 1 & 0 & 8 \\
\hline B. A blood pressure check & 1 & 0 & 8 \\
\hline $\begin{array}{l}\text { C. Your blood cholesterol check. Blood cholesterol is a } \\
\text { fatty substance found in the blood. }\end{array}$ & 1 & 0 & 8 \\
\hline D. A blood sugar/glucose check & 1 & 0 & 8 \\
\hline $\begin{array}{l}\text { E. Colon cancer screening: a stool test, sigmoidoscopy, or } \\
\text { colonoscopy. }\end{array}$ & 1 & 0 & 8 \\
\hline
\end{tabular}




\section{In the past 12 months, has a doctor, nurse or other health professional given you advice about your weight?}

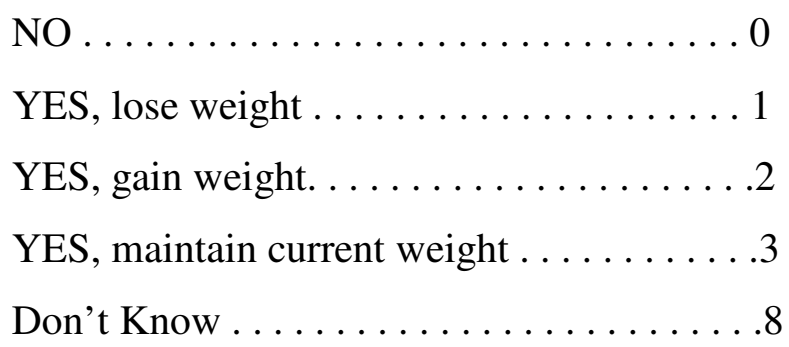

\section{Have you ever been told by a doctor, nurse, or other health professional} that:

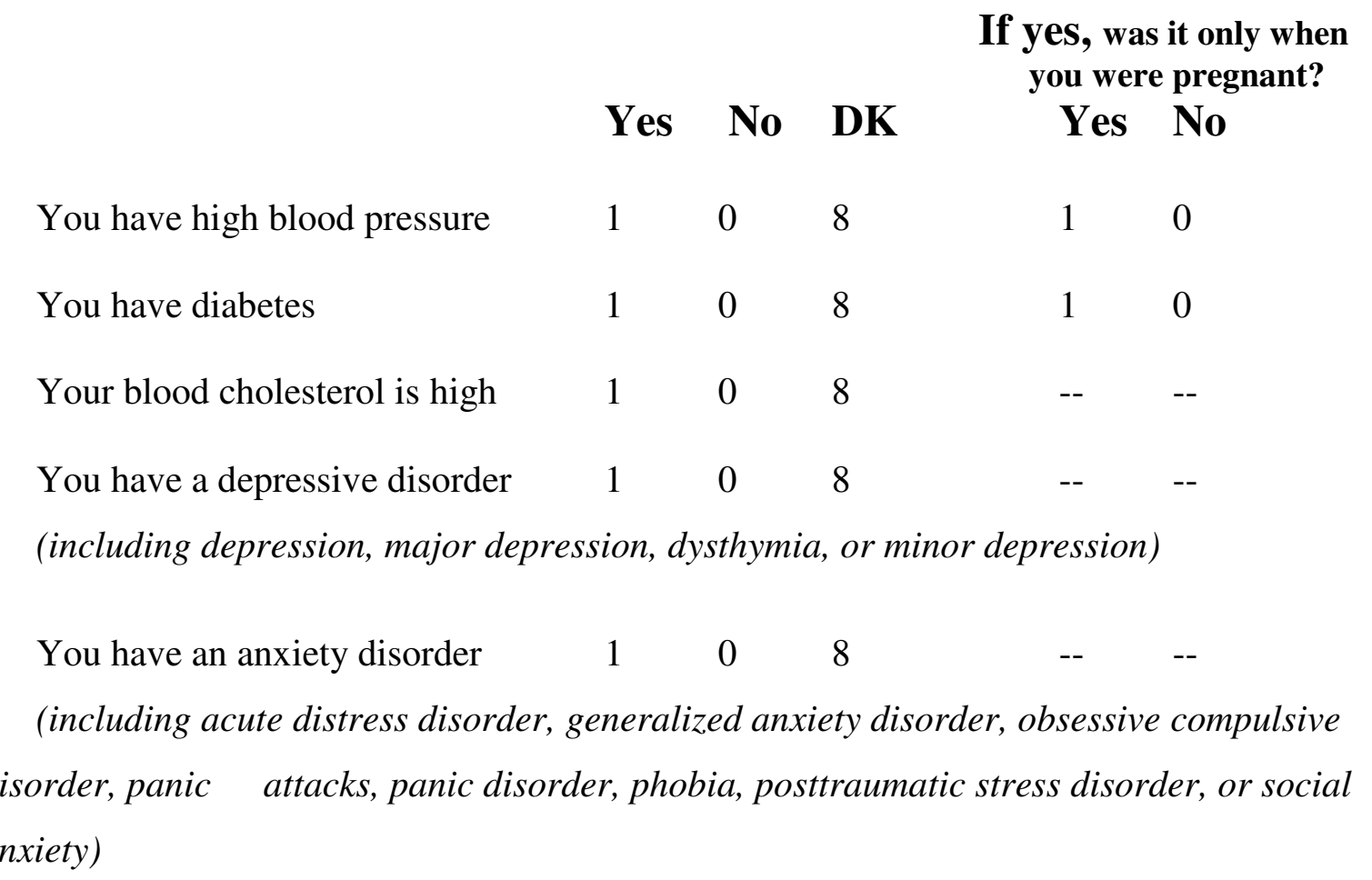


6 Are you currently taking medication for:

Yes No Don't Know

High cholesterol

High blood pressure

Diabetes
1

1

1

0

0

0
8

8

8

7 Has your father or a brother had a heart attack before the age of 55?

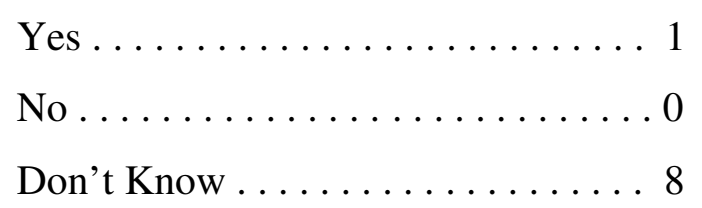

8 Has your mother or a sister had a heart attack before the age of 65 ?

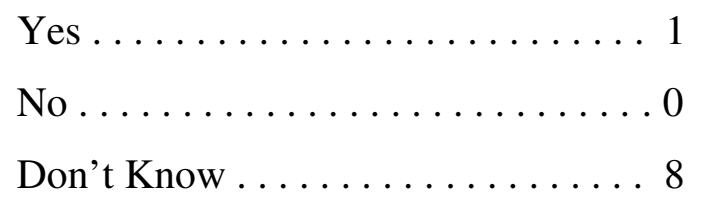

DIET These next set of questions are about the foods you eat.

9 What is your average frequency of fruit and vegetable consumption per day? (servings per day)

Never, or less than 1 a day.................. 1

1 to less than 3 a day........................

3 or less than 5 a day........................ 3

5 or more a day............................ 4

A. If 5 or more a day ------------------- $\rightarrow$ How long have you been doing this?

$<6$ months ............ 1

6 months or more..........2 
B. If less than 5 a day ----------- $\rightarrow$ Are you planning, thinking, or not thinking of eating more fruits and vegetables in the next 6 months?

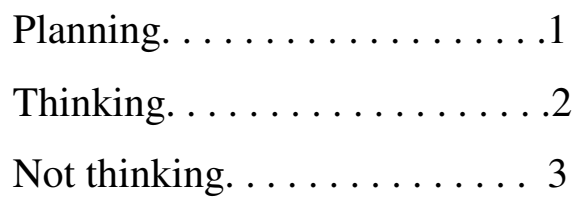

10 How sure/confident are you that you could eat more fruits and vegetables if you wanted to? Are you...

Very sure $\ldots \ldots \ldots \ldots \ldots \ldots$
Somewhat sure $\ldots \ldots \ldots \ldots \ldots .2$
Somewhat unsure $\ldots \ldots \ldots \ldots \ldots \cdot 3$
Very unsure $\ldots \ldots \ldots \ldots \ldots .4$

11 Do you stay away from foods high in fat like fatty red meats, fried chicken with the skin, regular milk, ice cream, cheese, butter or margarine, biscuits, doughnuts and french fries?

A. YES ------------------------ $\rightarrow$ How long have you been doing this?

$<6$ months ............ 1

6 months or more. .........2

B. NO ------------------------- $\rightarrow$ Are you planning, thinking, or not thinking about staying away from high fat foods in the next 6 months?

Planning. . . . . . . . . . . . 1

Thinking. ............. 2

Not thinking. ............ 3 
12 How sure/confident are you that you could eat fewer foods high in fat if you wanted to? Are you...

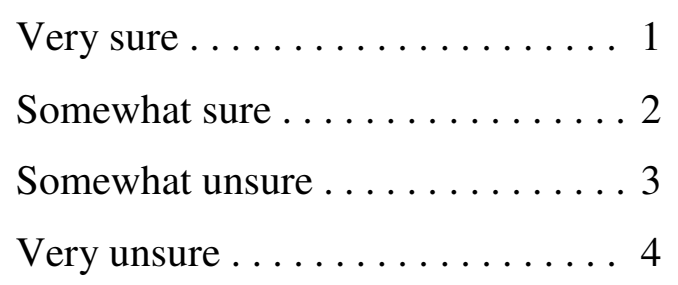

13 How much could you count on those close to you for support and help if you wanted to eat healthier foods (such as fruits and vegetables and less foods high in fat)? Could you count on them:

A lot .............. 1

Somewhat .............. 2

Very little or not at all ........ 3 
These next questions are about serving sizes, for example the serving size you see on food labels. (SHOW MEASURING CUPS)

\section{Please point to the measure you think is the correct serving size for each item, not the serving size you normally eat.}
A Spaghetti (cooked)
2 cup
1 cup
$1 / 2$ cup
$1 / 4 \operatorname{cup}$
DK
B Grains, such as rice (cooked)
2 cups
1 cup
$1 / 2$ cup
$1 / 4$ cup
DK
C Fresh or cooked vegetables
2 cups
1 cup
$1 / 2$ cup
$1 / 4$ cup
DK
D Salad greens
2 cups
1 cup
$1 / 2$ cup
$1 / 4$ cup
DK
E Greens (kale, spinach, collards)
2 cups
1 cup
$1 / 2$ cup
$1 / 4$ cup
DK
F Cut up fruits
2 cup
1 cup
$1 / 2$ cup
$1 / 4$ cup
DK
G Dried fruits

$$
2 \text { cup }
$$
1 cup
$1 / 2$ cup
$1 / 4$ cup
DK

(Say the choices)

$\mathrm{H}$ Whole fruits (fresh or canned)

$$
2 \text { pieces }
$$

1 piece

$1 / 2$ piece

DK

I Cheese (ounces)

4 slice

3 slices

2 slices

1 slice

DK

J Meat (ground, steaks) ounces

size $\mathrm{A} \quad$ size $\mathrm{B} \quad$ size $\mathrm{C}$

DK 


\section{Think about your eating habits during the past 4 weeks. About how often do you eat each of the following foods? Remember breakfast, lunch, dinner, snacks and eating out.}

SHOW ANSWER CHOICE CARD \#1

$\begin{array}{lllllllll}0 & 1 & 2 & 3 & 4 & 5 & 6 & 7 & 8\end{array}$

$\begin{array}{lll}0 & 1 & 2\end{array}$

\begin{tabular}{|c|c|c|c|c|c|c|c|c|c|c|c|c|}
\hline Meats & Never & $\begin{array}{l}1 \text { per } \\
\text { month }\end{array}$ & $\begin{array}{l}2-3 \\
\text { per } \\
\text { month }\end{array}$ & $\begin{array}{l}1 \text { Per } \\
\text { Week }\end{array}$ & $\begin{array}{l}2 \text { Per } \\
\text { Week }\end{array}$ & $\begin{array}{c}3-4 \\
\text { Per } \\
\text { Week }\end{array}$ & $\begin{array}{l}5-6 \\
\text { per } \\
\text { week }\end{array}$ & $\begin{array}{c}1 \\
\text { per } \\
\text { day }\end{array}$ & $\begin{array}{l}2+ \\
\text { per } \\
\text { day }\end{array}$ & $\begin{array}{l}\text { Med } \\
\text { Serving } \\
\text { size }\end{array}$ & $\begin{array}{l}< \\
\mathrm{L} \\
\mathrm{E} \\
\mathrm{S} \\
\mathrm{S} \\
\end{array}$ & $\begin{array}{l} \\
\mathrm{S} \\
\mathrm{A}\end{array}$ \\
\hline 1. Hamburger patty & & & & & & & & & & $\begin{array}{l}1 \\
\text { medium } \\
\text { or } 3 \\
\text { ounces }\end{array}$ & & \\
\hline 2. Beef: steaks, roasts & & & & & & & & & & 3 ounces & & \\
\hline $\begin{array}{l}\text { 3. Fried chicken or } \\
\text { nuggets }\end{array}$ & & & & & & & & & & $\begin{array}{l}1 \text { large } \\
\text { piece or } \\
6 \\
\text { nuggets }\end{array}$ & & \\
\hline 4. Hot dog & & & & & & & & & & 1 & & \\
\hline $\begin{array}{l}\text { 5. Cold cuts, lunch } \\
\text { meats, ham...not low-fat }\end{array}$ & & & & & & & & & & 2 slices & & \\
\hline 6. Bacon & & & & & & & & & & 3 strips & & \\
\hline 7. Breakfast sausage & & & & & & & & & & $\begin{array}{l}1 \text { patty } \\
\text { or } 2 \text { links }\end{array}$ & & \\
\hline $\begin{array}{l}\text { 8. Pork, including chops } \\
\text { and roasts }\end{array}$ & & & & & & & & & & 3 ounces & & \\
\hline $\begin{array}{l}\text { 9. White fish: sole, } \\
\text { snapper, halibut, cod, } \\
\text { catfish }\end{array}$ & & & & & & & & & & 3 ounces & & \\
\hline $\begin{array}{l}\text { 10. Dark fish: salmon, } \\
\text { mackerel, rainbow trout, } \\
\text { sardines, tuna }\end{array}$ & & & & & & & & & & 3 ounces & & \\
\hline 11. Peanut butter & & & & & & & & & & $\begin{array}{l}2 \text { Table } \\
\text { spoons }\end{array}$ & & \\
\hline 12. Gravy & & & & & & & & & & $1 / 4$ cup & & \\
\hline
\end{tabular}


$\begin{array}{lll}0 & 1 & 2\end{array}$

$\begin{array}{lllllllll}\mathbf{0} & 1 & 2 & 3 & 4 & 5 & 6 & 7 & 8\end{array}$

\begin{tabular}{|c|c|c|c|c|c|c|c|c|c|c|c|c|c|}
\hline Dairy Products \& Fats & Never & $\begin{array}{l}1 \text { per } \\
\text { month }\end{array}$ & $\begin{array}{l}2-3 \\
\text { per } \\
\text { month }\end{array}$ & $\begin{array}{l}1 \text { Per } \\
\text { Week }\end{array}$ & $\begin{array}{l}2 \text { Per } \\
\text { Week }\end{array}$ & $\begin{array}{c}3-4 \\
\text { Per } \\
\text { Week }\end{array}$ & $\begin{array}{c}5-6 \\
\text { per } \\
\text { week }\end{array}$ & $\begin{array}{l}1 \\
\text { per } \\
\text { day }\end{array}$ & $\begin{array}{l}2+ \\
\text { per } \\
\text { day }\end{array}$ & $\begin{array}{c}\text { Med } \\
\text { Serving } \\
\text { size }\end{array}$ & $\begin{array}{l}< \\
\mathrm{L} \\
\mathrm{E} \\
\mathrm{S} \\
\mathrm{S} \\
\end{array}$ & \begin{tabular}{l||} 
\\
$\mathrm{S}$ \\
$\mathrm{A}$ \\
$\mathrm{M}$ \\
$\mathrm{E}$
\end{tabular} & $\begin{array}{l} \\
\mathrm{M} \\
\mathrm{O} \\
\mathrm{R} \\
\mathrm{E}\end{array}$ \\
\hline 1. Skim or $1 \%$ milk & & & & & & & & & & $\begin{array}{l}8 \text { ounce } \\
\text { glass }\end{array}$ & & & \\
\hline $\begin{array}{l}\text { 2. Whole milk or } 2 \% \\
\text { milk }\end{array}$ & & & & & & & & & & $\begin{array}{l}8 \text { ounce } \\
\text { glass }\end{array}$ & & & \\
\hline 3. Cheese, cheese spread & & & & & & & & & & $\begin{array}{l}2 \text { slices } \\
\text { or } 1.5 \\
\text { ounces }\end{array}$ & & & \\
\hline 4. Margarine, hard & & & & & & & & & & $\begin{array}{c}1 \\
\text { teaspoon }\end{array}$ & & & \\
\hline 5. Butter or lard & & & & & & & & & & $\begin{array}{c}1 \\
\text { teaspoon }\end{array}$ & & & \\
\hline 6. Eggs & & & & & & & & & & 2 & & & \\
\hline 7. Salad dressing & & & & & & & & & & $\begin{array}{c}1 \text { Table } \\
\text { spoon }\end{array}$ & & & \\
\hline
\end{tabular}

\begin{tabular}{|c|c|c|c|c|c|c|c|c|c|c|c|c|c|}
\hline Vegetables & Never & $\begin{array}{l}1 \text { per } \\
\text { month }\end{array}$ & $\begin{array}{l}2-3 \\
\text { per } \\
\text { month }\end{array}$ & $\begin{array}{l}1 \text { Per } \\
\text { Week }\end{array}$ & $\begin{array}{l}2 \text { Per } \\
\text { Week }\end{array}$ & $\begin{array}{c}3-4 \\
\text { Per } \\
\text { Week }\end{array}$ & $\begin{array}{c}5-6 \\
\text { per } \\
\text { week }\end{array}$ & $\begin{array}{l}1 \\
\text { per } \\
\text { day }\end{array}$ & $\begin{array}{l}2+ \\
\text { per } \\
\text { day }\end{array}$ & $\begin{array}{c}\text { Med } \\
\text { Serving } \\
\text { size }\end{array}$ & $\begin{array}{l}< \\
\mathrm{L} \\
\mathrm{E} \\
\mathrm{S} \\
\mathrm{S}\end{array}$ & $\begin{array}{l}= \\
\mathrm{S} \\
\mathrm{A} \\
\mathrm{M} \\
\mathrm{E}\end{array}$ & $\begin{array}{l}> \\
\mathrm{M} \\
\mathrm{O} \\
\mathrm{R} \\
\mathrm{E}\end{array}$ \\
\hline 1. Green salad & & & & & & & & & & 1 cup & & & \\
\hline $\begin{array}{l}\text { 2. Broccoli, cabbage, } \\
\text { cauilflower }\end{array}$ & & & & & & & & & & $1 / 2$ cup & & & \\
\hline $\begin{array}{l}\text { 3. Turnip greens, } \\
\text { collards, spinach }\end{array}$ & & & & & & & & & & $1 / 2$ cup & & & \\
\hline $\begin{array}{l}\text { 4. Carrots, onions, } \\
\text { squash, other vegetables }\end{array}$ & & & & & & & & & & $1 / 2$ cup & & & \\
\hline $\begin{array}{l}\text { 5. Tomatoes or tomato } \\
\text { juice }\end{array}$ & & & & & & & & & & $\begin{array}{l}1 / 2 \text { cup or } \\
6 \text { ounces }\end{array}$ & & & \\
\hline $\begin{array}{l}\text { 6. Potatoes, including } \\
\text { baked, mashed, steamed, } \\
\text { or boiled }\end{array}$ & & & & & & & & & & $1 / 2$ cup & & & \\
\hline $\begin{array}{l}\text { 7. Beans: baked, pintos, } \\
\text { kidney, lima }\end{array}$ & & & & & & & & & & $1 / 2$ cup & & & \\
\hline
\end{tabular}




\begin{tabular}{|c|c|c|c|c|c|c|c|c|c|c|c|c|c|}
\hline Fruits & Never & $\begin{array}{l}1 \text { per } \\
\text { month }\end{array}$ & $\begin{array}{c}2-3 \\
\text { per } \\
\text { month }\end{array}$ & $\begin{array}{l}1 \text { Per } \\
\text { Week }\end{array}$ & $\begin{array}{l}2 \text { Per } \\
\text { Week }\end{array}$ & $\begin{array}{c}3-4 \\
\text { Per } \\
\text { Week }\end{array}$ & $\begin{array}{c}5-6 \\
\text { per } \\
\text { week }\end{array}$ & $\begin{array}{l}1 \\
\text { per } \\
\text { day }\end{array}$ & $\begin{array}{l}2+ \\
\text { per } \\
\text { day }\end{array}$ & $\begin{array}{l}\text { Med } \\
\text { Serving } \\
\text { size }\end{array}$ & $\begin{array}{l}< \\
\mathrm{L} \\
\mathrm{E} \\
\mathrm{S} \\
\mathrm{S}\end{array}$ & \begin{tabular}{|l|} 
\\
$\mathrm{S}$ \\
$\mathrm{A}$ \\
$\mathrm{M}$ \\
$\mathrm{E}$ \\
\end{tabular} & $\begin{array}{l}> \\
\mathrm{M} \\
\mathrm{O} \\
\mathrm{R} \\
\mathrm{E} \\
\end{array}$ \\
\hline 1. Apple & & & & & & & & & & $\begin{array}{l}1 \\
\text { medium } \\
\text { or } 1 \frac{1}{2} \text { cup }\end{array}$ & & & \\
\hline 2. Banana & & & & & & & & & & $\begin{array}{c}1 \text { small } \\
\text { or } 1 / 2 \text { cup } \\
\end{array}$ & & & \\
\hline 3. Grapes & & & & & & & & & & $1 / 2$ cup & & & \\
\hline $\begin{array}{l}\text { 4. Berries: strawberries, } \\
\text { blackberries }\end{array}$ & & & & & & & & & & $1 / 2$ cup & & & \\
\hline $\begin{array}{l}\text { 5. Melon: cantaloupe, } \\
\text { honeydew }\end{array}$ & & & & & & & & & & $1 / 2$ cup & & & \\
\hline 6. Orange & & & & & & & & & & $\begin{array}{c}1 \\
\text { medium } \\
\text { or } 1 / 2 \text { cup }\end{array}$ & & & \\
\hline 7. Grapefruit & & & & & & & & & & $\begin{array}{c}1 / 2 \text { or } 1 / 2 \\
\text { cup }\end{array}$ & & & \\
\hline $\begin{array}{l}\text { 8. Orange or grapefruit } \\
\text { juice }\end{array}$ & & & & & & & & & & 6 ounces & & & \\
\hline 9. Other fruits or juices & & & & & & & & & & $\begin{array}{l}1 / 2 \text { cup or } \\
6 \text { ounces } \\
\end{array}$ & & & \\
\hline Breads and Starches & Never & $\begin{array}{l}1 \text { per } \\
\text { month }\end{array}$ & $\begin{array}{c}2-3 \\
\text { per } \\
\text { month }\end{array}$ & $\begin{array}{l}1 \text { Per } \\
\text { Week }\end{array}$ & $\begin{array}{l}2 \text { Per } \\
\text { Week }\end{array}$ & $\begin{array}{c}3-4 \\
\text { Per } \\
\text { Week }\end{array}$ & $\begin{array}{r}5-6 \\
\text { per } \\
\text { week }\end{array}$ & $\begin{array}{l}1 \\
\text { per } \\
\text { day }\end{array}$ & $\begin{array}{l}2+ \\
\text { per } \\
\text { day }\end{array}$ & $\begin{array}{l}\text { Med } \\
\text { Serving } \\
\text { size }\end{array}$ & \begin{tabular}{l|l}
$<$ \\
$\mathrm{L}$ \\
$\mathrm{E}$ \\
$\mathrm{S}$ \\
$\mathrm{S}$
\end{tabular} & $\mid \begin{array}{l}\mathrm{E} \\
\mathrm{S} \\
\mathrm{A} \\
\mathrm{M} \\
\mathrm{E}\end{array}$ & $\begin{array}{l}> \\
\mathrm{M} \\
\mathrm{O} \\
\mathrm{R} \\
\mathrm{E}\end{array}$ \\
\hline $\begin{array}{l}\text { 1. Doughnuts, cookies, } \\
\text { cake, pastry, muffins, } \\
\text { sweet roll }\end{array}$ & & & & & & & & & & $\begin{array}{l}1 \text { piece } \\
\text { or } 3 \\
\text { cookies }\end{array}$ & & & \\
\hline $\begin{array}{l}\text { 2. French fries and other } \\
\text { fried potatoes }\end{array}$ & & & & & & & & & & $3 / 4$ cup & & & \\
\hline 3. Whole grain bread & & & & & & & & & & 1 slice & & & \\
\hline 4. Pizza & & & & & & & & & & 1 slice & & & \\
\hline $\begin{array}{l}\text { 5. Snack foods such as } \\
\text { crackers, potato chips, } \\
\text { etc. }\end{array}$ & & & & & & & & & & 1 ounce & & & \\
\hline
\end{tabular}


16 The following things can keep people from eating healthier (such as fruits and vegetables and less high fat foods). Which of the following are true for you?

Yes / True

No / False

\begin{tabular}{|l|c|c|}
\hline $\begin{array}{l}\text { You do not have time to prepare foods that are } \\
\text { healthier }\end{array}$ & $\mathbf{1}$ \\
\hline You do not have the money to buy healthier foods & 1 & 0 \\
\hline Your family does not want to eat fruits and vegetables & 1 & 0 \\
\hline Your family does not want to eat lower fat foods & 1 & 0 \\
\hline Healthy foods are not convenient for me to prepare & 1 & 0 \\
\hline I do not think I need to eat healthier & 1 & 0 \\
\hline
\end{tabular}

17 How important to you are each of the following for helping you eat healthier?

SHOW ANSWER CHOICE CARD \#2

\begin{tabular}{|l|ccc|}
\hline & $\begin{array}{c}\text { Very } \\
\text { Important }\end{array}$ & $\begin{array}{c}\text { Somewhat } \\
\text { Important }\end{array}$ & $\begin{array}{c}\text { Not at all } \\
\text { Important }\end{array}$ \\
\hline $\begin{array}{l}\text { Eating healthier foods can help prevent } \\
\text { heart disease }\end{array}$ & 1 & 2 & 3 \\
\hline $\begin{array}{l}\text { Eating healthier can help you control your } \\
\text { weight }\end{array}$ & 1 & 2 & 3 \\
\hline Eating healthier can help you feel better & 1 & 2 & 3 \\
\hline $\begin{array}{l}\text { You can set a good example for your family } \\
\text { if you eat healthier }\end{array}$ & 1 & 2 & 3 \\
\hline
\end{tabular}


18 When you buy foods, how often do you read food labels? Do you read labels...

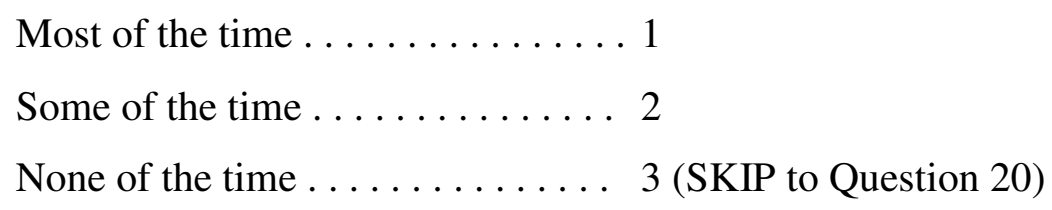

19 What do you usually look at on food labels?

\begin{tabular}{|c|c|}
\hline Yes & No \\
\hline Calories ... & 0 \\
\hline Fat grams ........... 1 & 0 \\
\hline Sodium . . . . . . . . . . . 1 & 0 \\
\hline Carbohydrates . . . . . . . . 1 & 0 \\
\hline Serving size $\ldots \ldots \ldots \ldots 1$ & 0 \\
\hline Ingredients . . . & 0 \\
\hline
\end{tabular}

20 How sure/confident are you that you could choose a low-fat meal when you eat out if you wanted to? Are you...

Very sure ............ 1

Somewhat sure .......... 2

Somewhat unsure .......... 3

Very unsure ........... 4 


\section{Which of the following is true about dietary fats?}

\section{$\begin{array}{ll}\text { True False } & \text { Don't } \\ \text { Know }\end{array}$}

You can tell if a food has hydrogenated fat in it by looking at the ingredient label . . . . . . 114008

A food is high in hydrogenated fat if it is one of the first three ingredients on the label ..... $1 \quad 1 \quad 0 \quad 8$

Removing skin from chicken helps reduce saturated fat .................. 1 . 0

Partially hydrogenated oils are also called by the

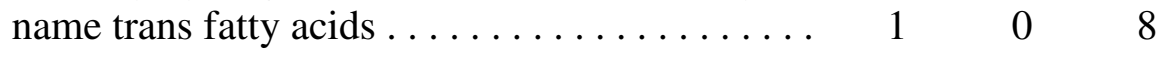

$\begin{array}{lc}\begin{array}{l}\text { PHYSICAL ACTIVITY } \\ \text { activity }\end{array} & \text { This next set of questions is about the physical } \\ \text { you do. }\end{array}$

\section{Are you physically active for at least 5 days a week for 30 minutes or more?}

A. YES $\rightarrow$ How long have you been doing this?

$<6$ months $\ldots \ldots \ldots \ldots \ldots 1$
6 months or more. $\ldots \ldots \ldots \ldots 2$

B. NO ----------------------- $\rightarrow$ Are you planning, thinking, or not thinking of increasing your physical activity in the next 6 months?

Planning. ............ 1

Thinking. ........... 2

Not thinking. ......... 3 
23 How sure/confident are you that you could be more physically active if you wanted to? Are you...

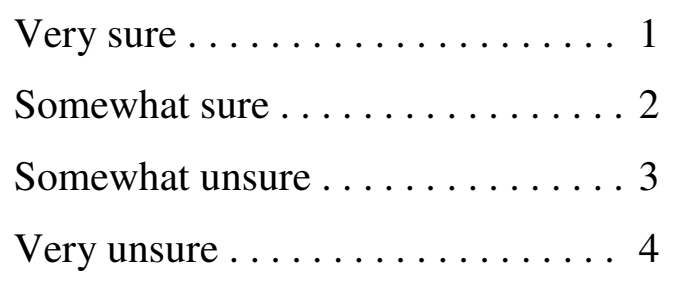

24 How much could you count on those close to you for support and help if you wanted to be more physically active? Could you count on them:

A lot $\ldots \ldots \ldots \ldots \ldots \ldots$
Somewhat $\ldots \ldots \ldots \ldots \ldots \ldots .2$
Very little or not at all $\ldots \ldots \ldots .3$

For the next three questions, we are interested in moderate physical activity.

Vigorous activities cause large increases in breathing or heart rate while moderate activities cause small increases in breathing or heart rate.

25 Now, thinking about the moderate physical activities you do as a part of your daily life (not while at work) in a usual week, do you do moderate activities for at least 10 minutes at a time, such as brisk walking, bicycling, vacuuming, gardening, or anything else that causes small increases in breathing or heart rate?

Yes $\ldots \ldots \ldots \ldots \ldots \ldots \ldots$

No ................ 0 (SKIP to Question 28)

Don't know/not sure . . . . . . . 8 (SKIP to Question 28) 
26 How many days per week do you do these moderate activities for at least 10 minutes at a time?

$\begin{array}{lllllllll}\text { Days per week ...... } 1 & 2 & 3 & 4 & 5 & 6 & 7\end{array}$

Don't know/not sure $\ldots \ldots \ldots \ldots \ldots \ldots \ldots$

27 On days when you do moderate activities for at least 10 minutes at a time, how much total time per day do you spend doing these activities?

Hours Minutes per day

Don't know/not sure .............. 888

28 The following questions are about activities that you may have done in the past 4 weeks. SHOW ANSWER CHOICE CARD \#3

In a typical week during the past 4 weeks did you ...

\begin{tabular}{|c|c|c|c|c|}
\hline Activity & Yes & No & $\begin{array}{l}\text { How many } \\
\text { times a } \\
\text { week? }\end{array}$ & $\begin{array}{l}\text { How many total hours a } \\
\text { week do you usually do it? }\end{array}$ \\
\hline $\begin{array}{l}\text { A. Do light gardening, such as } \\
\text { watering plants? }\end{array}$ & 1 & 0 & & $<1 \quad 1-2 \quad 3-4 \quad 5-6$ \\
\hline $\begin{array}{l}\text { B. Do light housework around the } \\
\text { house, such as sweeping or vacuuming? }\end{array}$ & 1 & 0 & & $<1 \quad 1-2 \quad 3-4 \quad 5-6$ \\
\hline \multirow[t]{2}{*}{$\begin{array}{l}\text { C. Walk to do errands, such as to/from } \\
\text { a store or to take children to school? } \\
\text { (Count walking time only) }\end{array}$} & 1 & 0 & & $<1 \quad 1-2 \quad 3-4 \quad 5-6$ \\
\hline & 1 & 0 & & $<1 \quad 1-2 \quad 3-4 \quad 5-6$ \\
\hline
\end{tabular}


In a typical week during the past 4 weeks did you ...

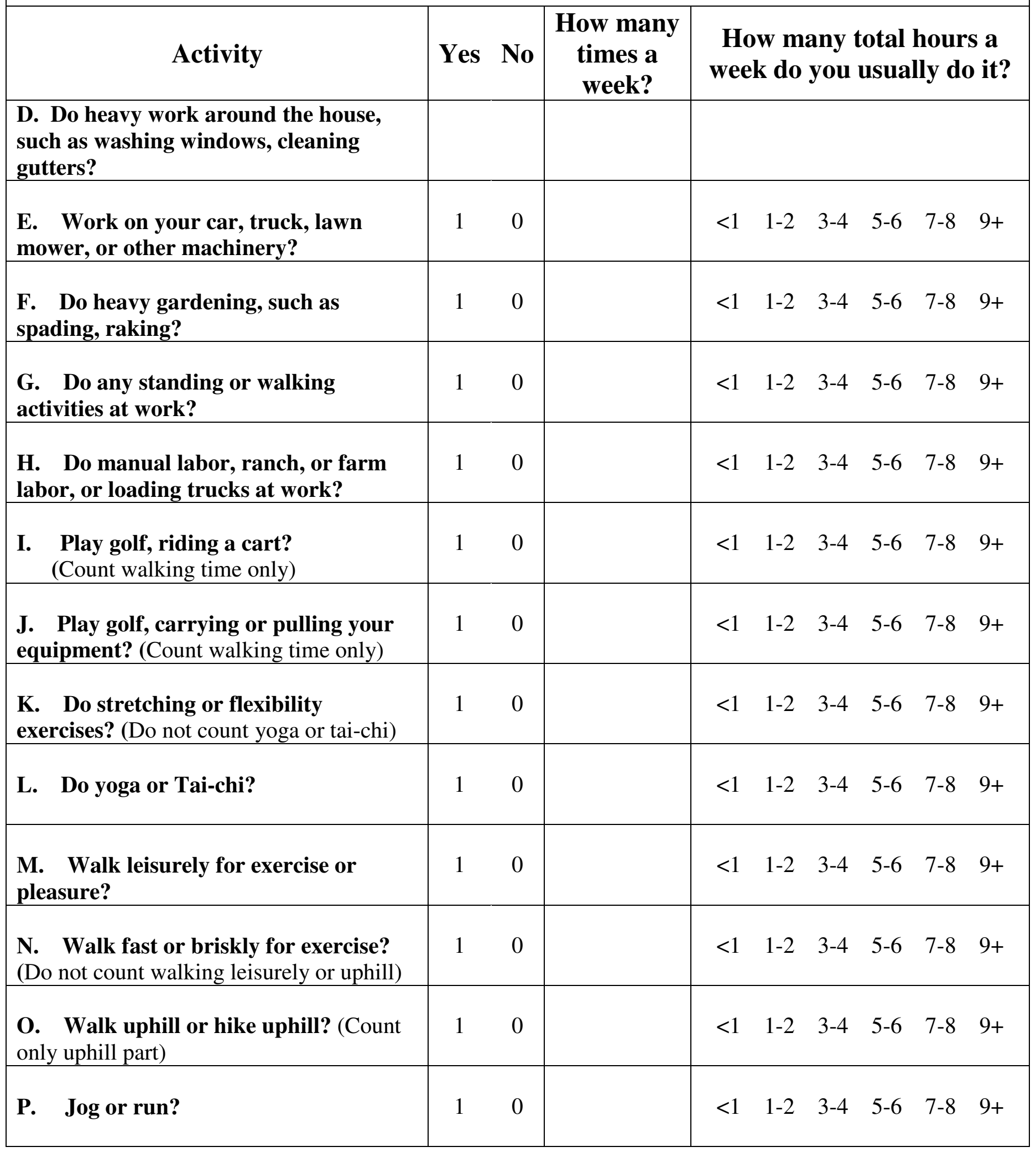




\section{In a typical week during the past 4 weeks did you ...}

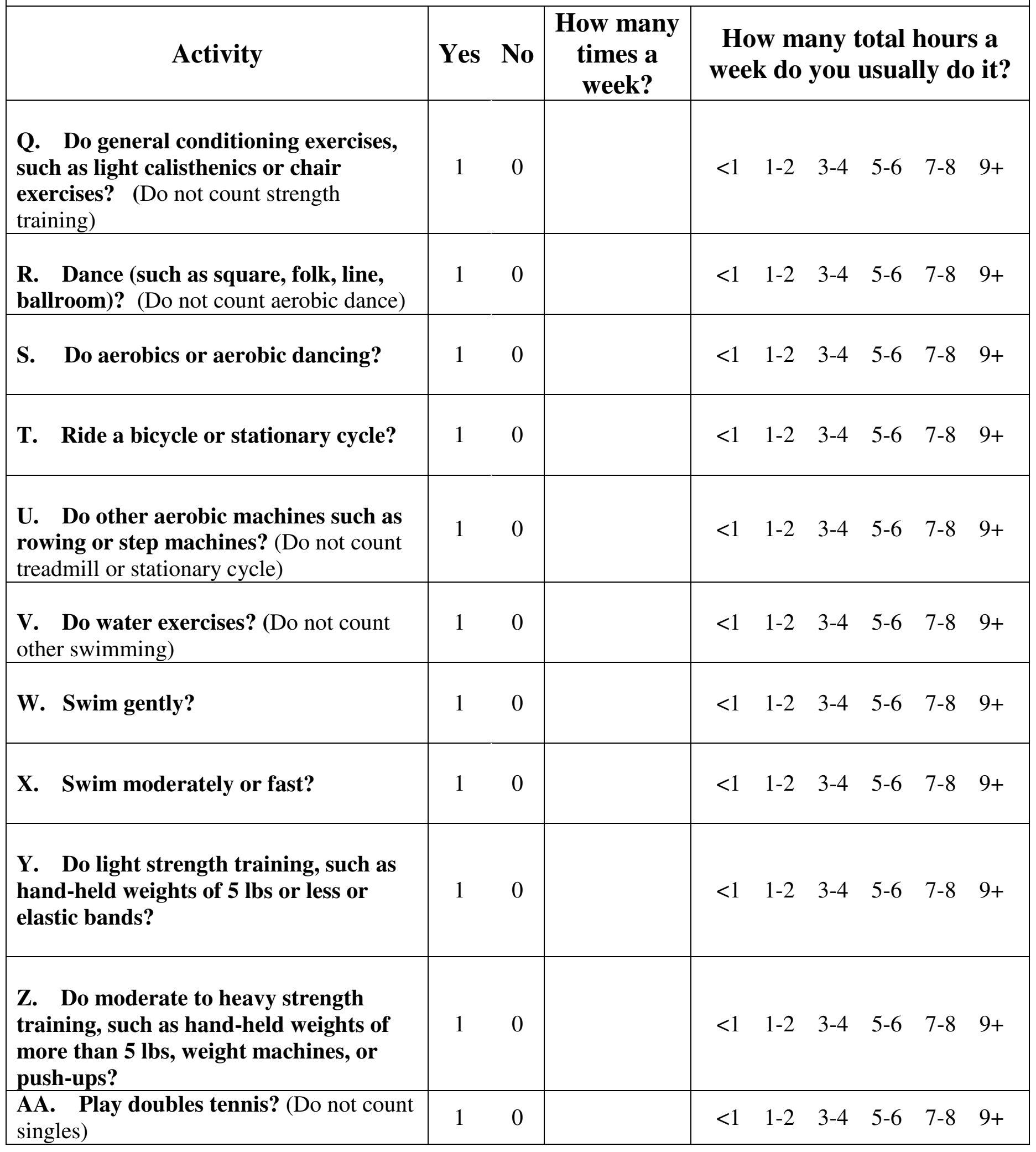


In a typical week during the past 4 weeks did you ...

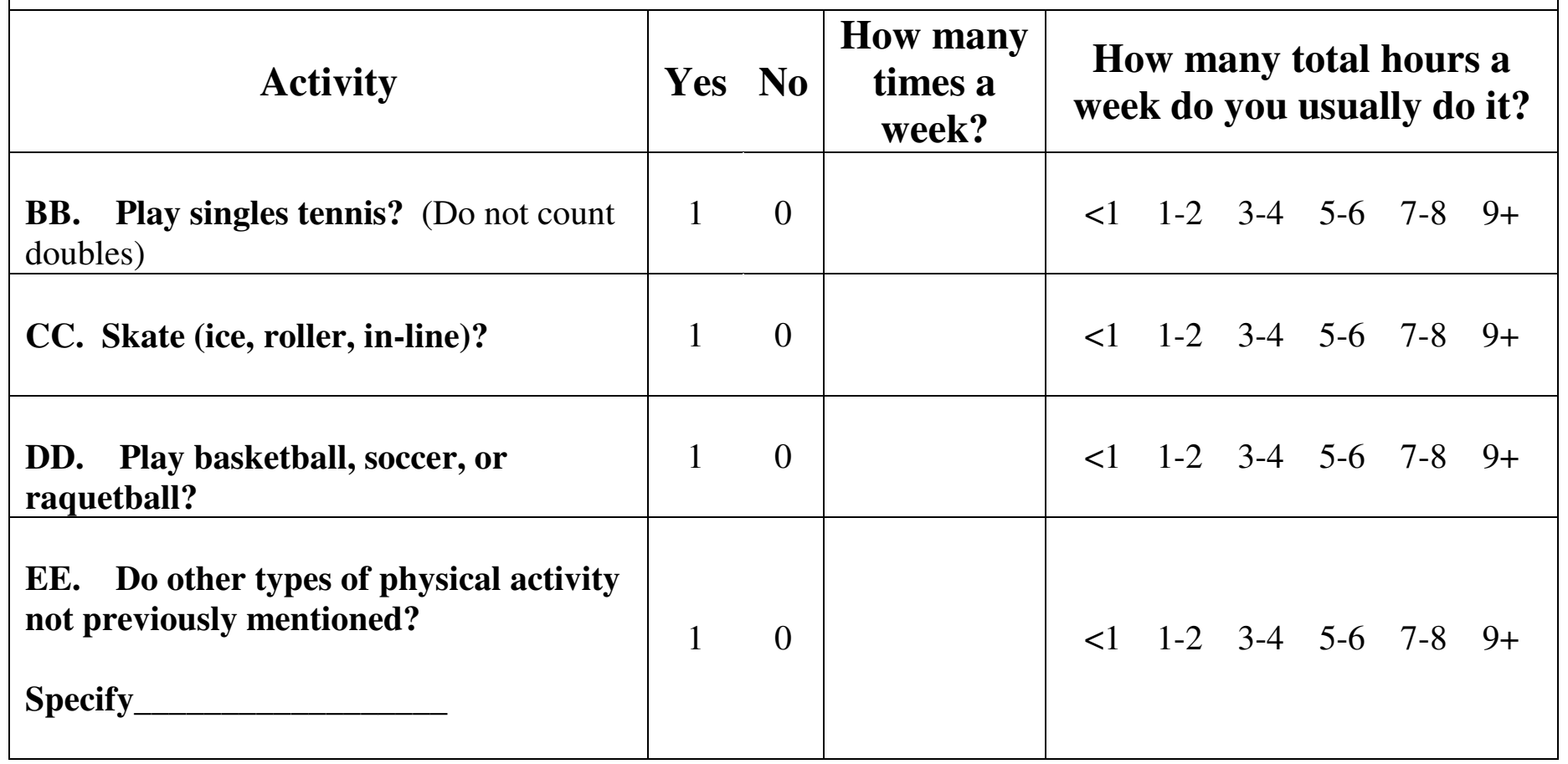

29 The following can keep people from being physically active? Which of the following are true for you?

Yes / True No / False

\begin{tabular}{|l|c|c|}
\hline You do not have time to be more physically active & 1 & $\mathbf{0}$ \\
\hline $\begin{array}{l}\text { You can't stick with it, you do not have the } \\
\text { willpower }\end{array}$ & 1 & $\mathbf{0}$ \\
\hline $\begin{array}{l}\text { You do not have anyone to exercise or be physically } \\
\text { active with }\end{array}$ & 1 & $\mathbf{0}$ \\
\hline You do not have anywhere to exercise & 1 & $\mathbf{0}$ \\
\hline You do not have the money to be physically active & 1 & $\mathbf{0}$ \\
\hline $\begin{array}{l}\text { You do not think you need to be more physically } \\
\text { active }\end{array}$ & & \\
\hline
\end{tabular}


30 How important to you are each of the following for helping you become more physically active?

SHOW ANSWER CHOICE CARD \#2

\begin{tabular}{|l|ccc|}
\hline & $\begin{array}{l}\text { Very } \\
\text { Important }\end{array}$ & $\begin{array}{c}\text { Somewhat Not at all } \\
\text { Important Important }\end{array}$ \\
\hline $\begin{array}{l}\text { Being more physically active can help prevent } \\
\text { heart disease }\end{array}$ & 1 & 2 & 3 \\
\hline $\begin{array}{l}\text { Regular physical activity can help you control } \\
\text { your weight }\end{array}$ & 1 & 2 & 3 \\
\hline $\begin{array}{l}\text { Being more physically active can help you look } \\
\text { and feel better }\end{array}$ & 1 & 2 & 3 \\
\hline $\begin{array}{l}\text { Regular physical activity can give you more } \\
\text { energy }\end{array}$ & 1 & 2 & 3 \\
\hline $\begin{array}{l}\text { You can set a good example for your family if you } \\
\text { are physically active }\end{array}$ & 1 & 2 & 3 \\
\hline $\begin{array}{l}\text { Being more physically active can help you feel less } \\
\text { stressed }\end{array}$ & 1 & 2 & 3 \\
\hline
\end{tabular}

31 Have you participated in any programs or classes about nutrition or physical activity in the last 6 months?

NO.....................

YES.....................

Type of program/class

32 Do you now smoke cigarettes?

Everyday.................... 1

Some days................. 2

Not at all.................... $3 \quad$ (SKIP to Question 35)

Don't know................... 4 (SKIP to Question 35) 
33 How sure/confident are you that you can stop smoking in the next 6 months? Are you...

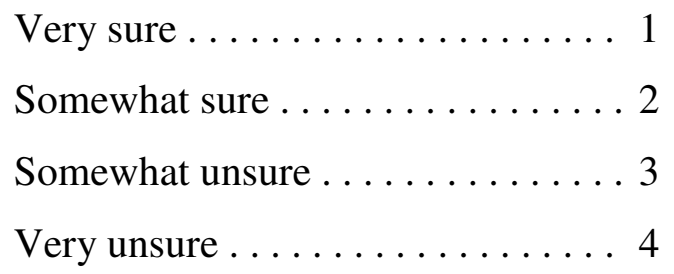

34 Are you planning, thinking, or NOT thinking about quitting smoking in the next 6 months?

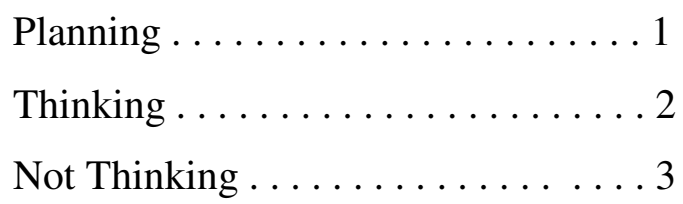

\section{HEALTH STATUS I have a few more questions about your health}

35 Thinking about your physical health, which includes physical illness and injury, for how many days during the past 30 days was your physical health not good?

Number of days (00-30):

Don't Know . . . . . . . . . . 88

36 Thinking about your mental health, which includes stress, depression, and problems with emotions, for how many days during the past 30 days was your mental health not good?

Number of days (00-30):

Don't Know . . . . . . . . . . . . . . 88 
37 During the past 30 days, for about how many days did poor physical or mental health keep you from doing your usual activities, such as self-care, work or recreation?

Number of days (00-30):

Don't Know .............. 88

\section{BACKGROUND I have some final questions}

38 Are you either married or living with a partner?

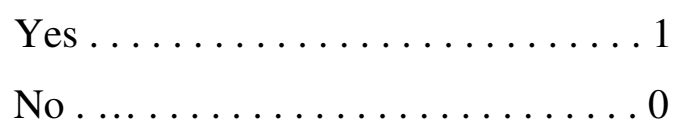

39 Are there any children under 18 living in your home?

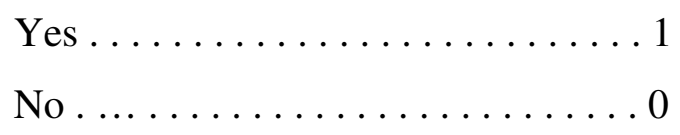

40 About how many close relatives or friends do you have? That is, people you really feel comfortable with, can talk to about private things, or can call on for help?

None ................ 0

About 1 or $2 \ldots \ldots \ldots \ldots \ldots$

About 3 to $5 \ldots \ldots \ldots \ldots \ldots$

About 6 to $9 \ldots \ldots \ldots \ldots$

10 or more ...........4 
41 About how many of your relatives or friends do you see or hear from at least once a week?

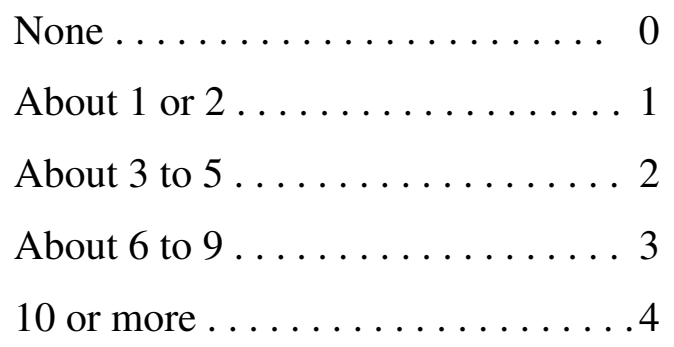

42 Do you talk with friends or family members about health issues?

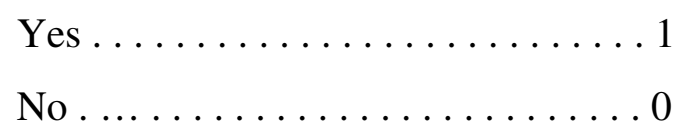

43 How tall are you without shoes?

Height in: feet ___ inches

Don't know . . . . . . . . . . . 888

44 About how much do you weigh without shoes?

Weight in pounds:

Don't know 888

45 How much would you like to weigh?

Weight in pounds:

Don't Know . . . . . . . . . 888 
46 What is the highest grade of school or amount of college you completed?

Less than $9^{\text {th }}$ grade $\ldots \ldots \ldots \ldots \ldots \ldots 1$

Some high school ............... 2

High school graduate or GED ........... 3

Some college or higher. ........... 4

\section{Are you of Hispanic or Latino Origin?}

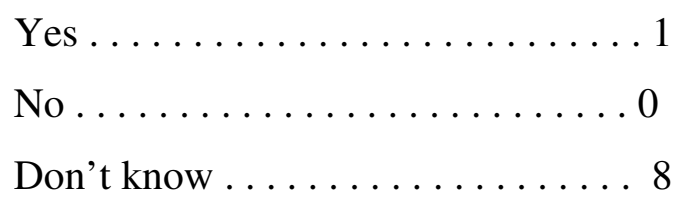

\section{Would you describe yourself as:}

First Race:

White $\ldots \ldots \ldots \ldots \ldots \ldots \ldots \ldots \ldots \ldots \ldots$

Black/African American ..................

Asian .................................

Native American or other Pacific Islander. . . . . . . .4

American Indian or Alaska Native ........... 5

Unknown ..........................

Second Race: $\quad$ White ......................... 1

Black/African American ................. 2

Asian ................................... 3

Native American or other Pacific Islander. . . . . . .4

American Indian or Alaska Native . . . . . . . . . 5

Unknown ........................ 
Third Race: $\quad$ White $\quad \ldots \ldots \ldots \ldots \ldots \ldots \ldots \ldots$

Black/African American ............ 2

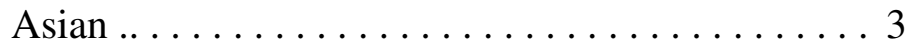

Native American or other Pacific Islander. . . . . . . .4

American Indian or Alaska Native . . . . . . . . 5

Unknown ....................

\section{End Time}


Appendix B

Introductory Letter to Participants

Interview Letter (given to participant at time of interview)

Telephone Text for Phone Call 


\section{West Virginia}

\section{University}

SCHOOL OF NURSING

\section{Dear Participant,}

This letter is a request for you to take part in a research project to help us better understand successful weight loss in women. We are contacting you because you have been identified as someone who lost weight during your participation in West Virginia WISEWOMAN. This project is being conducted by Jennifer Presley, MSN, RN in the School of Nursing at WVU with supervision of Dr. Irene Tessaro, RN, a professor in the School of Nursing. This research project is part of the dissertation process for J. Presley. Your participation in this project is greatly appreciated and will involve a personal interview with Jennifer Presley which will take approximately 45 to 60 minutes to complete.

Your involvement in this project will be kept as confidential as legally possible. You must be 18 years of age or older to participate. I will not ask any information that should lead back to your identity as a participant. Your participation is completely voluntary. You may skip any question that you do not wish to answer and you may discontinue at any time. Your medical care and participation in the West Virginia WISEWOMAN project will not be affected in any way by refusal to participate in this study or if you choose to withdraw from this study. West Virginia University's Institutional Review Board has acknowledged this project.

I hope that you will participate in this research project, as it could be beneficial in understanding the experience of successful weight loss in women. Should you have any questions about this letter or the research project, please feel free to contact Dr. Irene Tessaro at 303-293-1711 or by e-mail at itessaro@hsc.wvu.edu.

Thank you for your time and help with this project. I will be contacting you by phone to talk with you in more detail about the project and to set up a date and time for the interview if you agree to participate in the project.

Sincerely,

Jennifer Presley

304-482-5124

jpresley@suddenlink.net

Phone: 304-293-4298

Fax: 304-293-2546
Graduate and Academic Affairs

6417 Health Sciences South

PO Box 9640

Morgantown, WV 26506-9620

Equal Opportunity/Affirmative Action Institution 


\section{West Virginia}

University

SCHOOL OF NURSING

Dear

Thank you for agreeing to participate in this research study, investigating successful weight loss in women. This study is being conducted by Jennifer Presley, MSN, RN in the School of Nursing at West Virginia University, under the direction of Dr. Irene Tessaro, a professor in the school of nursing. Your participation in this study could be beneficial in understanding the experience of successful weight loss in women.

I would like to emphasize that your participation is completely voluntary, and you may skip any question that you do not wish to answer, and may discontinue the interview at any time. Your involvement in this project will be kept as confidential as legally possible. I will not ask any information that should lead back to your identity as a participant. Your medical care and participation in the West Virginia WISEWOMAN project will not be affected in any way by refusal to participate in this study or if you choose to withdraw from this study. West Virginia University's Institutional Review Board has acknowledged this project.

Your participation in this study will include an audio-taped interview with Jennifer Presley, which will last approximately 45 to 60 minutes. The audiotapes will be kept in a locked cabinet for three years and then destroyed, per research protocol. Should you have any questions about this letter or the research project, please feel free to contact Dr. Irene Tessaro at 303-293-1711 or by e-mail at itessaro@hsc.wvu.edu.

Thank you for your time and help with this project.

Sincerely,

Jennifer Presley, MSN, RN

Doctoral student

West Virginia University School of Nursing

Phone: 304-293-4298

Fax: 304-293-2546
Graduate and Academic Affairs

6417 Health Sciences South

PO Box 9640

Morgantown, WV 26506-9620
Equal Opportunity/Affirmative Action Institution 
Presley, Telephone text for phone call

Hello

This is Jennifer Presley, the doctoral nursing student conducting the research study on successful weight loss in women. How are you today?

Did you receive the letter explaining the research study that I mailed on (date)?

Do you have any questions or concerns that I can help with?

I'd like to emphasize that your participation in this study is completely voluntary and you will not face any consequences if you do not choose to participate. If you choose to participate, your information will be kept as confidential as legally permitted and you do not have to answer any question you do not want to answer.

Are you interested in participating in this research study?

If she agrees to participate: When is a good time for us to meet? (Get date, time, and directions.)

If she does not want to participate: I understand your decision not to participate and want to thank you for your time. Are there any questions you may still have that I can answer?

If you have any further questions or concerns, please feel free to contact me at 304-482-5124, or jpresley@suddenlink.net or my professor, Dr. Irene Tessaro at 304-293-1711 or itessaro@hsc.wvu.edu.

Thank you. Good bye. 
Appendix C

WISEWOMAN Questions 
WISEWOMAN Questions

\begin{tabular}{l} 
Question \\
(number of question in \\
WISEWOMAN questionnaire) \\
\hline AGE \\
(38)Are you either married or \\
living with a partner? \\
(46)What is the highest grade of \\
school or amount of college you \\
completed?
\end{tabular}

(15) Think about your eating habits during the past 4 weeks, about how often do you eat each of the following foods? Remember breakfast, lunch, dinner, snacks and eating out.
Answer Choices

Conversions for this study
Years

Yes or No

Less than $9^{\text {th }}$ grade

Some high school

High school graduate or GED

Some college or higher
Less than $9^{\text {th }}$ grade and some high school were combined to create "less than high school"

Final categories were: Less than high school High school graduate or GED

Some college or higher
Specific fruits and vegetables and standard portion sizes were listed with answer choices of:

Never

1 per month

2-3 per month

1 per week

2 per week

3-4 per week

5-6 per week

1 per day

$2+$ per day
Answer $=$ number of servings

Never $=0$

1 per month $=0.03$

2-3 per month $=0.08$

1 per week $=0.14$

2 per week $=0.29$

3-4 per week $=0.05$

$5-6$ per week $=0.79$

1 per day $=1$

$2+$ per day $=2$

Final categories were: $0-4$ servings $=$ did not meet recommendations (coded as 0)

5 or more servings $=$ met recommendations (coded as 1) 
(11)Do you stay away from foods high in fat like fatty red meats, fried chicken with the skin, regular milk, ice cream, cheese, butter or margarine, biscuits, doughnuts and french fries?

(28) In a typical week during the past 4 weeks did you...

How many times per week?

How many total hours a week do you usually do it?

(1)Would you say that in general your health is:
Yes or No

Various activities were listed with answer choices Yes

No (fill in)

Answer choices were (in
hours per week):
$<1$
$1-2$
$3-4$
$5-6$
$7-8$
$9+$

Excellent Very Good Good

Fair

Poor
Refer to description of physical activity variable on page 34 for details.
Physical activity was dichotomized into:

$0=$ Did not meet PA recommendations $1=$ Met PA recommendations

Excellent, Very Good and Good were combined

Fair and Poor were combined

Final categories were:

Excellent, Very Good and Good $=1$

Fair, and Poor $=2$

Dichotomized into

Number of days (00-30): Don't know
(35)Thinking about your physical health, which includes physical illness and injury, for how many days during the past 30 days was your physical health not good? 
(36)Thinking about your mental health, which includes stress, depression, and problems with emotions, how many days during the past 30 days was your mental health not good?

(37)During the past 30 days, for about how many days did poor physical or mental health keep you from doing your usual activities, such as self-care, work or recreation?

(13)How much could you count on those close to you for support and help if you wanted to eat healthier foods (such as fruits and vegetables and less foods high in fat)?

(24)How much could you count on those close to you for support and help is you wanted to be more physically active?

(40)About how many close relatives or friends do you have? That is, people you really feel comfortable with, can talk to about private things, or can call on for help?

(41)About how many of your relatives or friends do you see or hear from at least once a week?
Number of days (00-30): Don't know

Dichotomized into

$$
\begin{aligned}
& <14 \text { days }=0 \\
& \geq 14 \text { days }=1
\end{aligned}
$$

Number of days (00-30):

$$
\text { Don't know }
$$

Could you count on them:
A lot
Somewhat
Very little or not at all

Could you count on them:
A lot
Somewhat
Very little or not at all

None

About 1 or 2

About 3 to 5

About 6 to 9

10 or more
Recoded into:

None to $2=1$

About 3 to $5=2$

About 6 to $9=3$

About 10 or more $=4$
None

About 1 or 2

About 3 to 5

About 6 to 9

10 or more
Recoded into:

None to $2=1$

About 3 to $5=2$

About 6 to $9=3$

About 10 or more $=4$ 
(5)Have you ever been told by a doctor, nurse, or other health

professional that:

You have high blood pressure

You have diabetes

Your blood cholesterol is high
Answer choices for each question:

Yes

No

Don't know

John H.

$120 \begin{aligned} & \text { ou=Acquisitions Department, } \\ & \text { email=John. Hagen@mail.wvu.ed } \\ & \text { u, } c=\text { US } \\ & \text { Date: } 2010.12 .13 \text { 11:47:13-05'00' }\end{aligned}$ 